University of Denver

Digital Commons @ DU

$1-1-2019$

\title{
Highly Efficient Gan-Based Single-Phase Transformer-Less Pv Grid-Tied Inverter
}

Khaled Alatawi

University of Denver

Follow this and additional works at: https://digitalcommons.du.edu/etd

Part of the Electrical and Computer Engineering Commons

\section{Recommended Citation}

Alatawi, Khaled, "Highly Efficient Gan-Based Single-Phase Transformer-Less Pv Grid-Tied Inverter" (2019). Electronic Theses and Dissertations. 1637.

https://digitalcommons.du.edu/etd/1637

This Dissertation is brought to you for free and open access by the Graduate Studies at Digital Commons @ DU. It has been accepted for inclusion in Electronic Theses and Dissertations by an authorized administrator of Digital Commons@DU. For more information, please contact jennifer.cox@du.edu,dig-commons@du.edu. 
HIGHLY EFFICIENT GAN-BASED SINGLE-PHASE TRANSFORMER-LESS PV

\title{
GRID-TIED INVERTER
}

\author{
A Dissertation \\ Presented to \\ the Faculty of the Daniel Felix Ritchie School of Engineering and Computer Science \\ University of Denver \\ In Partial Fulfillment \\ of the Requirements for the Degree \\ Doctor of Philosophy \\ by \\ Khaled Alatawi \\ November 2019 \\ Advisor: Dr. Mohammad Matin
}


CCopyright by Khaled Alatawi 2019

All Rights Reserved 
Author: Khaled Alatawi

Title: HIGHLY EFFICIENT GAN-BASED SINGLE-PHASE TRANSFORMER-LESS

PV GRID-TIED INVERTER

Advisor: Dr. Mohammad Matin

Degree Date: November 2019

\begin{abstract}
Growing energy demand and environmental concerns have led to an increased interest in renewable energy resources to provide a sustainable and low carbon emission energy supply. Among these renewable energy resources, photovoltaic (PV) systems have been the focus of many scientific researchers. The most vital component of a PV system that needs to be improved is the power converter. Grid-tied transformer-less inverters have gained a lot of interest in recent years because of their higher efficiency, reduced volume and lower cost compared to traditional line transformer inverters.
\end{abstract}

This dissertation discusses single-phase transformer-less inverter challenges and provides solutions that could lead to a next generation, high performance, grid-connected, single-phase transformer-less inverter. A new topology with new current paths is proposed to increase efficiency and reduce the leakage current. A comparison study of the proposed topology and multiple transformer-less inverters is carried out in terms of leakage current, power losses and efficiency.

This dissertation also investigates the impact of emerging Gallium Nitride (GaN)based power devices on a single-phase transformer-less inverter in terms of efficiency, high switching frequency capability, volume and cooling efforts. GaN device structure, as well as static and dynamic characterization, are discussed.

Furthermore, this dissertation studies GaN power devices' reverse conduction capability to provide the proposed inverter with reactive power control. Existing PWM 
techniques cannot provide a freewheeling path in the negative power region to generate reactive power in a single-phase transformer-less inverter. Thus, a new PWM technique is proposed to provide new modes of operation to achieve reactive power generation capability in the proposed inverter.

Due to the increased penetration of PV systems into the grid and the updated grid codes concerning PV systems, next-generation PV systems will be required to have several features like high efficiency, high power quality, voltage regulation and fault ride through capability. This dissertation also explores these future requirements for PV system integration into the grid. To comply with the new grid codes and to enhance the PV inverter capability, a simple and flexible multifunctional control strategy is developed to provide PV inverters with advanced functions that will support the grid.

The simulation results validate the theory that the proposed topology reduces the conduction losses of the system. The conduction losses, switching losses, and thermal analysis at different output powers and switching frequencies verify the benefits of replacing Silicon (Si) MOSFET with Gallium Nitride (GaN) HEMTs. Moreover, the use of GaN HEMTs provides superior performance at higher frequencies when compared to their Si counterparts. Consequently, the filter volume is reduced, heatsink requirements are also reduced, and the cost is lowered. Furthermore, the simulation results validate the improvement of the proposed high efficiency transformer-less inverter with the new pulse width modulation (PWM) techniques to generate reactive power. The results also prove the effectiveness of the multifunctional control strategy to provide maximum active power injection, ride through faults, and support the grid by providing reactive power during grid faults. The high efficiency PV inverter equipped with advanced functions is 
the key to providing a reliable and cost-effective future grid tied to a PV system that can improve power quality. 


\section{Acknowledgments}

I would like to start by expressing my deepest gratitude and appreciation to my advisor Dr. Mohammad Matin for his support, advice and encouragement throughout this research. His mentorship and experienced guidance helped me strengthen my research skills. His valuable insight, motivation, and enthusiasm were the most important assets that led to the completion of this research.

I also would like to express my sincere appreciation to my dissertation committee members: Dr. Wenzhong Gao, Dr. Amin Khodaei, and Dr. Shimelis Assefa for their invaluable suggestions, comments and advice that helped me throughout my research progress.

My deepest thanks, gratitude, and respect go to my parents for a lifetime of unfailing love, encouragement, support and patience. Finally, I would like to thank my loving wife for her endless caring, understanding, and patience during my $\mathrm{PhD}$ study. 


\section{Table of Contents}

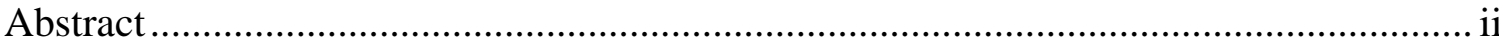

Acknowledgments.................................................................................................. V

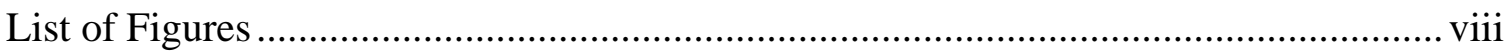

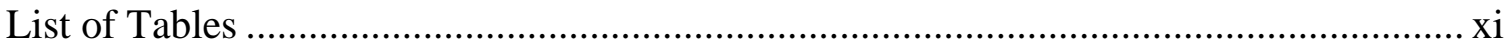

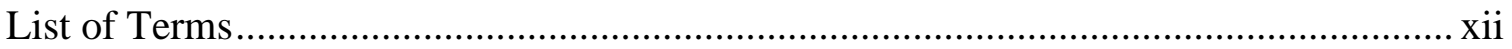

1. Chapter One: Introduction .................................................................................... 1

1.1 Research Objectives............................................................................... 4

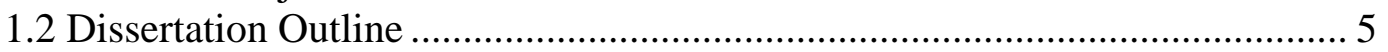

2. Chapter Two: Review of Single-phase Transformer-less Inverter Topologies............... 8

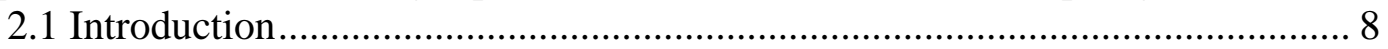

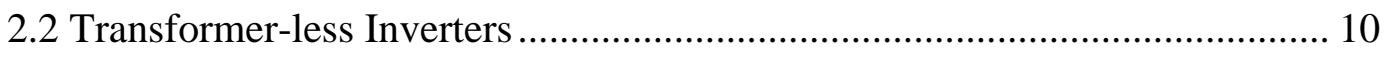

2.2.1 Full Bridge Inverter H4 .............................................................. 10

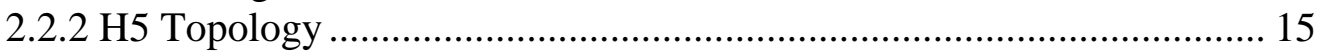

2.2.3 H6 Topology …………………..................................................... 18

2.3 Proposed High Efficiency Transformer-less Inverter ...................................... 22

2.3.1 Operation Modes Analysis of The Proposed Topology .......................... 23

2.3.2 Theoretical Power Loss Model Calculation............................................ 28

2.4 Simulation Comparison of Power Losses and Efficiency................................. 30

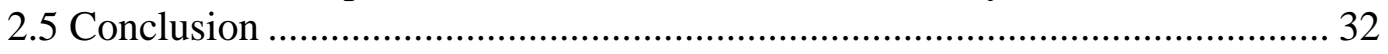

3. Chapter Three: Wide Bandgap (WBG) Power Switching Devices.............................. 34

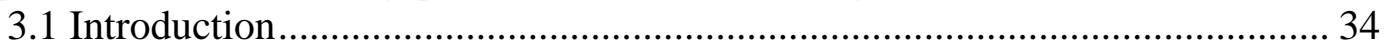

3.2 Performance Evaluation of Si MOSFET and GaN HEMT ............................ 34

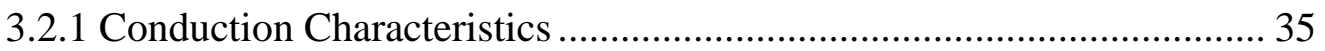

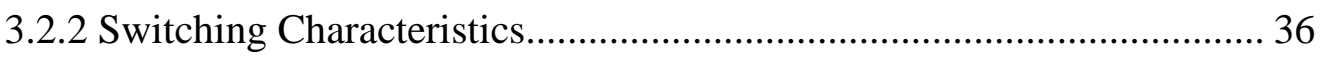

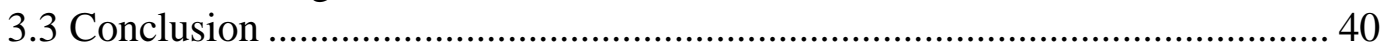

4. Chapter Four: Wide Bandgap Power Devices in PV Inverters .................................... 41

4.1 Introduction..................................................................................... 41

4.2 Proposed GaN-Based Single-Phase Transformer-Less PV Grid-Tied Inverter

4.2.1 Efficiency Improvement .................................................................... 44

4.2.2 Passive Component Reduction ........................................................... 44

4.2.3 Improvement in Power Rating ............................................................ 47

4.3 Thermal Design and Simulation Analysis ..................................................... 48

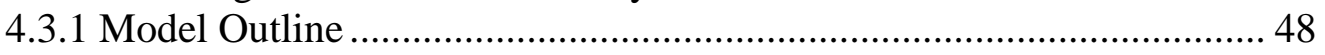

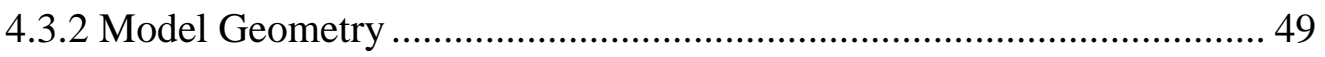

4.3.3 Model Simulation and Results ............................................................ 50 
5. Chapter Five: Improvement of Proposed Transformer-Less Inverter with Reactive

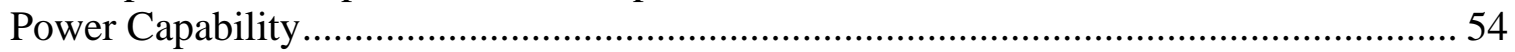

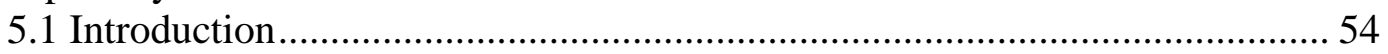

5.2 Reactive Power Capability of Current Transformer-less inverters.................. 55

5.3 Proposed GaN-Based Single-Phase Transformer-Less PV Grid-Tied Inverter

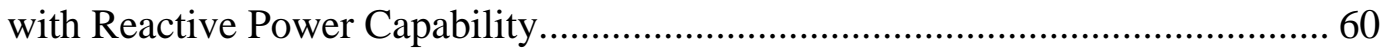

5.3.1 Modified PWM for Reactive Power Generation ................................... 61

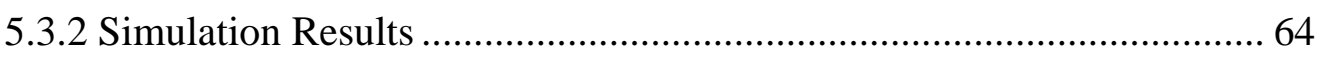

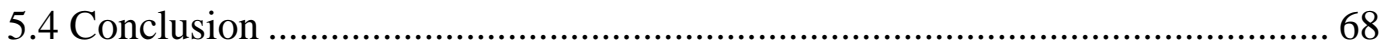

6. Multifunctional Control Strategy for PV Grid-Tied Inverter to Support the Grid ....... 70

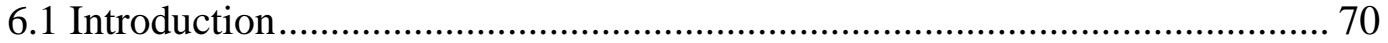

6.2 Grid-Tied Single-Phase Transformer-Less Inverter Control .......................... 71

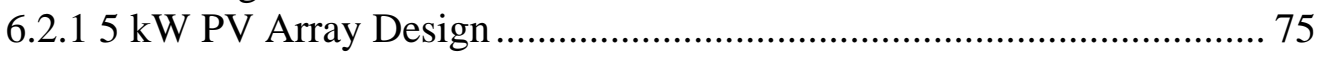

6.2.2 Maximum Power Point Tracking (MPPT) …………………………..... 75

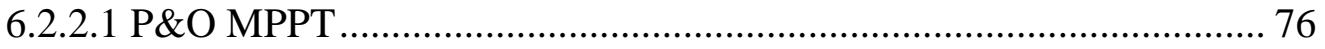

6.2.2.2 Incremental Conductance MPPT …………….................................... 78

6.2.2.3 Constant Voltage MPPT .................................................................... 80

6.2.2.4 P\&O MPPT Simulation in The Proposed Control System .................. 81

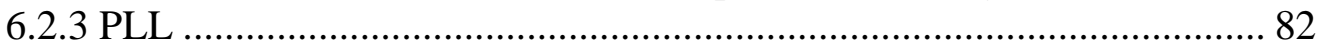

6.2.4 Power Calculation Algorithms............................................................ 82

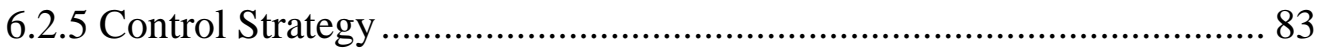

6.3 Case Studies Simulation Results.................................................................... 89

6.3.1 Normal Operation Mode ………………………................................ 90

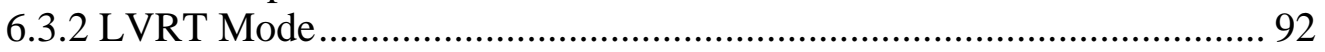

6.3.3 Low Solar Irradiance Operation Mode .................................................... 96

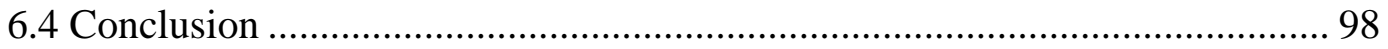

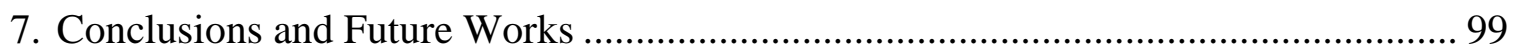

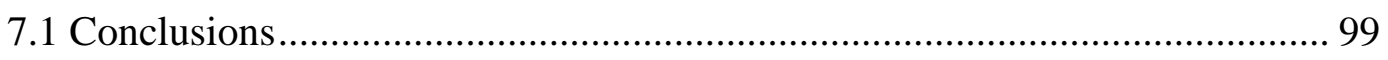

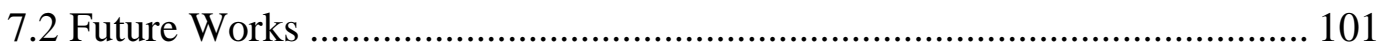

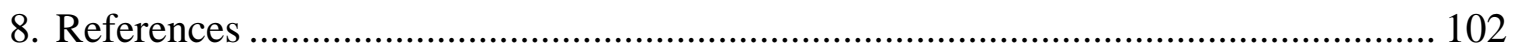

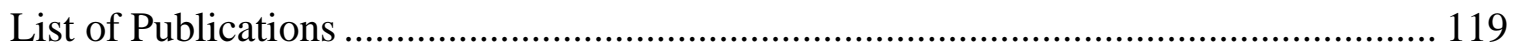




\section{List of Figures}

Fig. 1.1 Global cumulative installed capacity of PV systems [1] ............................... 2

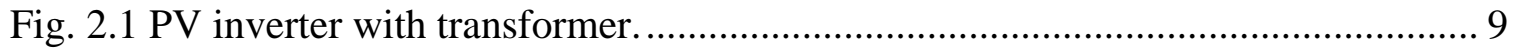

Fig. 2.2 PV transformer-less inverter............................................................... 9

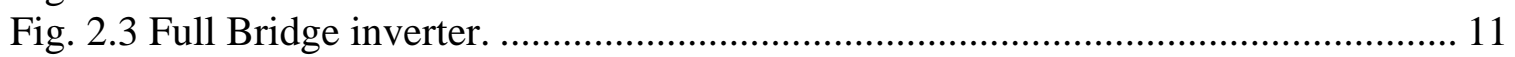

Fig. 2.4 Leakage current path for Full Bridge inverter. ............................................ 11

Fig. 2.5 PWM signals for Full Bridge inverter. .......................................................... 12

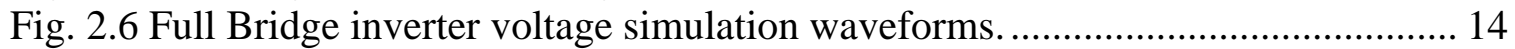

Fig. 2.7 Grid voltage and current and Full Bridge inverter leakage current..................... 14

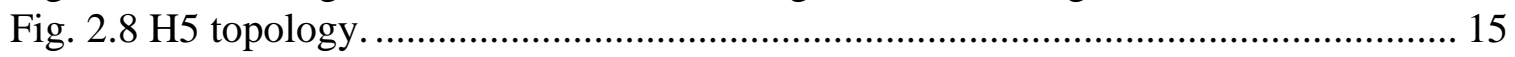

Fig. 2.9 Hybrid PWM signals for H5 topology. .................................................... 16

Fig. 2.10 H5 topology voltage simulation waveforms.............................................. 18

Fig. 2.11 Grid voltage and current and H5 topology leakage current............................ 18

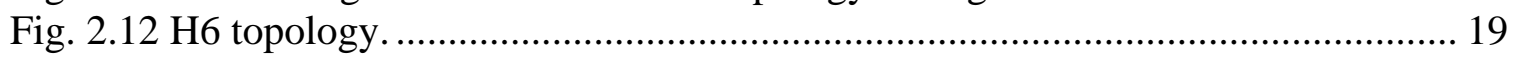

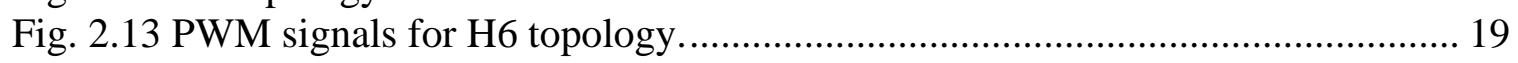

Fig. 2.14 H6 topology voltage simulation waveforms................................................ 21

Fig. 2.15 Grid voltage and current and H6 topology leakage current.............................. 21

Fig. 2.16 Proposed topology derived from H5 ..................................................... 22

Fig. 2.17 Gate drive signals with unity power factor................................................... 24

Fig. 2.18 Proposed topology operational modes: (a) Active state positive half- cycle; (b)

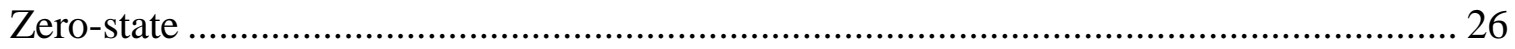

Fig. 2.19 Proposed topology voltage simulation waveforms......................................... 27

Fig. 2.20 Grid voltage and current and the proposed topology leakage current.............. 27

Fig. 2.21 Power losses for each topology at 5kW output power. .................................. 31

Fig. 2.22 Efficiency comparison of proposed topology and several topologies under

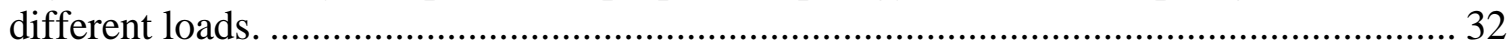

Fig. 2.23 Efficiency comparison of proposed topology and several topologies based on

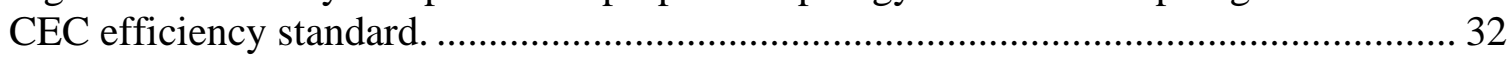

Fig. 3.1 Forward voltages of Si MOSFET and GaN HEMT at various current and

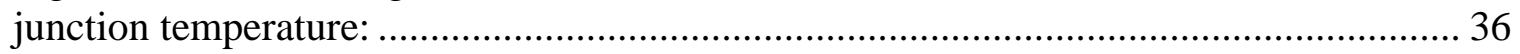

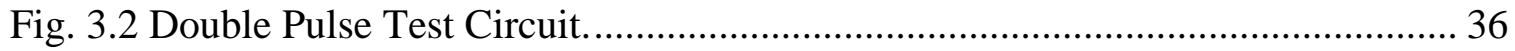
Fig. 3.3 The turn-on and turn-off waveforms of Si MOSFET and GaN HEMT at $400 \mathrm{~V}$ and 30 A: (a) Si MOSFET Turn-on; (b) GaN HEMT Turn-on; (c) Si MOSFET Turn-off; (d) GaN HEMT Turn-off. 38

Fig. 3.4 Turn-on and Turn-off switching energy losses of Si MOSFET and GaN HEMT:

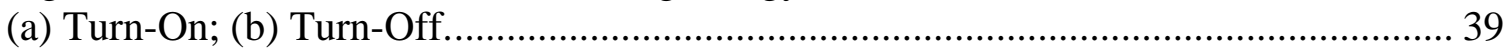

Fig. 4.1 Power losses of Si MOSFET and GaN HEMT: (a) at $50 \mathrm{kHz}$; (b) at $200 \mathrm{kHz} . .43$ Fig. 4.2 Efficiency comparison of Si MOSFET and GaN HEMT at different switching frequency 
Fig. 4.3 The balance point where GaN HEMT losses at $500 \mathrm{kHz}$ is equal to Si MOSFET

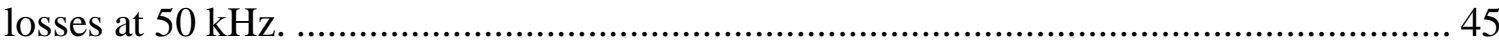

Fig. 4.4 The effect of increasing the switching frequency on inductance size. ................ 46

Fig. 4.5 The effect of increasing the switching frequency on magnetic core volume...... 46

Fig. 4.6 The effect of increasing the switching frequency on the inductor weight........... 47

Fig. 4.7 Power rating improvement, output power increase with same power losses..... 48

Fig. 4.8 xy-plane view of MOSFET modules: (a) for $\mathrm{Si}$; (b) for GaN. .......................... 49

Fig. 4.9 Temperature profile of Si model with heatsink visible .................................... 50

Fig. 4.10 Temperature profile of GaN model with heatsink visible................................ 50

Fig. 4.11 Heat Sink Comparison between Si MOSFET and GaN HEMT: (a) Heatsink surface area. (b) Heatsink volume ......................................................................... 52

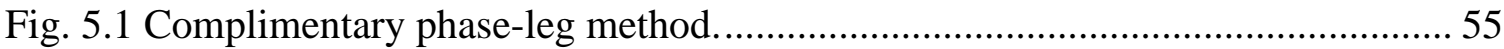

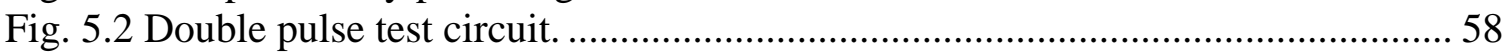

Fig. 5.3 Diode reverse recovery waveforms of Si MOSFET......................................... 59

Fig. 5.4 Reverse recovery waveforms of GaN HEMT. .................................................... 59

Fig. 5.5 Active state mode negative state voltage in negative power region.................... 61

Fig. 5.6 Active state mode positive state voltage in negative power region.......................61

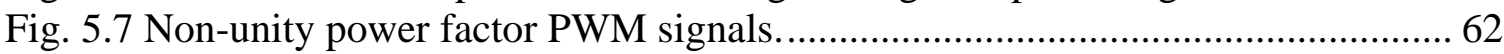

Fig. 5.8 Negative zero state voltage mode in negative power region.............................. 63

Fig. 5.9 Positive zero state voltage mode in negative power region.................................. 64

Fig. 5.10 Proposed inverter with modified PWM under unity power factor. .................... 65

Fig. 5.11 Proposed inverter with modified PWM under lagging power factor. ................ 65

Fig. 5.12 Proposed inverter with modified PWM under leading power factor.................. 66

Fig. 5.13 Transition from unity power factor to lagging power factor............................. 66

Fig. 5.14 Transition from unity power factor to leading power factor. ............................ 67

Fig. 5.15 Leakage current of proposed inverter with modified PWM.............................. 67

Fig. 5.16 Efficiency comparison of proposed inverter with conventional and proposed

PWM.

Fig. 6.1 Single Phase Transformer-less Inverter configuration with synchronous rotating

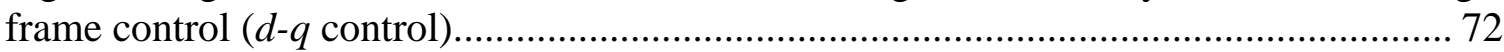

Fig. 6.2 Real $(\alpha)$ and imaginary $(\beta)$ signals. ............................................................. 74

Fig. 6.3 Maximum power point variation for different solar irradiance.......................... 77

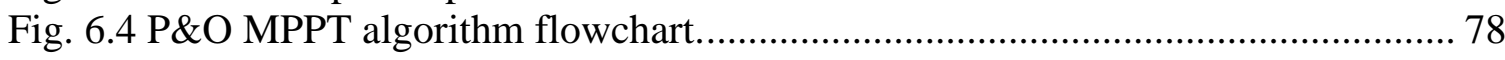

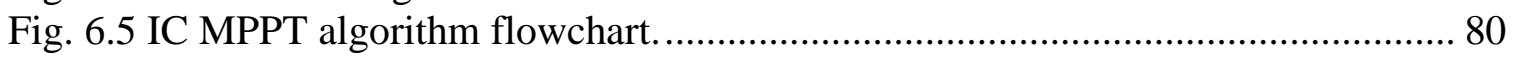

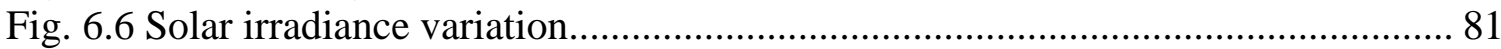

Fig. 6.7 PV output power under change in irradiance. .................................................... 82

Fig. 6.8 LVRT requirements for distributed generation systems from various countries

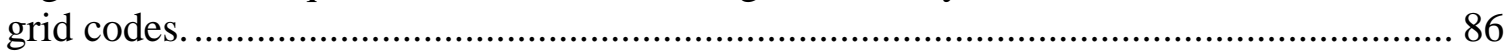

Fig. 6.9 Reactive current requirements to support the grid.............................................. 86

Fig. 6.10 Control flowchart of the multifunctional control strategy............................... 89

Fig. 6.11 The performance of the control system during normal mode: (a) active and reactive current, (b) Inverter active and reactive power, (c) Grid Voltage and current.... 92 
Fig. 6.12 The performance of the control system during LVRT mode during voltage sag when the voltage drops to 0.7 p.u: (a) active and reactive current, (b) Inverter active and reactive power, (c) Grid Voltage and current.

Fig. 6.13 The performance of the control system during LVRT mode during worst case of voltage sag when the voltage drops to 0.3 p.u: (a) active and reactive current, (b) Inverter active and reactive power, (c) Grid Voltage and current. 96

Fig. 6.14 The performance of the control system during low solar irradiance mode: (a) active and reactive current, (b) Inverter active and reactive power, (c) Grid Voltage and current. 


\section{List of Tables}

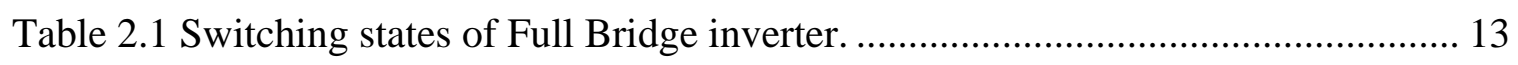

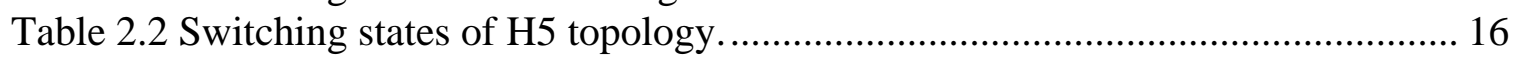

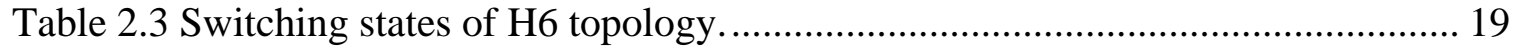

Table 2.4 Comparison of conducting devices for different topologies.......................... 23

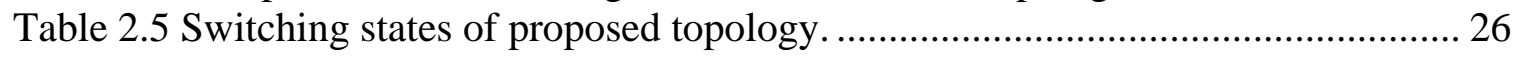

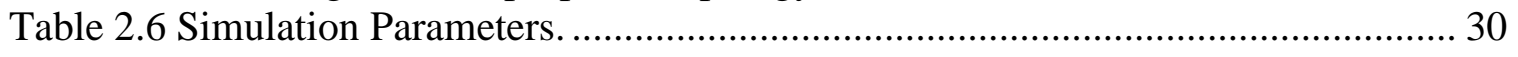

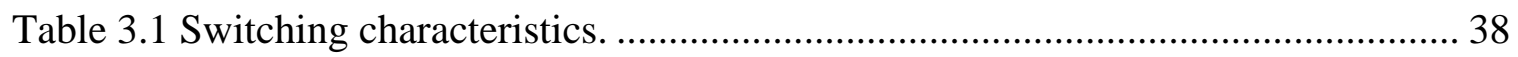

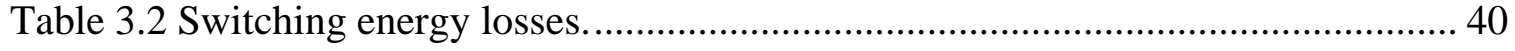

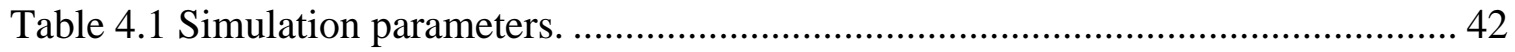

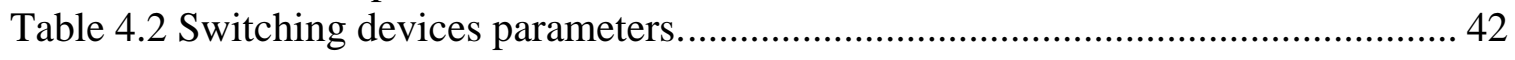

Table 5.1 Power switching devices characteristics ................................................. 58

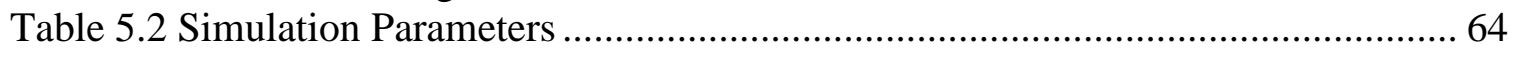

Table 6.1 Electrical Specification of CS60P-180P ................................................. 75

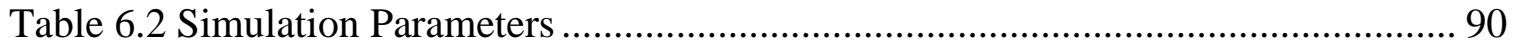




\section{List of Terms}

\begin{tabular}{|c|c|}
\hline PV & Photovoltaic \\
\hline WBG & Wide BandGap \\
\hline $\mathrm{Si}$ & Silicon \\
\hline $\mathrm{SiC}$ & Silicon Carbide \\
\hline $\mathrm{GaN}$ & Gallium Nitride \\
\hline $\mathrm{CM}$ & Common Mode \\
\hline DM & Deferential Mode \\
\hline PWM & Pulse Width Modulation \\
\hline MOSFET & Metal-Oxide-Semiconductor Field-Effect Transistor \\
\hline HEMT & High Electron Mobility Transistor \\
\hline IGBT & Insulated-Gate Bipolar Transistor \\
\hline JFETs & Junction Field-Effect Transistor \\
\hline GTO & Gate Turn-Off Thyristor \\
\hline$E_{\text {on }}$ & Turn-on switching energy \\
\hline$E_{\text {off }}$ & Turn-off switching energy \\
\hline NEC & National Electrical Code \\
\hline $\mathrm{DC}$ & Direct Current \\
\hline $\mathrm{AC}$ & Alternating Current \\
\hline RMS & Root Mean Square \\
\hline CEC & California Energy Commission \\
\hline FEA & Finite Element Analysis \\
\hline $\mathrm{Cu}$ & Copper \\
\hline
\end{tabular}




$\begin{array}{ll}\text { AlN } & \text { Aluminum Nitride } \\ \mathrm{k} & \text { Thermal conductivity } \\ \text { QRR } & \text { Reverse recovery charge } \\ \text { EMI } & \text { electromagnetic interference } \\ \text { IEEE } & \text { Institute of Electrical and Electronic Engineers } \\ \text { LVRT } & \text { Low Voltage Ride Through } \\ \text { MPPT } & \text { Maximum Power Point Tracking } \\ \text { OSG } & \text { Orthogonal Signal Generation } \\ \text { PLL } & \text { Phase Locked Loop }\end{array}$




\section{Chapter One: Introduction}

The rising cost of energy and the environmental issues of fossil resources led to the recent interest in renewable energy. Renewable resources provide clean and sustainable energy, which will reduce the pollution emissions; hence protecting the environment. Among renewable resources, photovoltaic (PV) gained a lot of interest in recent years; the power capacity of PV system installations has grown exponentially in the past decades being increased from 15 gigawatts in 2008 to 505 gigawatts in 2018 as shown in Fig. 1.1 [1]. In 2018, Solar PV power capacity saw a significant increase more than any other renewable source representing about $47 \%$ of renewable energy installation [1]. To satisfy and address this increasing demand of PV systems, power electronics converters 'which are vital components of the PV systems' should be realized and improved. 


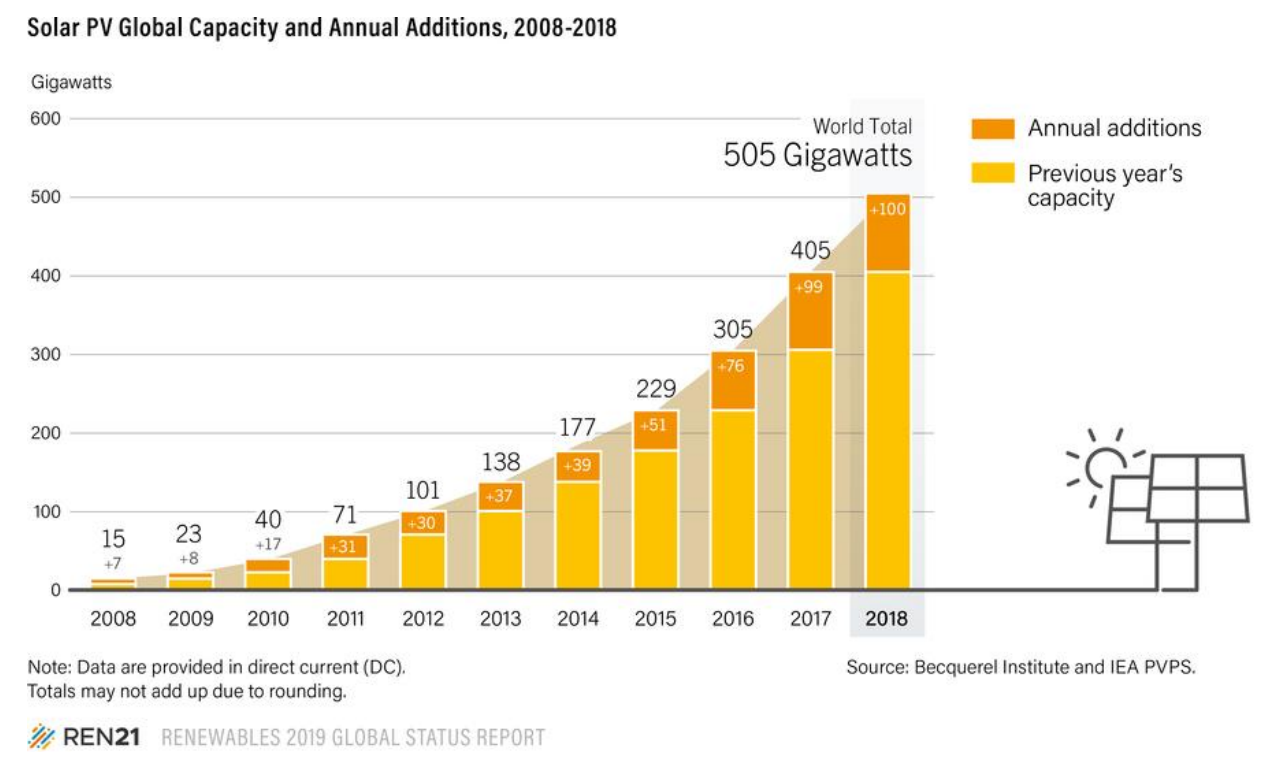

Fig. 1.1 Global cumulative installed capacity of PV systems [1].

The key enabling technology for residential PV systems is the power electronic converter. The reliability and efficiency of these power electronic converters play an important role in the system's overall performance since they provide the connection between the PV system and the grid [2]. Therefore, the focus of power electronics research has been on developing power converters with high efficiency and reliability to enhance the overall performance of the power system. In addition, providing low cost, reduced volume converters by emerging technologies is required to provide high switching frequency power electronic systems.

For residential PV system development, converter topologies and the emerging of Wide Bandgap (WBG) power semiconductor devices have received a lot of attention. Also, advanced control technologies, such as controlling the active and reactive power of PV inverters to compensate for any frequency or voltage disturbance, are important research areas. Several PV system structures and converter topologies with high efficiency have been reviewed and published in detail [3]-[9] . In addition, there is an 
increased interest in emerging WBG power devices with their superior performance compared to their Silicon ( $\mathrm{Si}$ ) counterparts in the power conversion system. Therefore, a proper assessment of the impact of WBG power devices is needed to understand the effect of employing such technology in a power conversion system. The benefits and potential performance enhancement of WBG applications in renewable energy converters have been widely discussed [10]-[12].

PV inverters in residential applications are either single or three phase inverters with or without galvanic isolation. Isolated inverters use transformers to provide a galvanic isolation between the input and the output. Consequently, efficiency is reduced, and the size, cost, and weight of the system are increased. On the other hand, non-isolated inverters (transformer-less inverters) do not provide galvanic isolation, which increases the efficiency of the system with lower cost and smaller size. The elimination of the transformer removes the galvanic isolation in the system, which causes many safety issues. In the absence of galvanic isolation, leakage current will flow through the PV parasitic capacitance due to the high frequency common mode (CM) voltage. This leakage current leads to higher losses, PV module degradation, electromagnetic interference, and safety issues. To eliminate the leakage current and maintain high efficiency, the topology and the switching strategies of the transformer-less inverter must be designed properly. Several new transformer-less inverter topologies have been developed and proposed to eliminate the leakage current and maintain high efficiency [13]-[18]. 
Transformer-less inverters are very efficient in connecting the PV system to the grid without galvanic isolation, thereby reducing the cost and the volume of the system. However, the leakage current problem, new standard requirements, and high efficiency requirements bring new challenges to transformer-less inverter design. To address and overcome these challenges, innovative transformer-less topologies, different PWM techniques, state-of-the-art power switching devices, and advanced functions capability, such as reactive power generation, need to be studied and investigated [19]-[23].

\subsection{Research Objectives}

The objective of this research is to address single-phase transformer-less inverter challenges and provide solutions that can lead to the next generation of high performance, grid-connected, single-phase transformer-less inverters. Considering the cost and the future standards' requirements, providing a high efficiency, transformer-less inverter is a challenge [24]-[27]. To address this challenge, a comparison of the state-of-the-art transformer-less inverter topologies is considered, and a new high efficiency topology is proposed and investigated. High efficiency is important to extract the maximum amount of solar energy and provide reliable operation of the system. Advanced transformer-less inverters have reached around 97\% efficiency and with WBG-based power-switching devices, they have the potential to reach over $98 \%$ efficiency. Another issue in transformer-less inverters is the leakage current since these inverters do not have isolation. Thus, there is a need to investigate new topologies and PWM techniques to overcome these issues. 
WBG power switching devices have attracted a lot of attention because of their superior performance. Thus, this research also investigates the impact of emerging WBGbased power devices on single-phase transformer-less inverters in terms of efficiency, high switching frequency, volume and cooling efforts. WBG device structure and static and dynamic characterization are discussed.

Another challenge is the reactive power generation capability of the single-phase transformer-less inverter. Existing PWM techniques cannot provide a freewheeling path in the negative power region to generate reactive power in single-phase transformer-less inverters. Thus, a new PWM technique is proposed to provide new modes of operation to achieve reactive power generation capability in single-phase transformer-less inverters.

The new and updated grid codes around the world regarding PV systems integration into the grid also impose another challenge for future PV inverters. Next generation PV inverters are required to provide a wide range of services to support the grid, such as Low Voltage Ride Through capability (LVRT), reactive power compensation and active power control. Thus, a simple and flexible multifunctional control system is designed to provide the PV inverter with advanced functions that will be required to support the grid.

\subsection{Dissertation Outline}

This dissertation is organized as follows: chapter one provides an introduction of the research topic and its objectives. Chapter two presents a review of single-phase transformer-less inverter topologies with their operation principles. A comparison of different topologies in terms of eliminating the leakage of current, the component count, 
power losses and efficiency is presented. Also, a modified topology derived from an H5 inverter is proposed. Detailed operation modes, inverter structure and switching strategy of the proposed topology are investigated. Chapter three presents a comparison of the static ad dynamic characteristics of Si power devices and WBG power devices (mainly GaN HEMTs) under different currents and heat temperature conditions. Chapter four explores the benefits of employing Gallium Nitride $(\mathrm{GaN})$ power devices in PV transformer-less inverters. Employing GaN HEMTs in the proposed topology is analyzed in terms of efficiency, power losses and converter volume by reducing passive component size and heatsink requirements. The discussion starts by inverter description and test parameters, followed by simulation results. The results provide a comparison of efficiency and power losses of the proposed topology under different switching efficiencies and load conditions using two different power devices (Si MOSFET and GaN HEMT) to evaluate the performance of each device. Finally, the impact of GaN power switching devices on the PV inverter is evaluated and discussed in terms of passive component volume and heatsink requirements.

Chapter five introduces reactive power generation in PV inverters. A PV inverter's reactive power capability will be required by future standards to enhance the functions of these inverters. Si MOSFETs can't be used to generate reactive power because their body diodes slow reverse recovery and because of their high reverse recovery losses. On the other hand, GaN HEMTs do not have body diodes and are naturally capable of reverse conduction, so that makes them capable of reactive power generation with very low power losses and fast reverse recovery. This chapter focuses on 
enhancing the PV inverter topologies and provides a modified PWM to generate reactive power.

Chapter six focuses on designing a control system for single-phase grid-tied PV inverters. A multifunction control strategy is developed and presented. In addition, multiple case studies are studied and presented to test the effectiveness of the proposed control strategy. Chapter seven presents the conclusions and discusses the future work. 


\section{Chapter Two: Review of Single-phase Transformer-less Inverter Topologies}

\subsection{Introduction}

PV systems in recent years have gained a lot of interest because of their reduced cost and increased efficiency. A strong demand has arisen for power generated by PV systems. To satisfy and address this demand, power electronic converter systems must be realized and improved to address efficiency concerns and new standards. In North America, it is required by the National Electrical Code (NEC) for PV inverters over 50V DC voltage to have a ground conductor as shown in Fig. 2.1 [28]. As a result, the PV system will need an isolation transformer since both the grid and the PV source are grounded. After adding sections 690.25 in 2005 and 690.35 (D) in 2008 to the NEC, it became allowed to operate the PV inverter with ungrounded PV source as shown in Fig. 2.2. This change allowed the use of transformer-less PV inverters, which improves the

efficiency of the system with lower cost and smaller size. However, eliminating the transformer will allow the flow of leakage current through the parasitic capacitance of the PV module. This leakage current will lead to many safety issues. New topologies and new PWM techniques are required to eliminate the leakage current and achieve high system efficiency. VDE 126-1-1 and UL 1741 standards provide the requirements to reduce and limit the leakage current [22], [29]. 


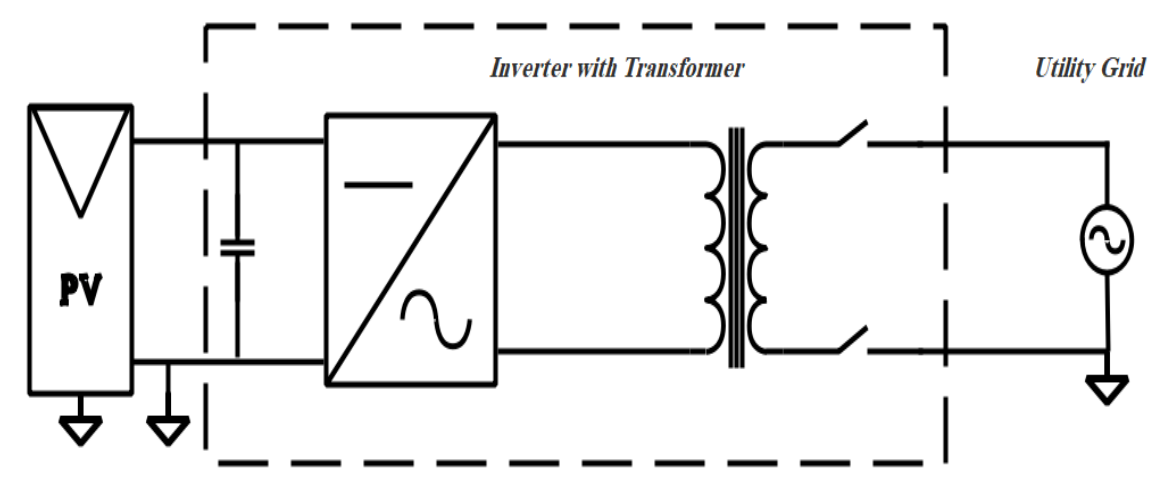

Fig. 2.1 PV inverter with transformer.

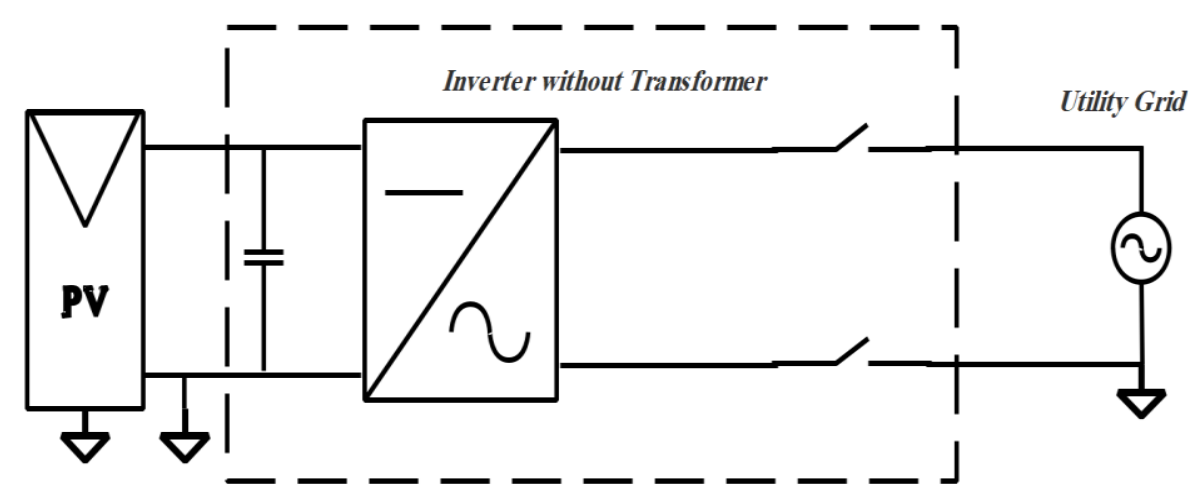

Fig. 2.2 PV transformer-less inverter.

As mentioned previously, transformer-less inverters can increase the system's efficiency and lower costs; however, new PWM techniques and new topologies are required to overcome the leakage current problem. In this chapter, first, a review of single-phase transformer-less topologies is presented. A modified single-phase transformer-less inverter is proposed with detailed operation modes, inverter structure and switching strategy. Then, a comparison of efficiency, power losses and leakage current of different topologies and the proposed topology is presented. Finally, simulation results are discussed to verify the effectiveness of the proposed inverter. 


\subsection{Transformer-less Inverters}

Leakage current can lead to many safety issues and needs to be eliminated or reduced to a certain level. To eliminate the leakage current, CM voltage must be kept constant for all switching states. A half-bridge inverter is the typical solution to keep the $\mathrm{CM}$ voltage constant [4]. However, a half-bridge inverter requires double the DC input voltage of the full bridge inverter, which requires a DC-DC converter with an extremely high conversion ratio. As a result, this can lead to a huge decrease in system efficiency.

\subsubsection{Full Bridge Inverter H4}

The full bridge inverter shown in Fig. 2.3 is an attractive solution because it requires only half of the half-bridge input voltage. In addition, it has higher conversion efficiency and small current ripples. However, the variation of the CM voltage at the switching frequency in a full bridge inverter can lead to high leakage currents. Fig. 2.4 shows the ground leakage current path of the full bridge topology. Voltage variation across the $\mathrm{PV}$ parasitic capacitance $\mathrm{C}_{\mathrm{PV} 1}$ and $\mathrm{C}_{\mathrm{PV} 2}$ are the main causes of ground leakage current. The VDE 0126-1-1 standard limits the allowable maximum RMS leakage current to $300 \mathrm{~mA}$. The differential voltage $\mathrm{V}_{\mathrm{DM}}$ and common mode voltage $\mathrm{V}_{\mathrm{CM}}$ of transformer-less inverter is given by [30]:

$$
\begin{aligned}
& \mathrm{V}_{\mathrm{DM}}=\mathrm{V}_{\mathrm{AN}}-\mathrm{V}_{\mathrm{BN}}=\mathrm{V}_{\mathrm{AB}} \\
& \mathrm{V}_{\mathrm{CM}}=\frac{\mathrm{V}_{\mathrm{AN}}+\mathrm{V}_{\mathrm{BN}}}{2}
\end{aligned}
$$




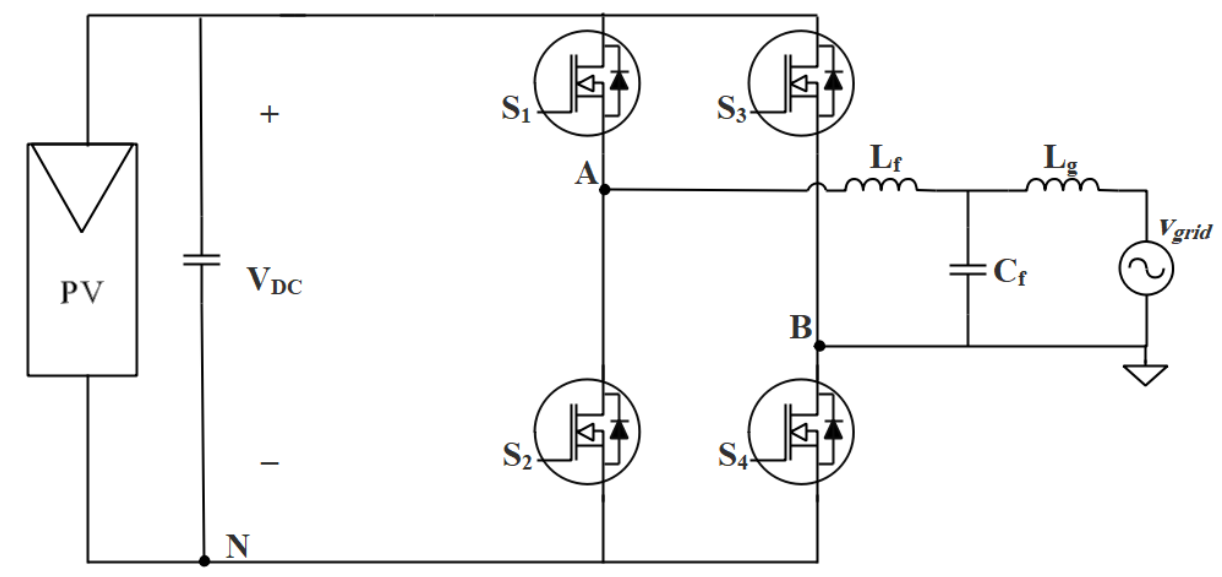

Fig. 2.3 Full Bridge inverter.

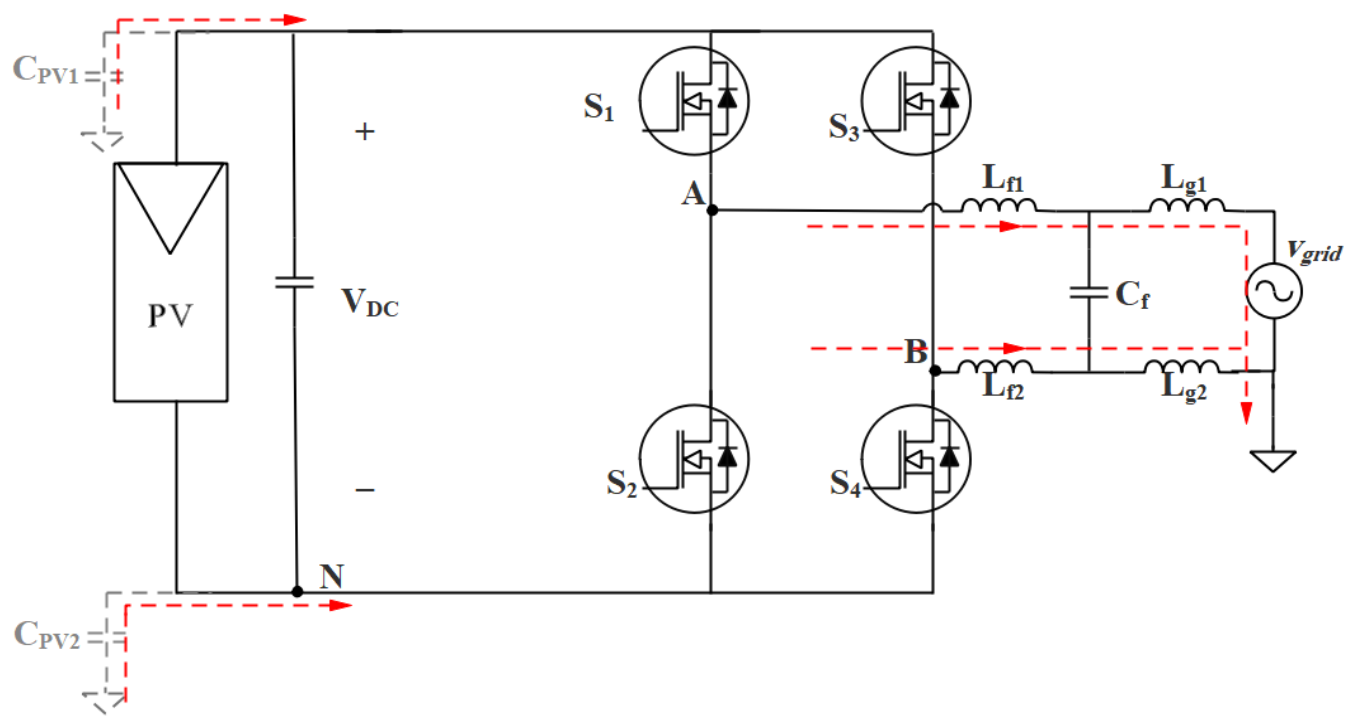

Fig. 2.4 Leakage current path for Full Bridge inverter.

Fig. 2.5 shows unipolar PWM signals for a full bridge inverter. Unipolar PWM can achieve three level output voltage and there are four modes of operation. 


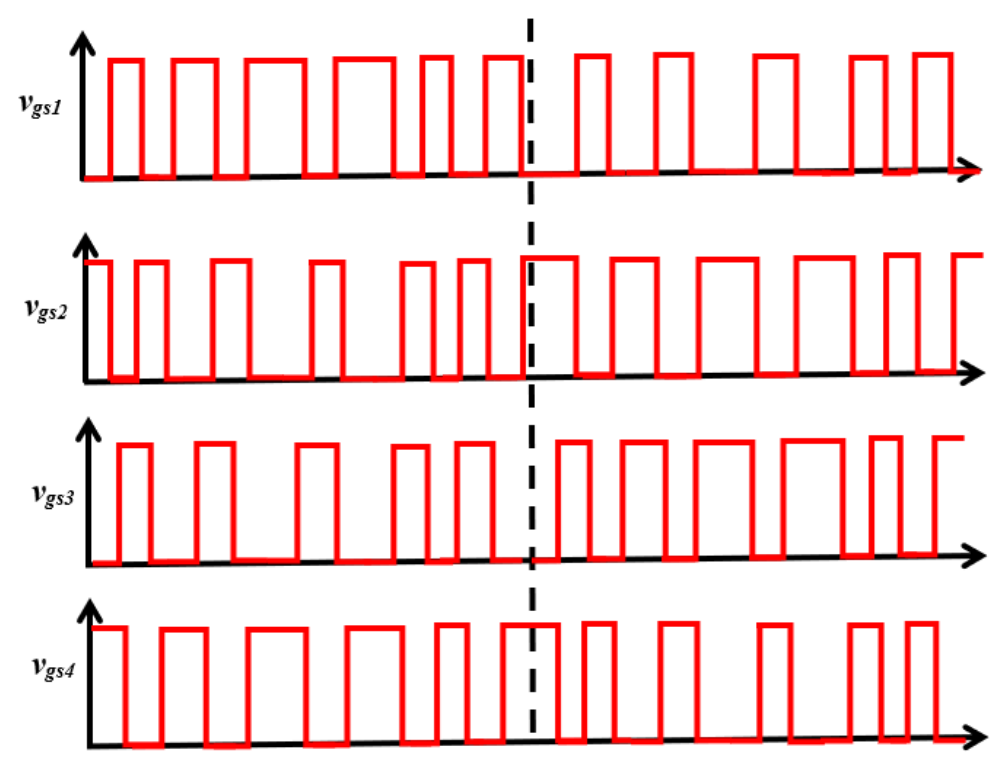

Fig. 2.5 PWM signals for Full Bridge inverter.

In Mode 1, S1 and S4 are turned ON, which is the positive half-period in the active state and all other switches are turned OFF. The current during this mode flows through $\mathrm{S} 1$ and $\mathrm{S} 4 . \mathrm{V}_{\mathrm{DM}}=\mathrm{V}_{\mathrm{AB}}=\mathrm{V}_{\mathrm{DC}}$, and the Common Mode voltage $\mathrm{V}_{\mathrm{CM}}=\left(\mathrm{V}_{\mathrm{AN}}+\right.$ $\left.\mathrm{V}_{\mathrm{BN}}\right) / 2=+\mathrm{V}_{\mathrm{DC}} / 2$

In Mode 2, S1 and S3 are turned $\mathrm{ON}$, which is the positive half-period in the freewheeling (Zero) state, and all other switches are turned OFF. The current during this mode flows through $\mathrm{S} 1$, and the anti-paralleled diode of $\mathrm{S} 3 . \mathrm{V}_{\mathrm{DM}}=\mathrm{V}_{\mathrm{AB}}=0$, and $\mathrm{V}_{\mathrm{CM}}=$ $\left(\mathrm{V}_{\mathrm{AN}}+\mathrm{V}_{\mathrm{BN}}\right) / 2=+\mathrm{V}_{\mathrm{DC}}$

In Mode 3, S2 and S3 are turned ON, which is the negative half-period in the active state and all other switches are turned OFF. The current during this mode flows in the opposite direction through $\mathrm{S} 2$ and $\mathrm{S} 3 . \mathrm{V}_{\mathrm{DM}}=\mathrm{V}_{\mathrm{AB}}=-\mathrm{V}_{\mathrm{DC}}$, and $\mathrm{V}_{\mathrm{CM}}=\left(\mathrm{V}_{\mathrm{AN}}+\mathrm{V}_{\mathrm{BN}}\right) / 2$ $=+\mathrm{V}_{\mathrm{DC}} / 2$. 
In Mode 4, S2 and S4 is turned ON, which is the negative half-period in the freewheeling (Zero) state, and all other switches turned OFF. The current during this mode flows through $\mathrm{S} 2$, and the anti-paralleled diode of $\mathrm{S} 4$. $\mathrm{V}_{\mathrm{DM}}=\mathrm{V}_{\mathrm{AB}}=0$, and $\mathrm{V}_{\mathrm{CM}}=$ $\left(\mathrm{V}_{\mathrm{AN}}+\mathrm{V}_{\mathrm{BN}}\right) / 2=0$. Table 2.1 summarizes the switching states of the full bridge inverter. As can be noticed from the operation modes of the full bridge inverter, the common mode voltage is not constant and it varies during the zero states between $+\mathrm{V}_{\mathrm{DC}}$ and 0 . This variation will lead to high ground leakage current flowing through the PV system.

Table 2.1 Switching states of Full Bridge inverter.

\begin{tabular}{ccccccc}
\hline \hline Operation modes & $\mathbf{S 1}$ & $\mathbf{S 2}$ & $\mathbf{S 3}$ & $\mathbf{S 4}$ & $\mathbf{V}_{\mathbf{D M}}$ & $\mathbf{V}_{\mathbf{C M}}$ \\
\hline$+\mathbf{V}_{\mathbf{D C}}$ & 1 & 0 & 0 & 1 & $+\mathrm{V}_{\mathrm{DC}}$ & $+\mathrm{V}_{\mathrm{DC}} / 2$ \\
$\mathbf{+ 0}$ & 1 & 0 & 1 & 0 & 0 & $+\mathrm{V}_{\mathrm{DC}}$ \\
$\mathbf{- 0}$ & 0 & 1 & 0 & 1 & 0 & 0 \\
$-\mathbf{V}_{\mathbf{D C}}$ & 0 & 1 & 1 & 0 & $-\mathrm{V}_{\mathrm{DC}}$ & $+\mathrm{V}_{\mathrm{DC}} / 2$ \\
\hline
\end{tabular}

Fig. 2.6 and Fig 2.7 show the simulation waveforms of the full bridge inverter. Fig. 2.6 shows the unipolar three level voltage generated from the inverter $\mathrm{V}_{\mathrm{AB}}$. Also, it shows $\mathrm{V}_{\mathrm{AN}}$ and $\mathrm{V}_{\mathrm{BN}}$ of the inverter, and since they are floating, this will lead to variation of common mode voltage during the zero states between $+\mathrm{V}_{\mathrm{DC}}$ and 0 .; thus, the common mode voltage is not constant. Fig. 2.7 shows the grid voltage and current. Also, it shows the leakage current. The full bridge inverter has high leakage current of almost $1.2 \mathrm{~A}$ RMS value, and the standards' requirement for a PV transformer-less inverter is less than 300mA. Hence, a full bridge inverter is not suitable for PV transformer-less application in its current form. 

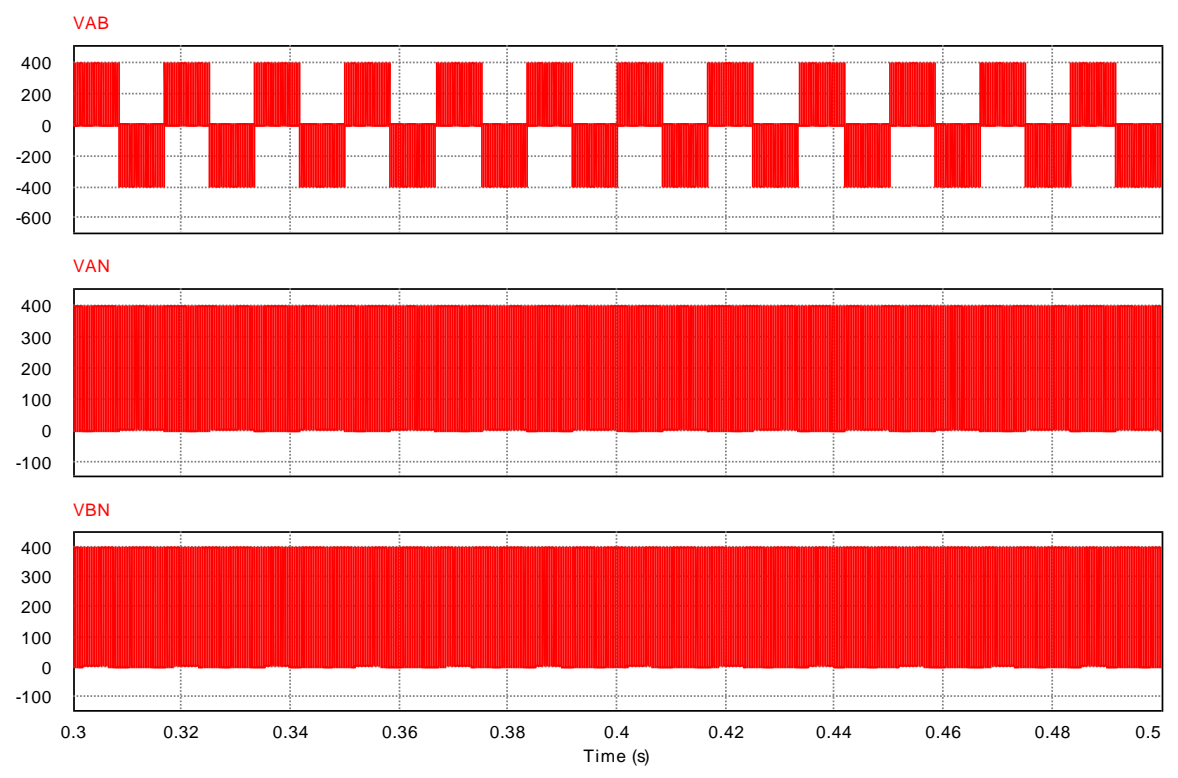

Fig. 2.6 Full Bridge inverter voltage simulation waveforms.
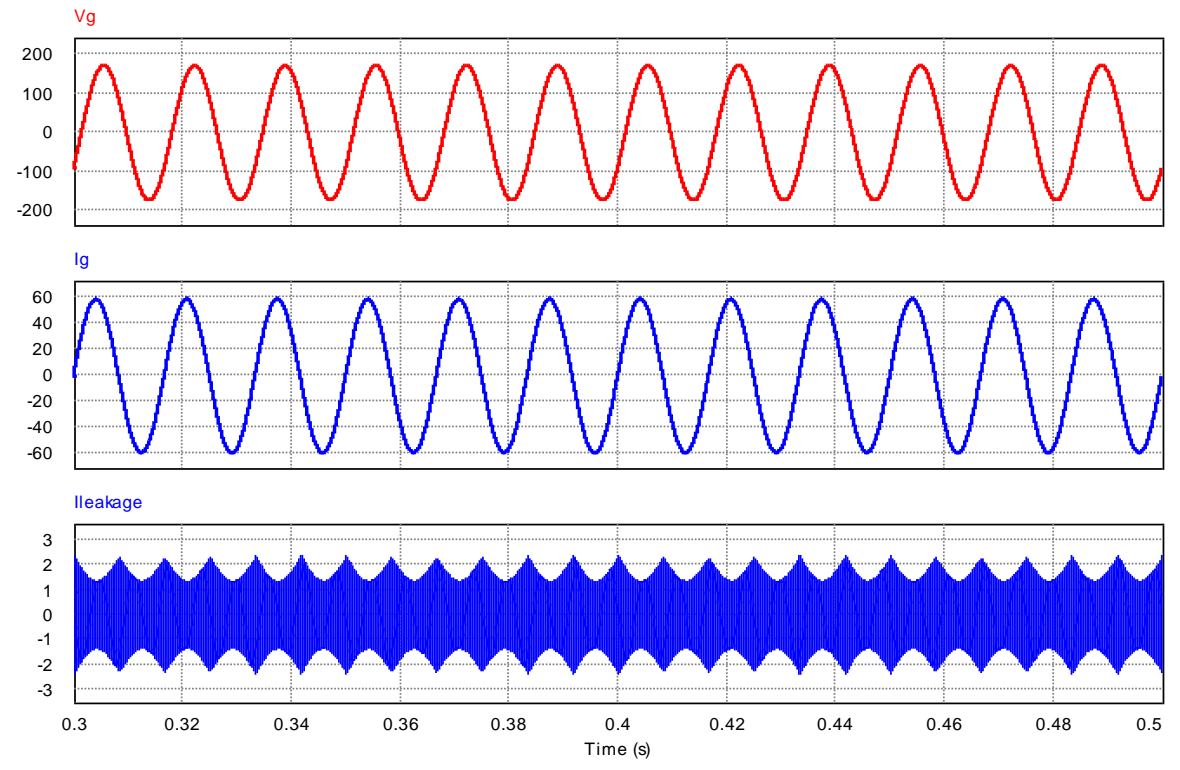

Fig. 2.7 Grid voltage and current and Full Bridge inverter leakage current.

Multiple transformer-less inverter topologies have been proposed [31]-[35] to eliminate the leakage current problem in full bridge inverters. One of the solutions proposed to minimize the leakage current is to maintain a constant $\mathrm{CM}$ voltage for all switching states [36]. However, such a solution requires a higher number of components that then increase the system's complexity. Another solution to minimize the leakage 
current is to isolate the two sources of the system (PV, grid) during the zero-state by modifying the PWM to keep the CM voltage constant [37], [38]. Multiple topologies have been developed based on this solution, such as the H5 topology [39] and H6 topology [40].

\subsubsection{H5 Topology}

One of the first derived PV transformer-less topologies from the full bridge inverter is H5 which is shown in Fig. 2.8 [39]. In this inverter, an extra switch S5 has been introduced to decouple the inverter output from the PV module during the zero state. By using this method, the common mode voltage can be kept constant and the leakage current can be reduced. Fig. 2.9 shows the hybrid PWM signals for the H5 topology where S1 and S3 are low frequency switches (switch at grid frequency) and S5, S2 and S4 are high frequency switches. This modulation can achieve three level output voltage and there are four modes of operation.

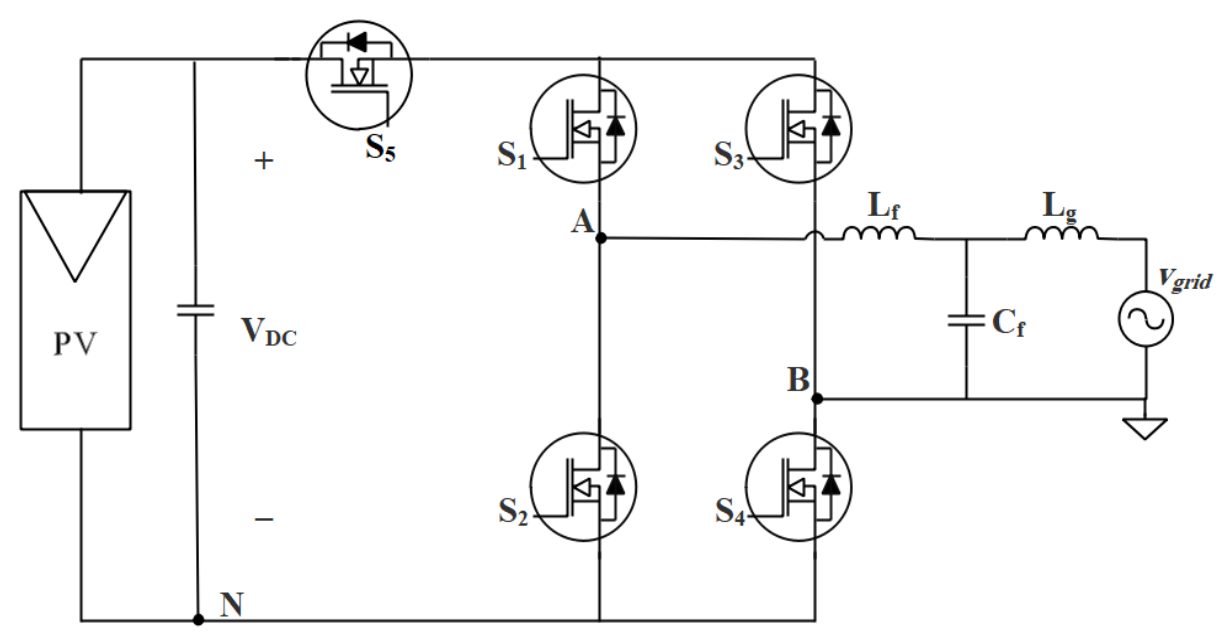

Fig. 2.8 H5 topology. 


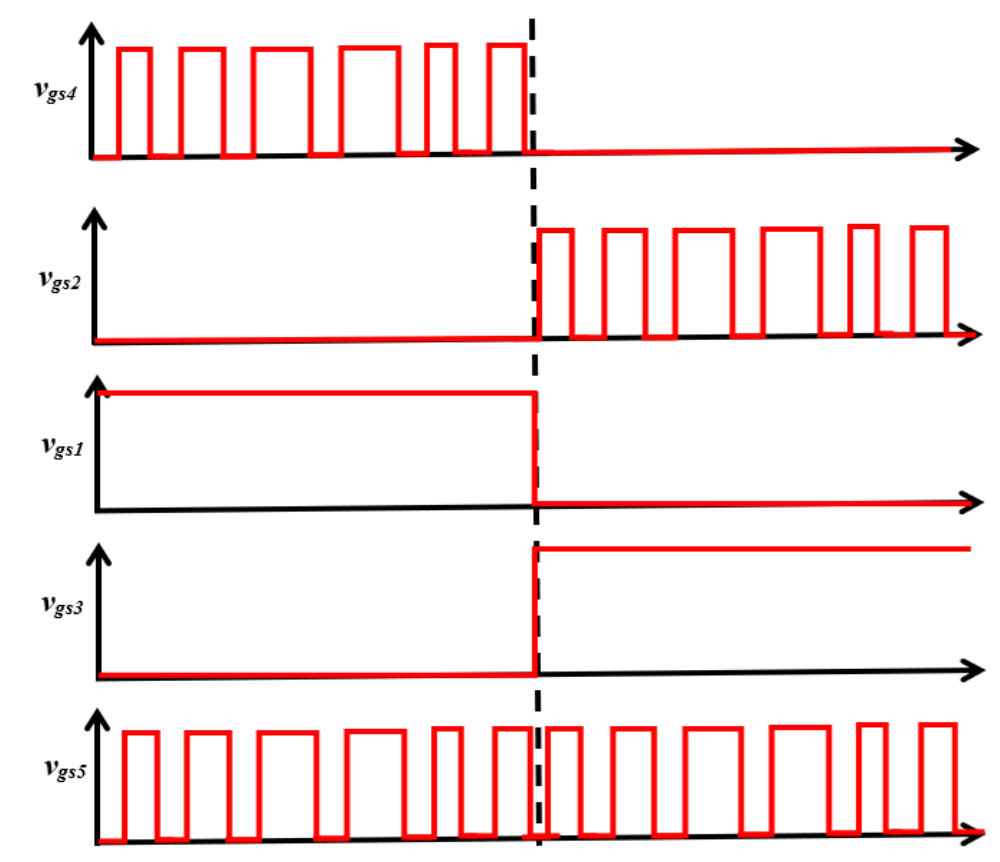

Fig. 2.9 Hybrid PWM signals for H5 topology.

In Mode 1, S1, S4 and S5 are turned ON, which is the positive half-period in the active state, and all other switches are turned OFF. The current during this mode flows through $\mathrm{S} 1, \mathrm{~S} 4$ and $\mathrm{S} 5 . \mathrm{V}_{\mathrm{DM}}=\mathrm{V}_{\mathrm{AB}}=+\mathrm{V}_{\mathrm{DC}}$, and the Common Mode voltage $\mathrm{V}_{\mathrm{CM}}=\left(\mathrm{V}_{\mathrm{AN}}+\right.$ $\left.\mathrm{V}_{\mathrm{BN}}\right) / 2=+\mathrm{V}_{\mathrm{DC}} / 2$.

In Mode 2, S1 is turned $\mathrm{ON}$, which is the positive half-period in the freewheeling (zero) state, and all other switches are turned OFF. The current during this mode flows through $\mathrm{S} 1$, and the anti-paralleled diode of $\mathrm{S} 3 . \mathrm{V}_{\mathrm{DM}}=\mathrm{V}_{\mathrm{AB}}=0$, and $\mathrm{V}_{\mathrm{CM}}=\left(\mathrm{V}_{\mathrm{AN}}+\mathrm{V}_{\mathrm{BN}}\right) / 2$ $=+\mathrm{V}_{\mathrm{DC}} / 2$.

In Mode 3, S2, S3 and S5 are turned ON, which is the negative half-period in the active state, and all other switches are turned OFF. The current during this mode flows in the opposite direction through $\mathrm{S} 2$, S3 and S5. $\mathrm{V}_{\mathrm{DM}}=\mathrm{V}_{\mathrm{AB}}=-\mathrm{V}_{\mathrm{DC}}$, and $\mathrm{V}_{\mathrm{CM}}=\left(\mathrm{V}_{\mathrm{AN}}+\right.$ $\left.\mathrm{V}_{\mathrm{BN}}\right) / 2=+\mathrm{V}_{\mathrm{DC}} / 2$. 
In Mode 4, S3 is turned ON, which is the negative half-period in the freewheeling (zero) state, and all other switches are turned OFF. The current during this mode flows through $\mathrm{S} 3$ and the anti-paralleled diode of $\mathrm{S} 1 . \mathrm{V}_{\mathrm{DM}}=\mathrm{V}_{\mathrm{AB}}=0$, and $\mathrm{V}_{\mathrm{CM}}=\left(\mathrm{V}_{\mathrm{AN}}+\mathrm{V}_{\mathrm{BN}}\right) / 2$ $=+\mathrm{V}_{\mathrm{DC}} / 2$. Table 2.2 summarizes the switching states of the $\mathrm{H} 5$ inverter.

Table 2.2 Switching states of H5 topology.

\begin{tabular}{|c|c|c|c|c|c|c|c|}
\hline Operation modes & S1 & S2 & $\overline{\mathbf{S 3}}$ & S4 & S5 & $\overline{V_{\text {DM }}}$ & $\overline{V_{\mathrm{CM}}}$ \\
\hline$+V_{D C}$ & 1 & 0 & 0 & 1 & 1 & $+\mathrm{V}_{\mathrm{DC}}$ & $+\mathrm{V}_{\mathrm{DC}} / 2$ \\
\hline$+\mathbf{0}$ & 1 & 0 & 0 & 0 & 0 & 0 & $+\mathrm{V}_{\mathrm{DC}} / 2$ \\
\hline-0 & 0 & 0 & 1 & 0 & 0 & 0 & $+\mathrm{V}_{\mathrm{DC}} / 2$ \\
\hline$-V_{D C}$ & 0 & 1 & 1 & 0 & 1 & $-\mathrm{V}_{\mathrm{DC}}$ & $+\mathrm{V}_{\mathrm{DC}} / 2$ \\
\hline
\end{tabular}

Fig. 2.10 and Fig. 2.11 show the simulation waveforms of the H5 inverter. Fig. 2.10 shows the unipolar three level voltage generated from the inverter $\mathrm{V}_{\mathrm{AB}}$. Also, it shows $\mathrm{V}_{\mathrm{AN}}$ and $\mathrm{V}_{\mathrm{BN}}$ of the inverter, and it can be seen that they are floating during the zero state; thus, the common mode voltage is not constant. Fig. 2.11 shows the grid voltage and current. Also, it shows the leakage current. It can be seen that the H5 inverter can achieve a lower leakage current of $134.6 \mathrm{~mA}$ compared to the full bridge inverter. However, the major drawback of this topology is the high conduction losses because six switches are conducting during the active states. 


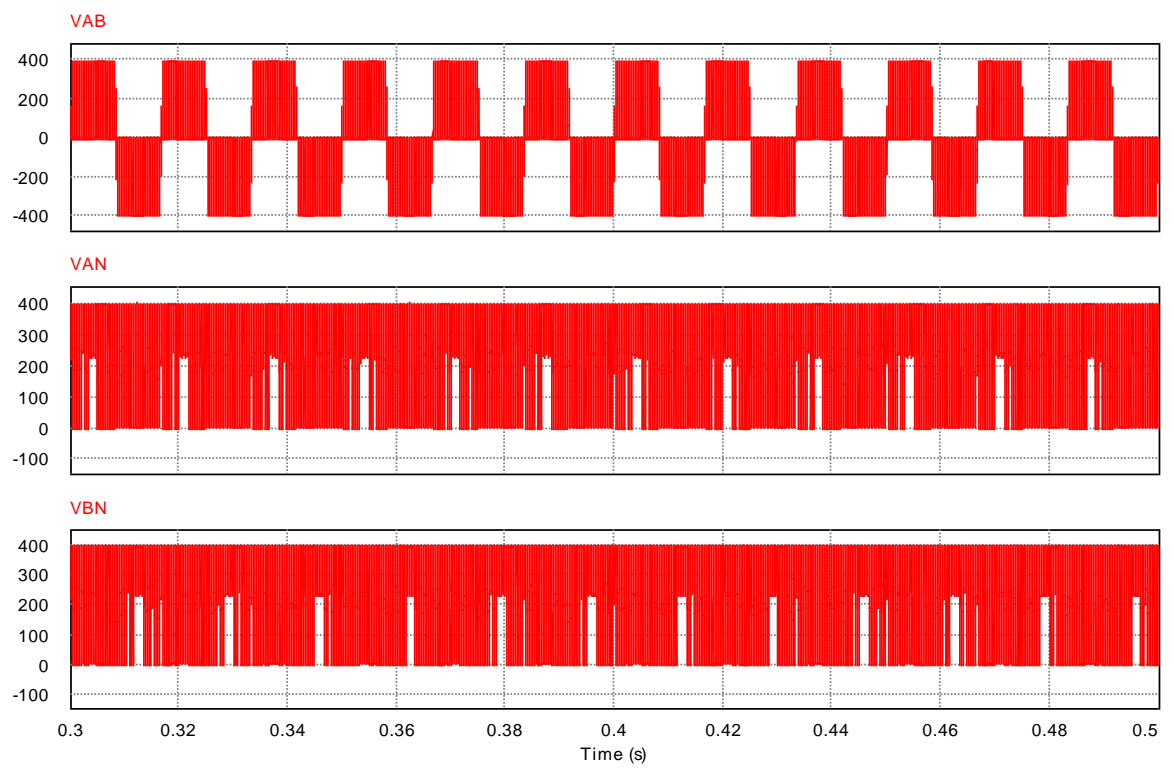

Fig. 2.10 H5 topology voltage simulation waveforms.

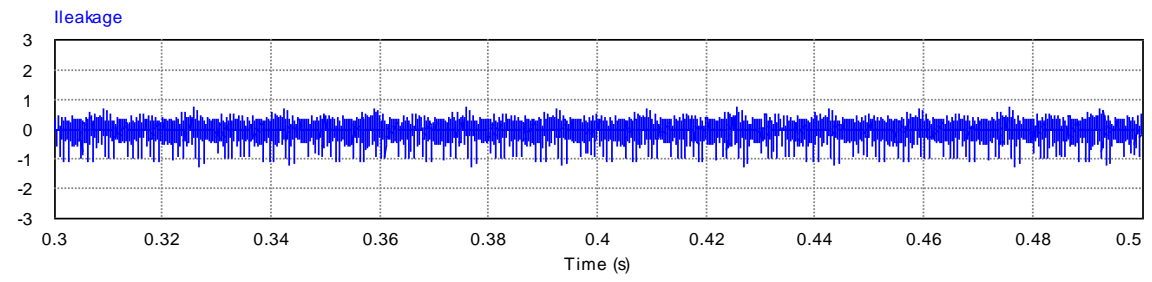

Fig. 2.11 Grid voltage and current and H5 topology leakage current.

\subsubsection{H6 Topology}

The H6 inverter [40] consists of six switches and two freewheeling diodes-D7 and D8 - as shown in Fig. 2.12. Fig. 2.13 shows the hybrid PWM signals for this topology where S5 and S6 are low frequency switches (switch at grid frequency) and S1, $\mathrm{S} 2, \mathrm{~S} 3$ and S4 are high frequency switches. This modulation can achieve three level output voltage and there are four modes of operation. 


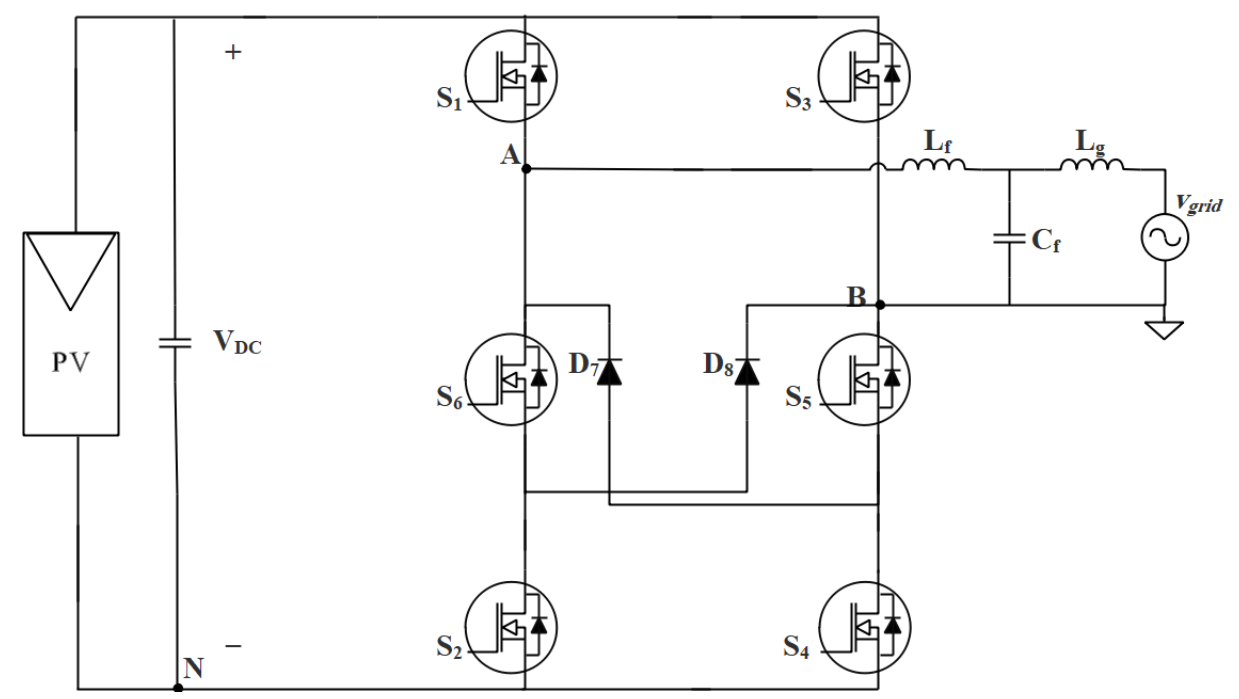

Fig. 2.12 H6 topology.

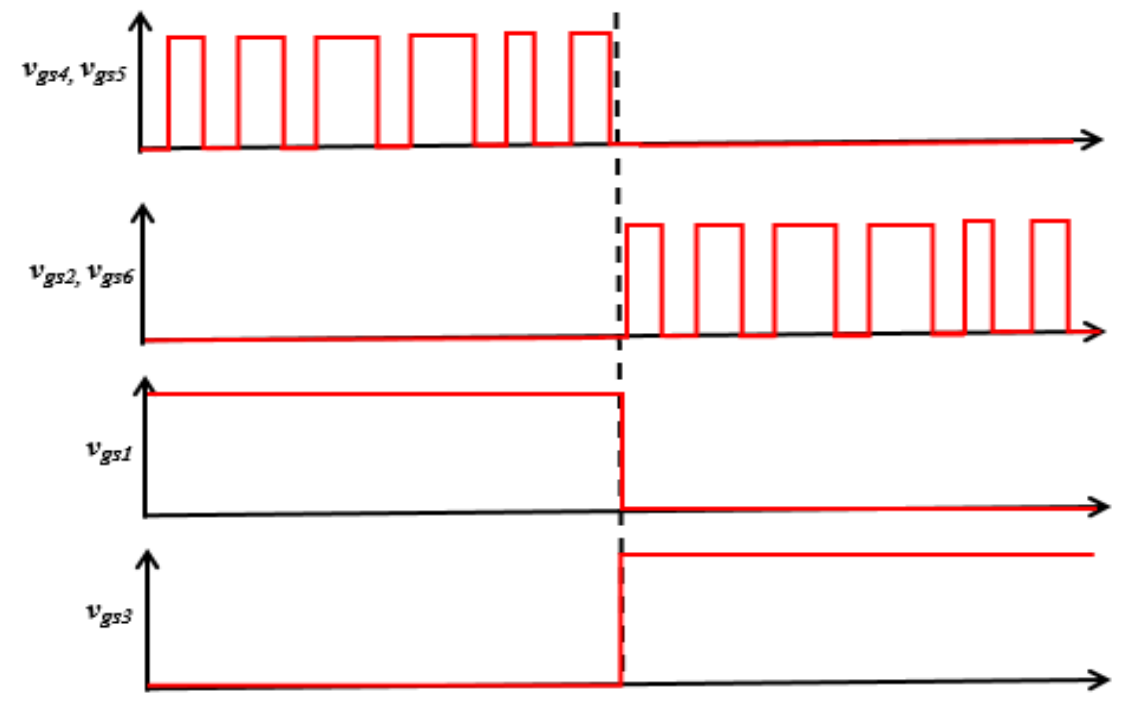

Fig. 2.13 PWM signals for H6 topology.

In Mode 1, S1, S4 and S5 are turned ON, which is the positive half-period in the active state, and all other switches are turned OFF. The current during this mode flows through S1, S4 and S5. $\mathrm{V}_{\mathrm{DM}}=\mathrm{V}_{\mathrm{AB}}=+\mathrm{V}_{\mathrm{DC}}$, and the Common Mode voltage $\mathrm{V}_{\mathrm{CM}}=\left(\mathrm{V}_{\mathrm{AN}}+\right.$ $\left.\mathrm{V}_{\mathrm{BN}}\right) / 2=+\mathrm{V}_{\mathrm{DC}} / 2$. 
In Mode 2, S5 is turned ON, which is the positive half-period in the freewheeling (zero) state, and all other switches are turned OFF. The current during this mode flows through S5, and D7. $\mathrm{V}_{\mathrm{DM}}=\mathrm{V}_{\mathrm{AB}}=0$, and $\mathrm{V}_{\mathrm{CM}}=\left(\mathrm{V}_{\mathrm{AN}}+\mathrm{V}_{\mathrm{BN}}\right) / 2=+\mathrm{V}_{\mathrm{DC}} / 2$.

In Mode 3, S2, S3 and S6 are turned ON, which is the negative half-period in the active state, and all other switches are turned OFF. The current during this mode flows in the opposite direction through $\mathrm{S} 2, \mathrm{~S} 3$ and $\mathrm{S} 6 . \mathrm{V}_{\mathrm{DM}}=\mathrm{V}_{\mathrm{AB}}=-\mathrm{V}_{\mathrm{DC}}$, and $\mathrm{V}_{\mathrm{CM}}=\left(\mathrm{V}_{\mathrm{AN}}+\right.$ $\left.\mathrm{V}_{\mathrm{BN}}\right) / 2=+\mathrm{V}_{\mathrm{DC}} / 2$.

In Mode 4, S6 is turned ON, which is the negative half-period in the freewheeling (zero) state, and all other switches are turned OFF. The current during this mode flows through S6 and D8. $\mathrm{V}_{\mathrm{DM}}=\mathrm{V}_{\mathrm{AB}}=0$, and $\mathrm{V}_{\mathrm{CM}}=\left(\mathrm{V}_{\mathrm{AN}}+\mathrm{V}_{\mathrm{BN}}\right) / 2=+\mathrm{V}_{\mathrm{DC}} / 2$. Table 2.3 summarizes the switching states of the H6 inverter.

Table 2.3 Switching states of H6 topology.

\begin{tabular}{cccccccccc}
\hline \hline Operation modes & $\mathbf{S 1}$ & $\mathbf{S 2}$ & $\mathbf{S 3}$ & $\mathbf{S 4}$ & $\mathbf{S 5}$ & $\mathbf{S 6}$ & $\mathbf{V}_{\mathbf{D M}}$ & $\mathbf{V}_{\mathbf{C M}}$ \\
\hline$+\mathbf{V}_{\mathbf{D C}}$ & 1 & 0 & 0 & 1 & 1 & 0 & $+\mathrm{V}_{\mathrm{DC}}$ & $+\mathrm{V}_{\mathrm{DC}} / 2$ \\
$\mathbf{+ 0}$ & 0 & 0 & 0 & 0 & 1 & 0 & 0 & $+\mathrm{V}_{\mathrm{DC}} / 2$ \\
$\mathbf{- 0}$ & 0 & 0 & 0 & 0 & 0 & 1 & 0 & $+\mathrm{V}_{\mathrm{DC}} / 2$ \\
$-\mathbf{V}_{\mathbf{D C}}$ & 0 & 1 & 1 & 0 & 0 & 1 & $-\mathrm{V}_{\mathrm{DC}}$ & $+\mathrm{V}_{\mathrm{DC}} / 2$ \\
\hline \hline
\end{tabular}

Fig. 2.14 and Fig. 2.15 show the simulation waveforms of the H6 inverter. Fig. 2.14 shows the unipolar three level voltage generated from the inverter $\mathrm{V}_{\mathrm{AB}}$. Also, it shows $\mathrm{V}_{\mathrm{AN}}$ and $\mathrm{V}_{\mathrm{BN}}$ of the inverter. Fig. 2.15 shows the grid voltage and current. Also, it shows the leakage current. It can be seen that the H6 inverter can achieve significantly 
lower leakage current of $12.2 \mathrm{~mA}$ compared to the $\mathrm{H} 5$ inverter. However, H6 also suffers from high conduction losses because six switches are conducting during the active states.
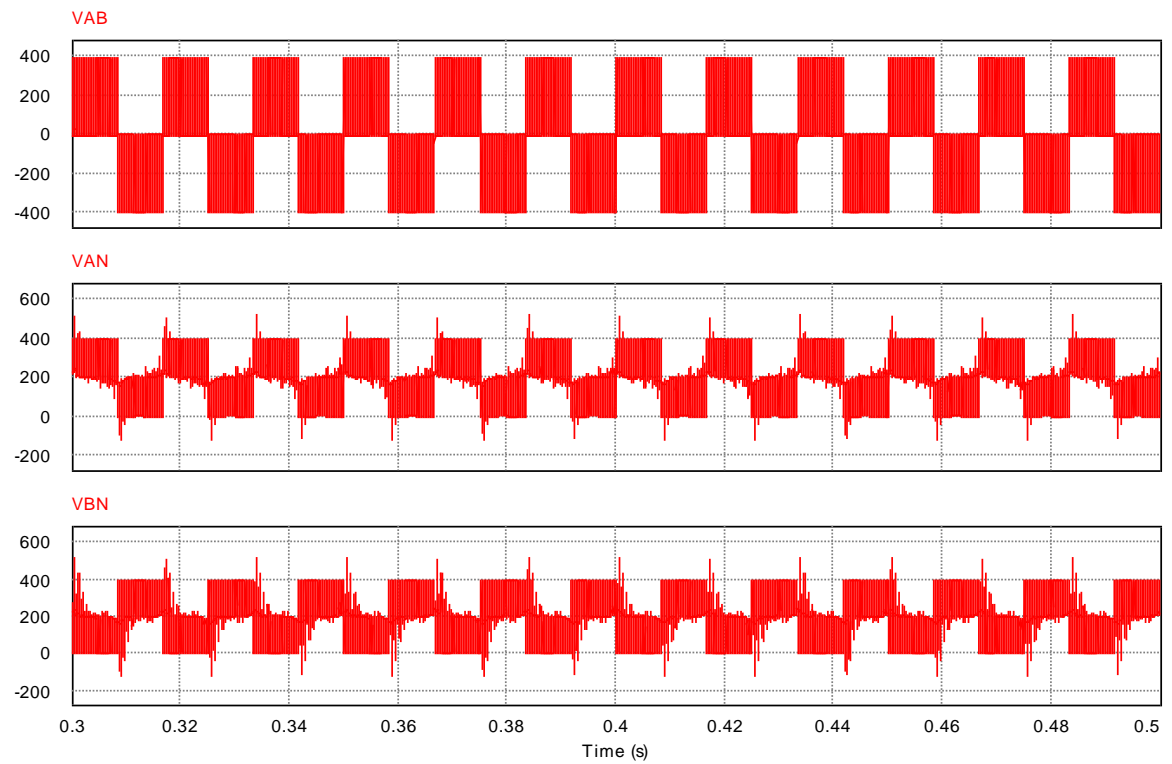

Fig. 2.14 H6 topology voltage simulation waveforms.
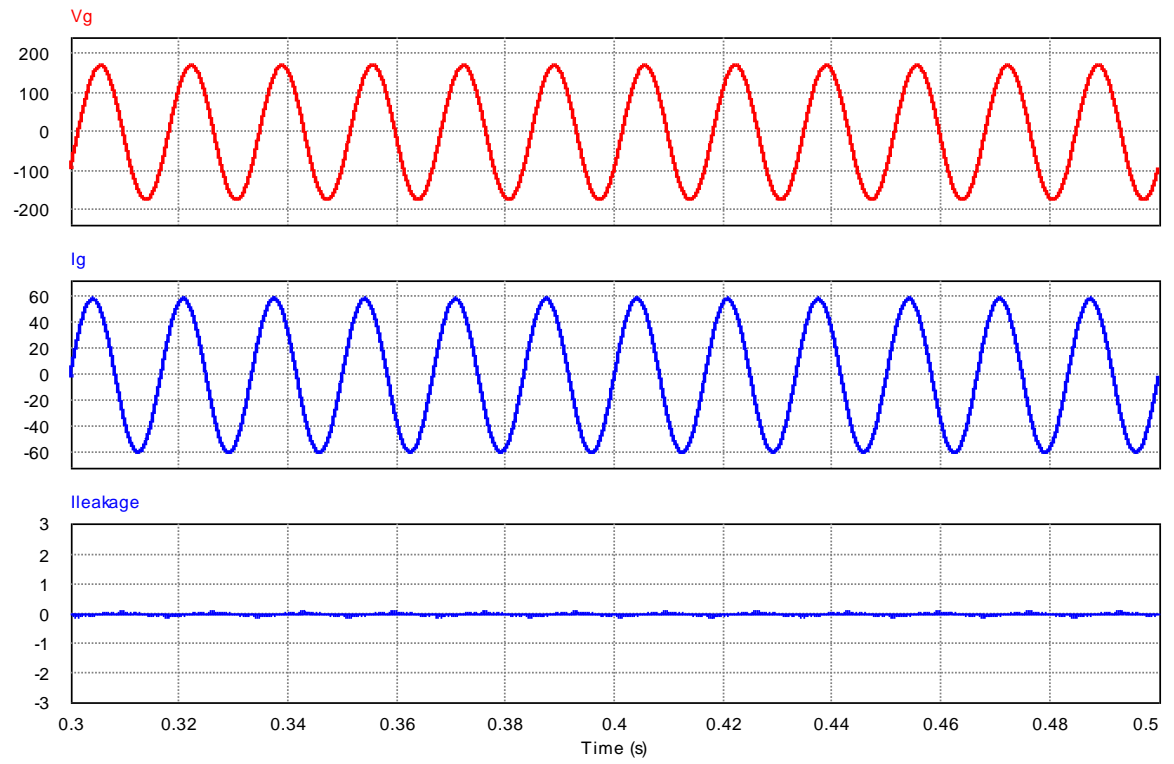

Fig. 2.15 Grid voltage and current and H6 topology leakage current. 


\subsection{Proposed High Efficiency Transformer-less Inverter}

The proposed design is derived from the H5 topology in Fig. 2.8 [41]. By disconnecting S5 from S1 and connecting it to terminal A, during the positive half cycle the current will flow through switches S4 and S5. Also, an extra switch S6 is added between the DC link and terminal B, which will form a new current path. Thus, the current during the negative half cycle active mode will flow through switches S6 and S2. Thus, a new transformer-less inverter topology is derived as shown in Fig. 2.16, where S2, S4, S5 and S6 are high frequency switches, and S1 and S3 are low frequency freewheeling switches. The new topology forms new current paths, which lower the conduction loss when compared to the H5 and H6 topologies. Therefore, the current of the proposed topology in the active mode flows through four switches. As a result, compared to the H5 and H6 topologies, the proposed topology has achieved the lowest conduction losses. Table 2.4 shows a comparison between the proposed topology, H5 topology and H6 topology in terms of the number of conducting switches during the active states.

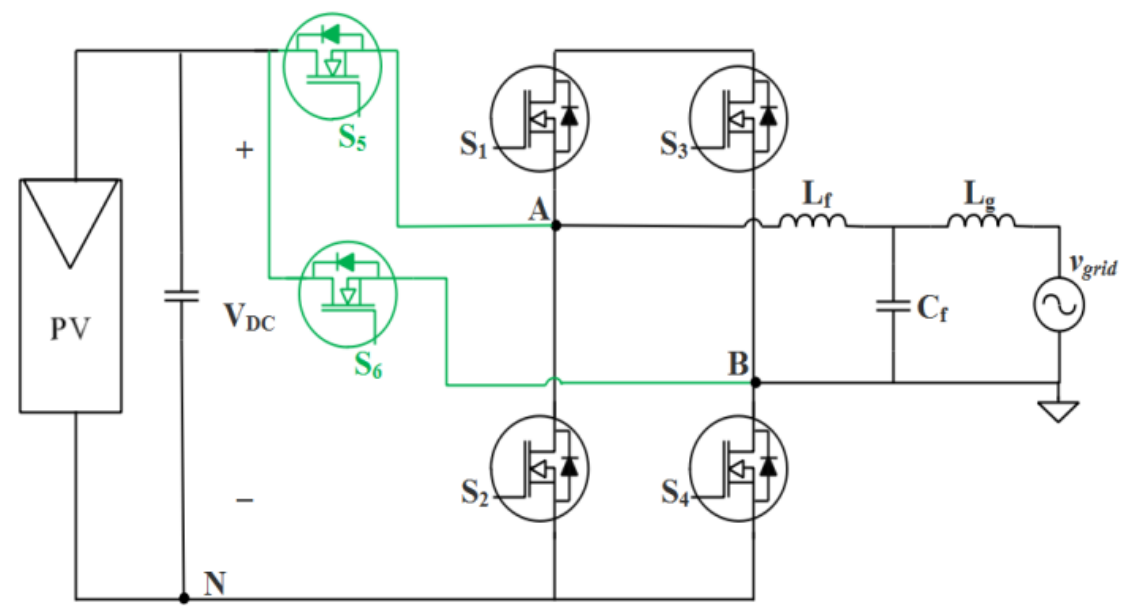

Fig. 2.16 Proposed topology derived from H5. 
Table 2.4 Comparison of conducting devices for different topologies.

\begin{tabular}{cccc}
\hline \hline & H5 & H6 & $\begin{array}{c}\text { Proposed } \\
\text { topology }\end{array}$ \\
\hline $\begin{array}{c}\text { Total number of devices } \\
\text { Number of conducting devices }(\mathbf{v}>\mathbf{0})\end{array}$ & 5 & 6 & 6 \\
Number of conducting devices $(\mathbf{v}<\mathbf{0})$ & 3 & 3 & 2 \\
Total Number of conducting devices during active & 3 & 3 & 2 \\
$\begin{array}{c}\text { modes } \\
\text { Number of devices in freewheeling }\end{array}$ & 2 & 2 & 4 \\
& & & 2 \\
\hline \hline
\end{tabular}

\subsubsection{Operation Modes Analysis of The Proposed Topology}

The gate drive signals of the proposed topology are shown in Fig. 2.17, where $\mathrm{vg}$ is the grid voltage; $\mathrm{I}_{\text {ref }}$ is the reference current of the system; and $\mathrm{Vgs}_{\mathrm{gs}}, \mathrm{Vgs}_{\mathrm{gs}}, \mathrm{Vgs}_{\mathrm{g} 3}, \mathrm{~V}_{\mathrm{gs}} 4, \mathrm{vgs}_{\mathrm{gs}}$ and $\mathrm{Vgs}_{\mathrm{g} 6}$ are the gate drive signals of switches $\mathrm{S} 1, \mathrm{~S} 2, \mathrm{~S} 3, \mathrm{~S} 4, \mathrm{~S} 5$ and $\mathrm{S} 6$, respectively for unity power factor. Modes of operation of the proposed topology are shown in Fig. 2.18. There are four operation modes to generate inverter output voltage:

$$
V_{\text {Inv }}=\left\{\begin{array}{c}
+V_{D c} \\
0 \\
-V_{D C}
\end{array}\right\}
$$




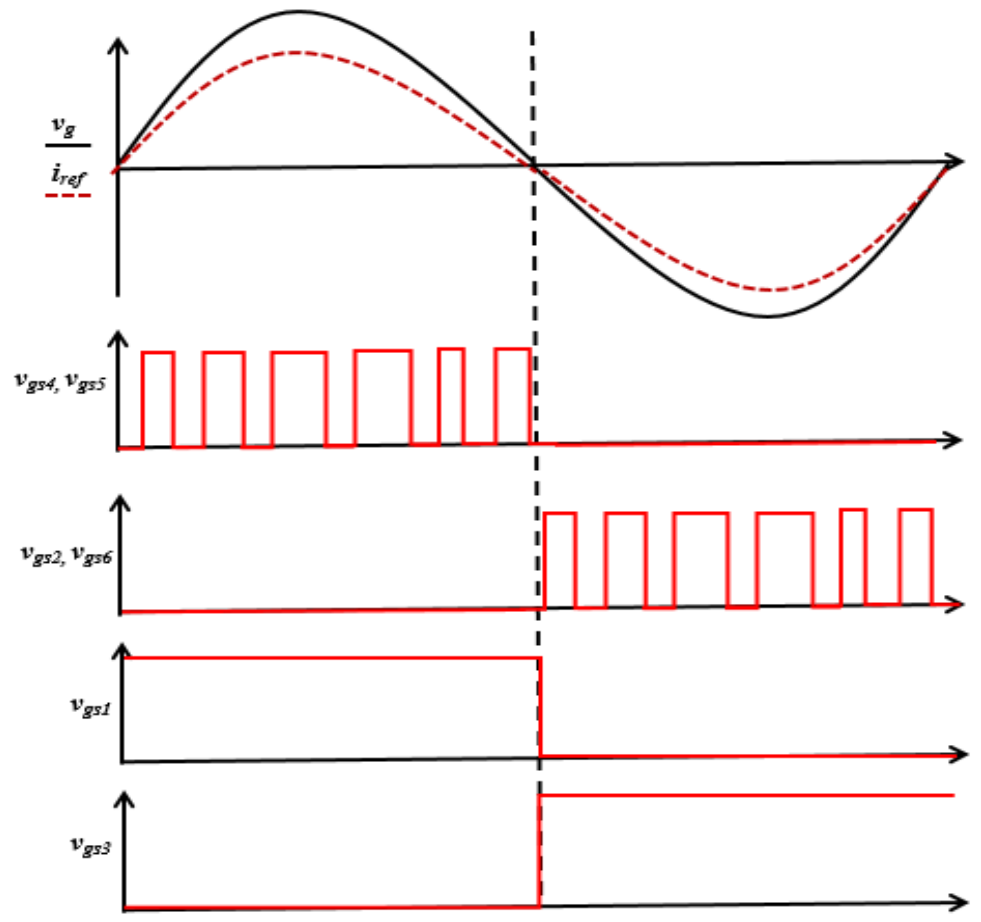

Fig. 2.17 Gate drive signals with unity power factor.

In Mode 1, S1, S4 and S5 are turned ON, which is the positive half-period in the active state, and all other switches are turned OFF. The current during this mode flows through S4 and S5. $\mathrm{V}_{\mathrm{AB}}=\mathrm{V}_{\mathrm{DC}}$, and the Common Mode voltage $\mathrm{V}_{\mathrm{CM}}=\left(\mathrm{V}_{\mathrm{AN}}+\mathrm{V}_{\mathrm{BN}}\right) / 2=$ $\left(\mathrm{V}_{\mathrm{DC}}+0\right) / 2=\mathrm{V}_{\mathrm{DC}} / 2$.

In Mode 2, S1 is turned ON, which is the positive half-period in the freewheeling state, and all other switches are turned OFF. The current during this mode flows through $\mathrm{S} 1$, and the anti-paralleled diode of $\mathrm{S} 3 . \mathrm{V}_{\mathrm{AB}}=0$, and $\mathrm{V}_{\mathrm{CM}}=\left(\mathrm{V}_{\mathrm{AN}}+\mathrm{V}_{\mathrm{BN}}\right) / 2=\left(\mathrm{V}_{\mathrm{DC}} / 2+\right.$ $\mathrm{VDC} / 2) / 2=\mathrm{V}_{\mathrm{DC}} / 2$

In Mode 3, S2, S6 and S3 are turned ON, which is the negative half-period in the active state, and all other switches are turned OFF. The current during this mode flows in 
the opposite direction through $\mathrm{S} 6$ and $\mathrm{S} 2 . \mathrm{V}_{\mathrm{AB}}=-\mathrm{V}_{\mathrm{DC}}$, and $\mathrm{V}_{\mathrm{CM}}=\left(\mathrm{V}_{\mathrm{AN}}+\mathrm{V}_{\mathrm{BN}}\right) / 2=$ $\left(0+\mathrm{V}_{\mathrm{DC}}\right) / 2=\mathrm{V}_{\mathrm{DC}} / 2$.

In Mode 4, S3 is turned ON, which is the negative half-period in the freewheeling state, and all other switches turned OFF. The current during this mode flows through S3 and the anti-paralleled diode of $\mathrm{S} 1 . \mathrm{V}_{\mathrm{AB}}=0$, and $\mathrm{V}_{\mathrm{CM}}=\left(\mathrm{V}_{\mathrm{AN}}+\mathrm{V}_{\mathrm{BN}}\right) / 2=\left(\mathrm{V}_{\mathrm{DC}} / 2+\right.$ $\left.\mathrm{V}_{\mathrm{DC}} / 2\right) / 2=\mathrm{V}_{\mathrm{DC}} / 2$. Table 2.5 summarizes the switching states of the proposed inverter.

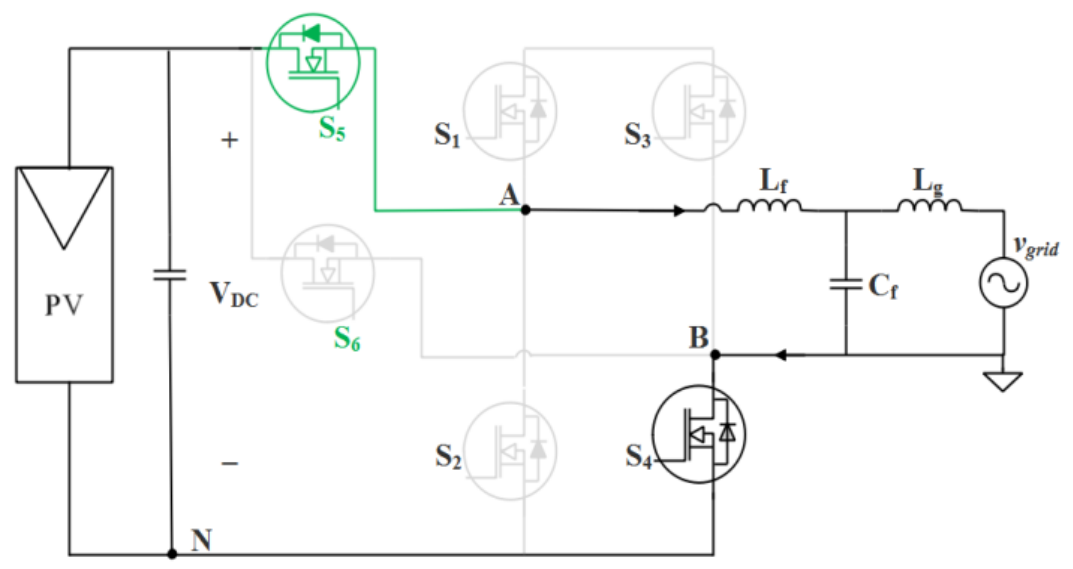

(a)

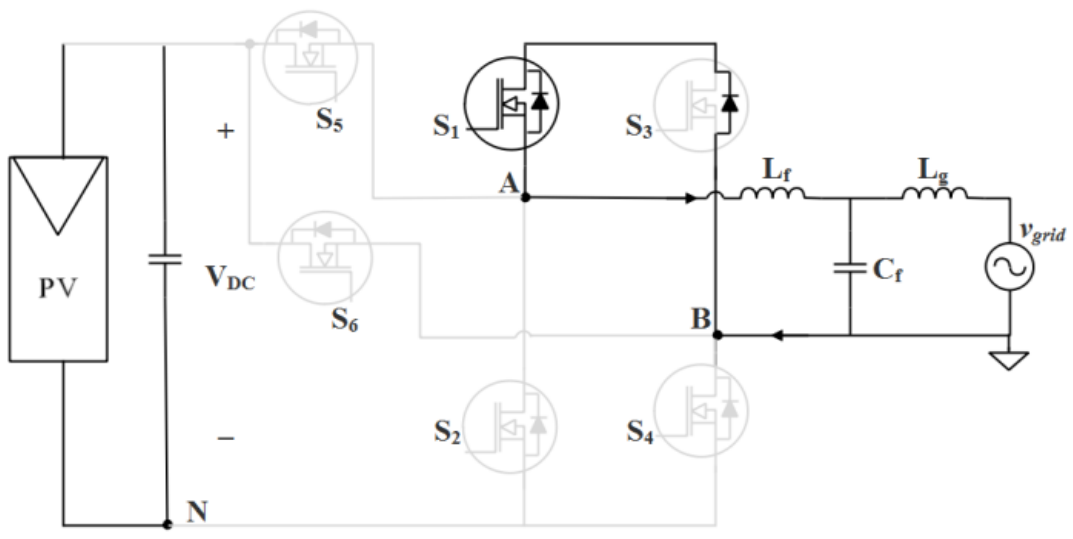

(b) 


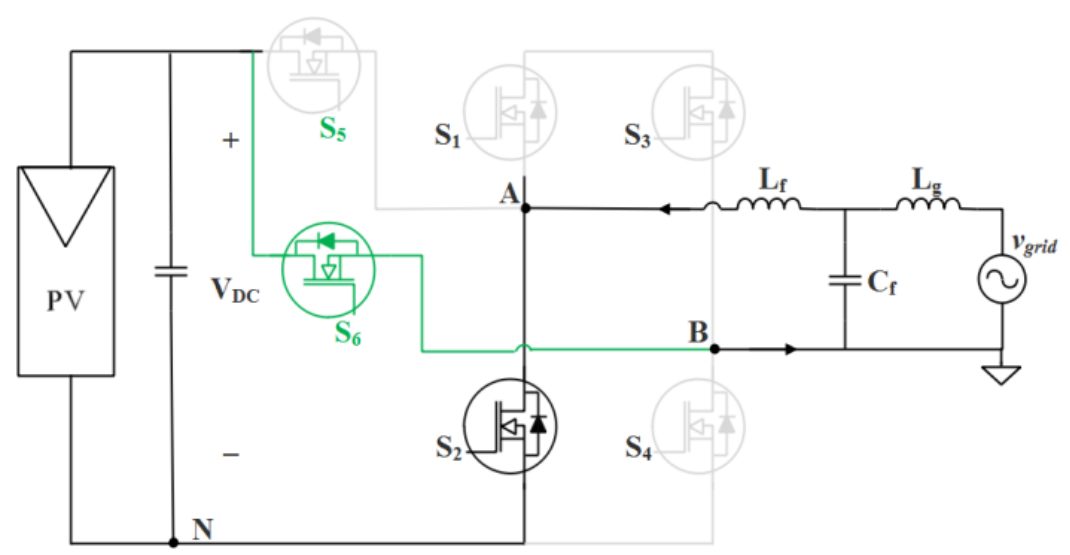

(c)

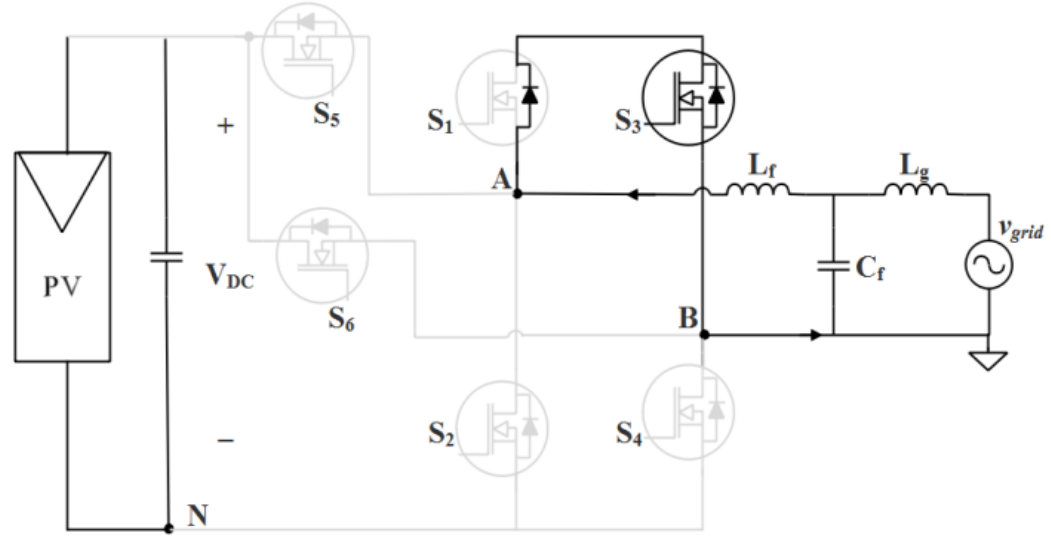

(d)

Fig. 2.18 Proposed topology operational modes: (a) Active state positive half- cycle; (b) Zero-state positive half cycle; (c) Active state negative half- cycle; (d) Zero-state negative half cycle.

Table 2.5 Switching states of proposed topology.

\begin{tabular}{ccccccccc}
\hline \hline Operation modes & $\mathbf{S 1}$ & $\mathbf{S 2}$ & $\mathbf{S 3}$ & $\mathbf{S 4}$ & $\mathbf{S 5}$ & $\mathbf{S 6}$ & $\mathbf{V}_{\mathbf{D M}}$ & $\mathbf{V}_{\mathbf{C M}}$ \\
\hline$+\mathbf{V}_{\mathbf{D C}}$ & 0 & 0 & 0 & 1 & 1 & 0 & $+\mathrm{V}_{\mathrm{DC}}$ & $+\mathrm{V}_{\mathrm{DC}} / 2$ \\
$\mathbf{+ 0}$ & 1 & 0 & 0 & 0 & 0 & 0 & 0 & $+\mathrm{V}_{\mathrm{DC}} / 2$ \\
$\mathbf{- 0}$ & 0 & 0 & 1 & 0 & 0 & 1 & 0 & $+\mathrm{V}_{\mathrm{DC}} / 2$ \\
$-\mathbf{V}_{\mathbf{D C}}$ & 0 & 1 & 0 & 0 & 0 & 1 & $-\mathrm{V}_{\mathrm{DC}}$ & $+\mathrm{V}_{\mathrm{DC}} / 2$ \\
\hline \hline
\end{tabular}

Fig. 2.19 and Fig 2.20 show the simulation waveforms of the proposed inverter.

Fig. 2.19 shows the unipolar three level voltage generated from the inverter $\mathrm{V}_{\mathrm{AB}}$. Also, it shows $\mathrm{V}_{\mathrm{AN}}$ and $\mathrm{V}_{\mathrm{BN}}$ of the inverter. Fig. 2.20 shows the grid voltage and current. Also, it 
shows the leakage current and it can be seen that the proposed inverter can achieve significantly lower leakage current of $11.7 \mathrm{~mA}$ compared to the $\mathrm{H} 5$ inverter and is almost like that of the H6 topology. However, the proposed topology achieves lower conduction losses than the H6 topology because only four switches are conducting during the active states.

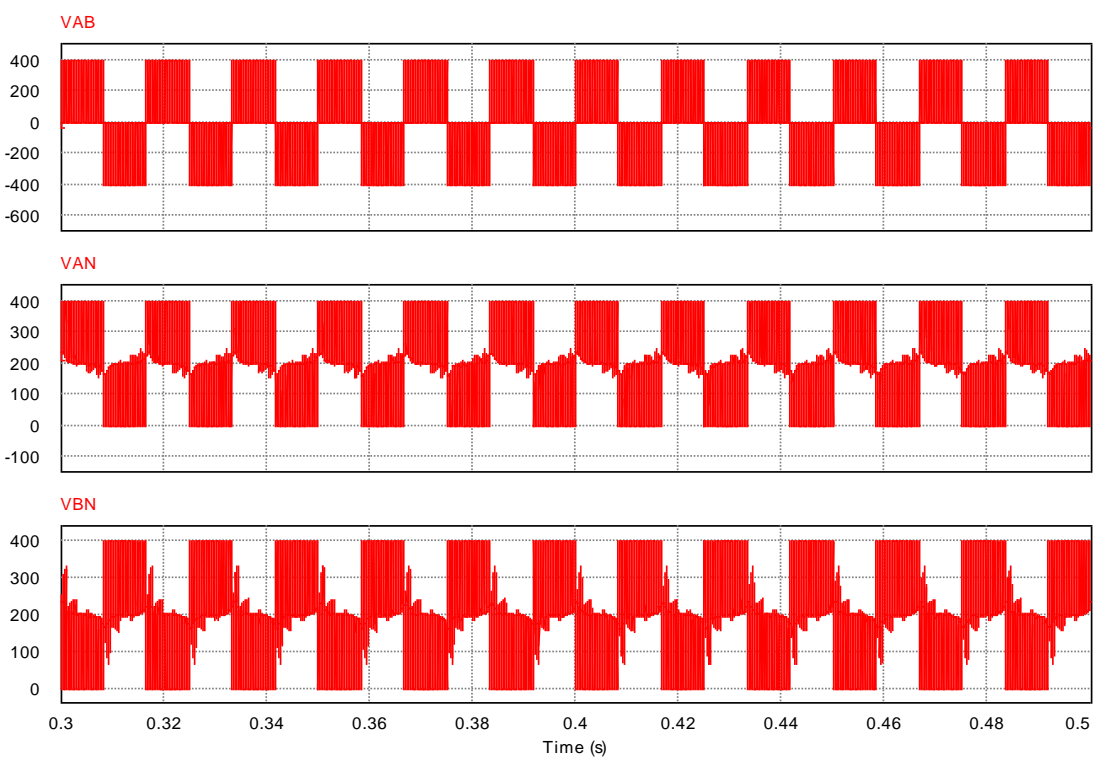

Fig. 2.19 Proposed topology voltage simulation waveforms.
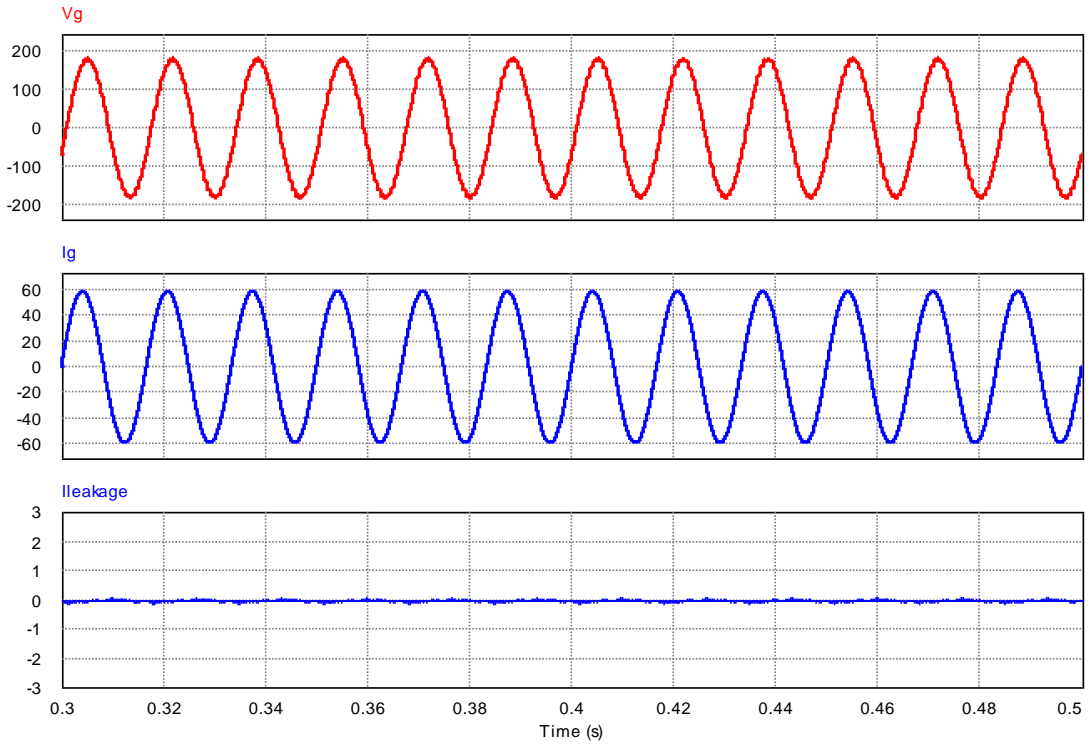

Fig. 2.20 Grid voltage and current and the proposed topology leakage current. 


\subsubsection{Theoretical Power Loss Model Calculation}

The power losses of the semiconductor devices are analyzed using different power loads. The semiconductor power device losses are divided into conduction and switching losses. The switching losses can be divided to Switch-ON losses and SwitchOFF losses. The semiconductor power device losses have been explained and derived in detail [9], [41]. To calculate the conduction losses, voltage drop across each device must be identified and is given by:

$$
\begin{aligned}
& \mathrm{v}_{\mathrm{DS}}(\operatorname{MOSFET})=\mathrm{i}(\mathrm{t}) * \mathrm{R}_{\mathrm{DS}} \\
& \mathrm{v}_{\mathrm{AK}}(\text { Diode })=\mathrm{V}_{\mathrm{f}} * \mathrm{R}_{\mathrm{AK}}
\end{aligned}
$$

where vDs is MOSFET's drain to source voltage drop, and RDs is the MOSFET ON state resistance. $\mathrm{V}_{\mathrm{AK}}$ is the voltage drop between the diode anode and cathode; $\mathrm{V}_{\mathrm{f}}$ is diode voltage drop under zero current conditions, and $\mathrm{R}_{\mathrm{AK}}$ is the diode $\mathrm{ON}$ resistance. The current that passes the device is $\mathrm{i}(\mathrm{t})$. Thus, the conduction losses of one device during the active state can be calculated as follows:

$$
\begin{aligned}
& \mathrm{P}_{\text {Con }_{\text {active }}}=\frac{1}{2 \pi} \int_{0}^{\pi} \mathrm{v}_{\text {con }} * \mathrm{i}(\mathrm{t})^{*} \mathrm{D}_{\text {active }}(\mathrm{t}) \mathrm{d}(\omega \mathrm{t}) \\
& \mathrm{i}(\mathrm{t})=\mathrm{I}_{\mathrm{m}} \sin (\omega \mathrm{t}+\theta) \\
& \mathrm{D}_{\text {active }}(\mathrm{t})=\mathrm{M} \sin (\omega \mathrm{t})
\end{aligned}
$$

where $I_{m}$ is the peak in the inverter output current; $\omega$ is the angular frequency; $\theta$ is the phase displacement between voltage and grid current; $D_{a c t i v e}$ is the duty ratio during active state, and $\mathrm{M}$ can take a value between 0 and 1 . The conduction losses of one device during zero states can be calculated as follows:

$$
\mathrm{P}_{\text {Con }_{\text {zero }}}=\frac{1}{2 \pi} \int_{0}^{\pi} \mathrm{v}_{\text {con }} * \mathrm{i}(\mathrm{t}) * \mathrm{D}_{\text {zero }}(\mathrm{t}) \mathrm{d}(\omega \mathrm{t})
$$




$$
\mathrm{D}_{\text {zero }}(\mathrm{t})=1-\mathrm{M} \sin (\omega \mathrm{t})
$$

where $D_{\text {zero }}$ is the duty ratio during zero state. The switching loss for one device during turn on and turn off are given by:

$$
\begin{aligned}
& P_{S_{\text {Switch_on }}}=\left(\frac{I_{m} V_{D C}}{2 \pi}\right) \cdot f_{S W} \cdot\left(\frac{E_{\text {on }}}{V_{\text {test }} I_{\text {test }}}\right) \\
& P_{\text {Switch_off }}=\left(\frac{I_{m} V_{D C}}{2 \pi}\right) \cdot f_{S w} \cdot\left(\frac{E_{\text {off }}}{V_{\text {test }} I_{\text {test }}}\right)
\end{aligned}
$$

where $E_{o n}$ and $E_{\text {off }}$ are the turn on and turn off energy losses. These energy losses are measured for specific test conditions (specific test voltage $\mathrm{V}_{\text {test }}$ and test current $\mathrm{I}_{\text {test }}$ ).

For the proposed inverter topology in Fig. 2.16, four devices (either HEMTs or MOSFETs) in series conduct current during the active states, while during the zero state the current flows through two devices (either HEMTs or MOSFETs) and two diodes. The low frequency switching losses are neglected. The conduction and switching losses of the proposed inverter can be given by:

$$
\begin{aligned}
& \mathrm{P}_{\text {total }\left(\mathrm{Con}_{\text {active }}\right)}=4\left(\mathrm{P}_{\text {Con }_{\text {active }}}(\text { HEMT or MOSFET })\right) \\
& \mathrm{P}_{\text {total }\left(\mathrm{Con}_{\text {zero }}\right)}=2\left(\mathrm{P}_{\text {Con }_{\text {zero }}}(\text { HEMT or MOSFET })\right)+\left(\mathrm{P}_{\text {Con }_{\text {zero }}}(\text { Diode })\right) \\
& \mathrm{P}_{\text {total }\left(\mathrm{SW}_{\text {loss }}\right)}=4\left(\mathrm{P}_{\text {Swtih__on }}+\mathrm{P}_{\text {Swtihc_off }}\right)
\end{aligned}
$$

As can be seen from the power loss calculations the proposed topology achieves lower conduction losses than that of the H5 and H6 topologies, while maintaining the same switching losses. 


\subsection{Simulation Comparison of Power Losses and Efficiency}

The proposed topology in Fig. 2.16 was simulated and analyzed using PSIM environment with MATLAB/Simulink Co-simulation. The proposed topology was compared to the H5 and H6 topologies in terms of power losses, and efficiency at different levels of output power.

The simulation specifications are given in Table 2.6. Infineon 650V CoolMOS IPW60R045CP has been used for efficiency evaluation. The inductor current ripple was chosen to be $20 \%$ of the maximum output current and the values of the inductor and the capacitance were selected based on this assumption. The maximum output power for each inverter is $5 \mathrm{~kW}$ and the input DC voltage is $400 \mathrm{~V}$. California's Energy Commission (CEC) standard was used for the efficiency evaluation which defines the inverter efficiency with different weighted factors and percentage of load as shown in equation (2.15) [5]:

$$
\begin{aligned}
& \eta_{\text {CEC }}=0.04 \cdot \eta_{10 \%}+0.05 \cdot \eta_{20 \%}+0.12 \cdot \eta_{30 \%}+0.21 \cdot \eta_{50 \%}+0.53 \cdot \eta_{75 \%} \\
& +0.05 \cdot \eta_{100 \%}
\end{aligned}
$$

Table 2.6 Simulation Parameters.

\begin{tabular}{cc}
\hline \hline Parameter & Value \\
\hline Output Power & $5 \mathrm{KW}$ \\
Input Voltage & $400 \mathrm{~V}$ \\
Grid Voltage & 120 \\
Grid Frequency & $60 \mathrm{~Hz}$ \\
Switching Frequency & $50 \mathrm{kHz}$ \\
Input Capacitance (CDC) & $1 \mathrm{mF}$ \\
Filter Inductors (Lf, Lg) & $1 \mathrm{mH}, 0.6 \mathrm{mH}$ \\
Filter Capacitance (Cf) & $6.8 \mu \mathrm{F}$ \\
PV Parasitic Capacitance (CPV) & $100 \mathrm{nF}$ \\
\hline
\end{tabular}


Fig. 2.21 Shows the breakdown of power losses for each topology during active and zero modes. It can be seen from the figure that the proposed topology has the lowest conduction losses among all topologies, and this is because of the new current path that has been proposed. The switching loss of the proposed topology, H5 topology, and H6 topology are almost the same. The Full bridge inverter is not considered for this comparison because it was established earlier that it is not suitable for PV transform-less application because of its high leakage current.

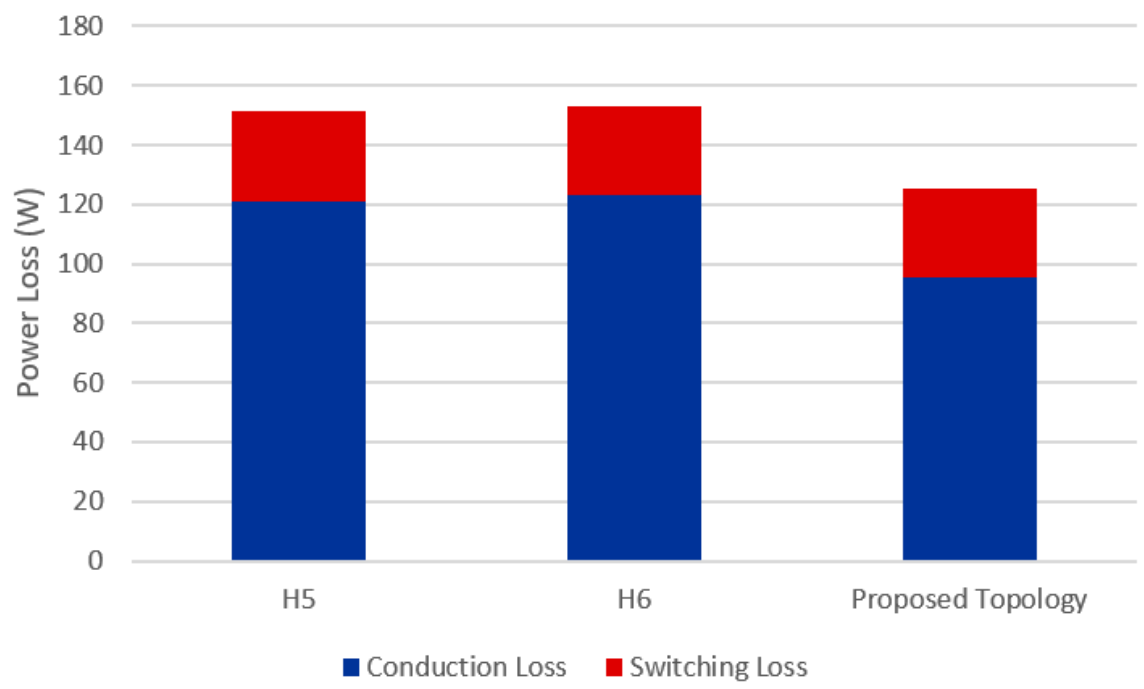

Fig. 2.21 Power losses for each topology at 5kW output power.

The efficiency curve of each topology at different load power is presented in Fig. 2.22. The proposed topology has the highest efficiency among all topologies. Fig. 2.23 shows the calculated efficiencies of each topology according to equation (2.15) the CEC standard. As can be seen from the figure, the proposed inverter has the highest efficiency among all topologies. The proposed inverter achieves efficiency of $98.4 \%$, while H5 and H6 efficiencies are $98 \%$ and $97.9 \%$, respectively. 


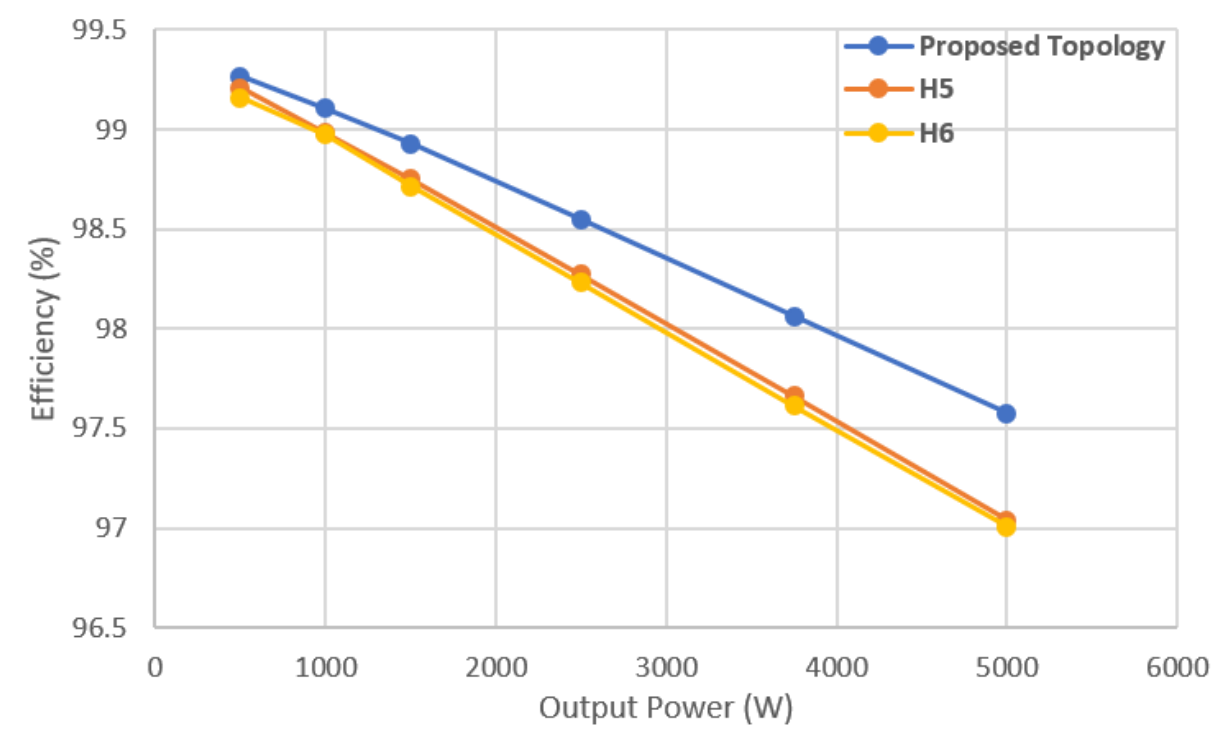

Fig. 2.22 Efficiency comparison of proposed topology and several topologies under different loads.

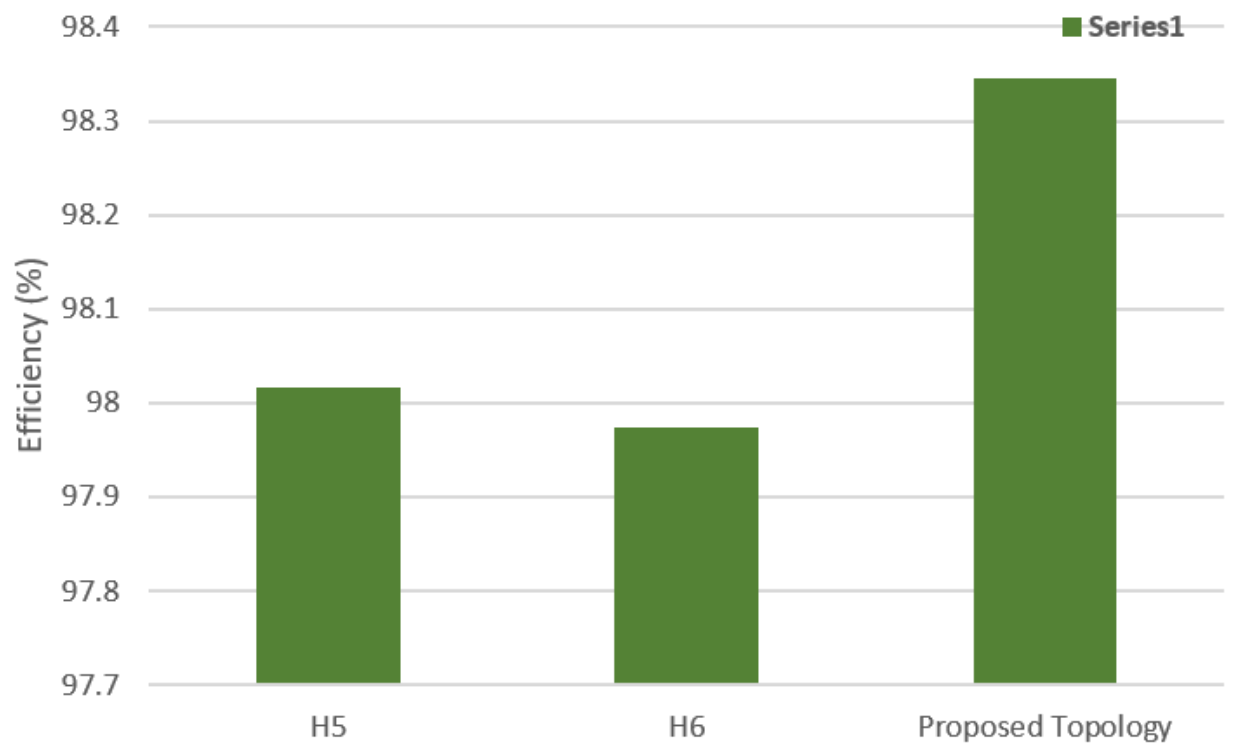

Fig. 2.23 Efficiency comparison of proposed topology and several topologies based on CEC efficiency standard.

\subsection{Conclusion}

In this chapter, a review of the advances on transformer-less inverters based on full bridge topology has been presented. Challenges and leakage current requirements for transformer-less inverters have been discussed. Full Bridge, H5 and H6 topologies have been presented and compared in terms of leakage current and power losses. A new 
transformer-less Inverter has been proposed to enhance efficiency and reduce the leakage current. The new topology forms new current paths which lower the conduction losses when compared to the H5 and H6 topologies. Therefore, the current of the proposed topology in the active mode flows through four switches instead of the six switches of the H6 and H5 topologies. The reviewed inverters and the proposed inverter have been simulated and tested to evaluate their performance under different load conditions. The results show that, the proposed inverter achieves the lowest conduction losses and the highest efficiency among all presented topologies. 


\section{Chapter Three: Wide Bandgap (WBG) Power Switching Devices}

\subsection{Introduction}

To enhance the efficiency and reliability of the transformer-less inverter, it is necessary to choose the appropriate switching devices. WBG devices, such as SiC MOSFETs, and GaN HEMTs, have been widely employed in renewable energy to enhance efficiency and reduce the power losses of the system. The advantages and the superior performance of wide bandgap semiconductor power devices have been reported in several studies [42]-[50]. According to these studies, by replacing Si IGBT by SiC MOSFET, the overall losses of the system can be reduced by half. Driven by their capability for high switching frequency with high efficiency and the reduction of transformer size, Gallium Nitride transistors (GaN HEMTs) are considered as promising devices for power conversion applications [51]-[53]. Using WBG power devices, the PV inverter can operate at high switching frequencies, which reduces the size and the volume of the system, thereby lowering the system's overall cost.

\subsection{Performance Evaluation of Si MOSFET and GaN HEMT}

Evaluating the performance and loss profiles of Si CoolMOS and GaN HEMT requires study and analysis of the switching and conduction characteristics of each device for the proposed inverter application. Manufacturer's datasheets can be used to provide the detailed data of the conduction characteristics of each device. However, using the 
datasheet to determine the switching characteristics is difficult because normally, switching characteristics are determined for specific operation conditions. Therefore, to provide an accurate comparison between Si CoolMOS and GaN HEMT in terms of switching characteristics and losses; a double pulse test circuit is designed to provide the same operating conditions that will be used in the proposed system.

\subsubsection{Conduction Characteristics}

The voltage drop and the current that flows through the power switching devices are used to determine the conduction losses. For the selected switching devices $\mathrm{Si}$ MOSFET (CoolMOS) IPW60R045CP and GaN HEMT GS66516T, the forward voltage versus current at different temperature can be extracted from the manufacturer's datasheet of each device, and they are shown in Fig. 3.1 [54], [55]. These forward voltages are used to determine the conduction losses of each device. Fig. 3.1 shows that GaN HEMT has a smaller voltage drop than Si CoolMOS over the current range of the system; thus, GaN HEMT will have lower conduction losses than Si CoolMOS.

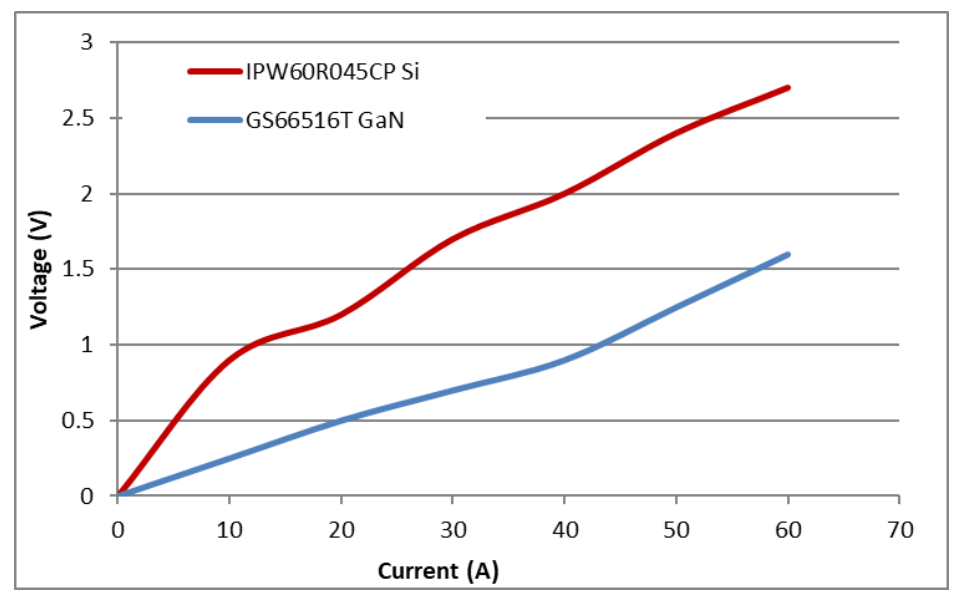

(a) 


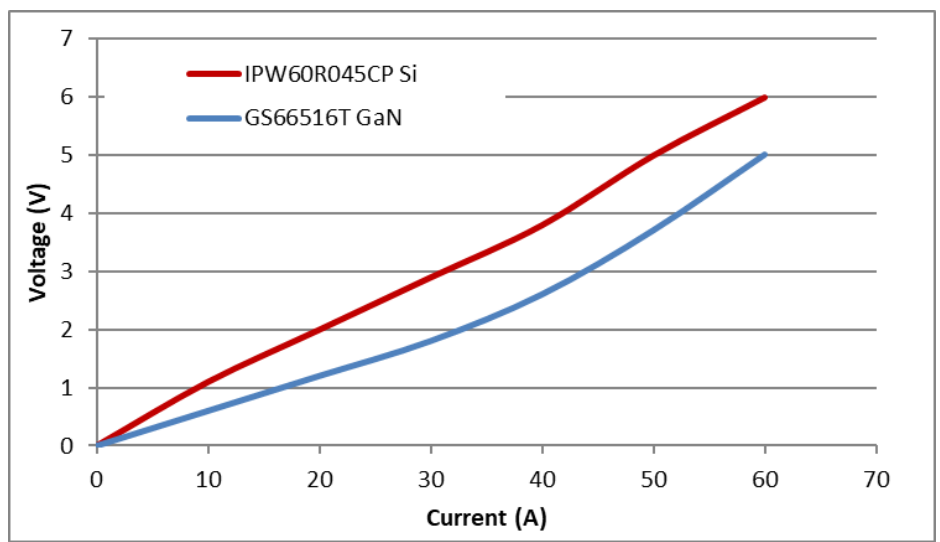

(b)

Fig. 3.1 Forward voltages of Si MOSFET and GaN HEMT at various current and junction temperature:

(a) Si MOSFET and GaN HEMT forward voltage at $25^{\circ} \mathrm{C}$ junction temperature; (b) Si MOSFET and GaN HEMT forward voltage at $150^{\circ} \mathrm{C}$ junction temperature.

\subsubsection{Switching Characteristics}

As mentioned previously, to provide an accurate comparison between $\mathrm{Si}$ CoolMOS and GaN HEMT in terms of switching characteristics and losses, their switching characteristics and losses are measured using a double pulse test circuit shown in Fig. 3.2 to provide the same operating conditions that are used in the proposed system. Fig. 3.3 shows the turn-on and turn-off waveforms of Si MOSFET and GaN HEMT at $400 \mathrm{~V}$ and $30 \mathrm{~A}$.

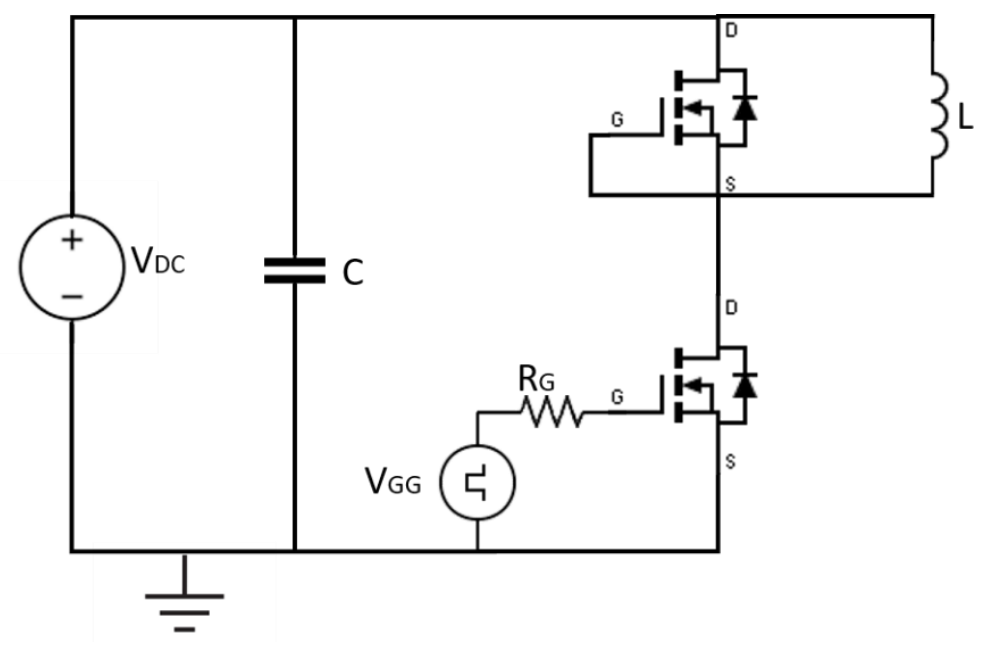

Fig. 3.2 Double Pulse Test Circuit. 
Fig. $3.3 \mathrm{a}$ and $\mathrm{b}$ show the drain-source voltage, and drain current, during turn-on transition for Si MOSFET and GaN HEMT, respectively. Fig. $3.3 \mathrm{c}$ and d show the drainsource voltage, and drain current, during turn-off transition for Si MOSFET and GaN HEMT, respectively. The superior performance in the switching characteristics of the GaN HEMT in terms of di/dt and dv/dt can be seen in the figures. As an example, from Fig. $3.3 \mathrm{c}$ and d, during the turn-off stage, GaN HEMT switches at $15.8 \mathrm{kV} / \mu \mathrm{s}$ while $\mathrm{Si}$ MOSFET switches at $4.9 \mathrm{kV} / \mu \mathrm{s}$. Table 3.1 presents the switching characteristics for both devices in terms of di/dt and dv/dt during turn-on and turn-off transitions.

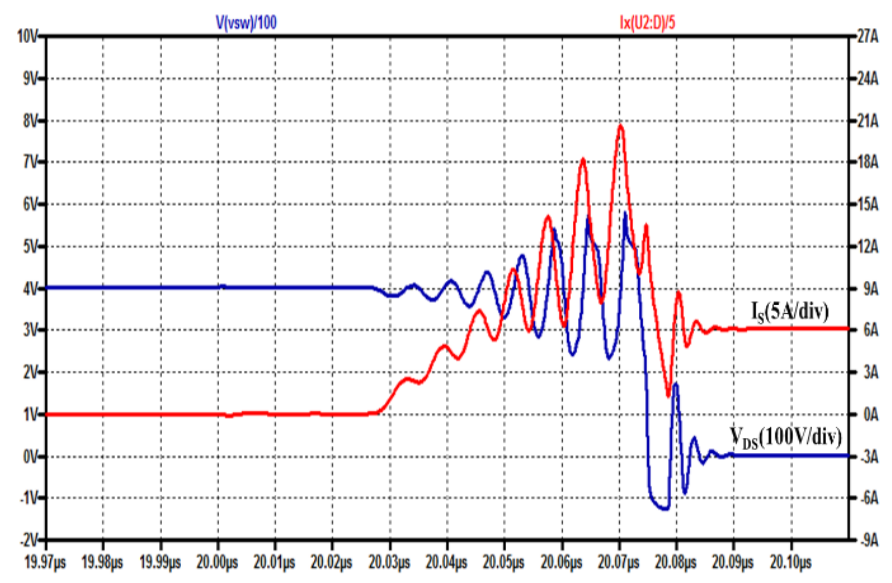

(a)

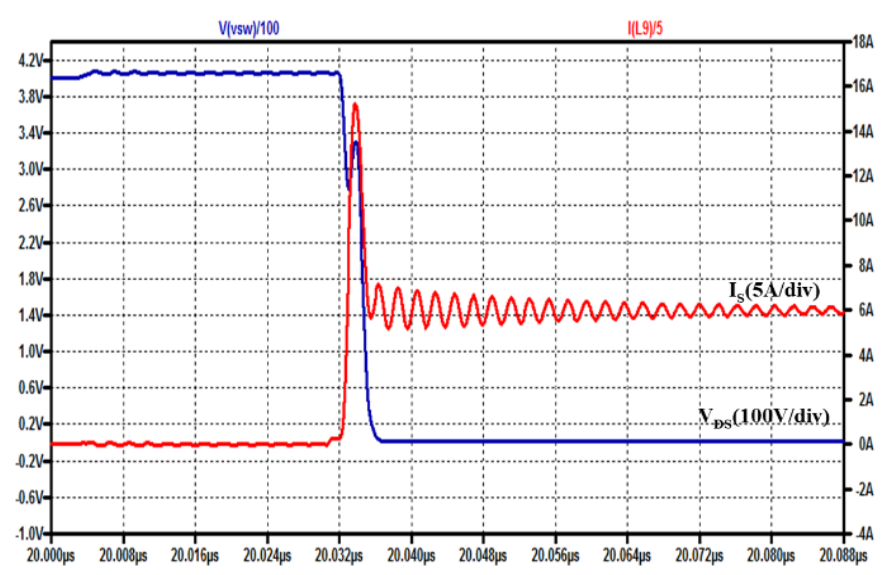

(b) 


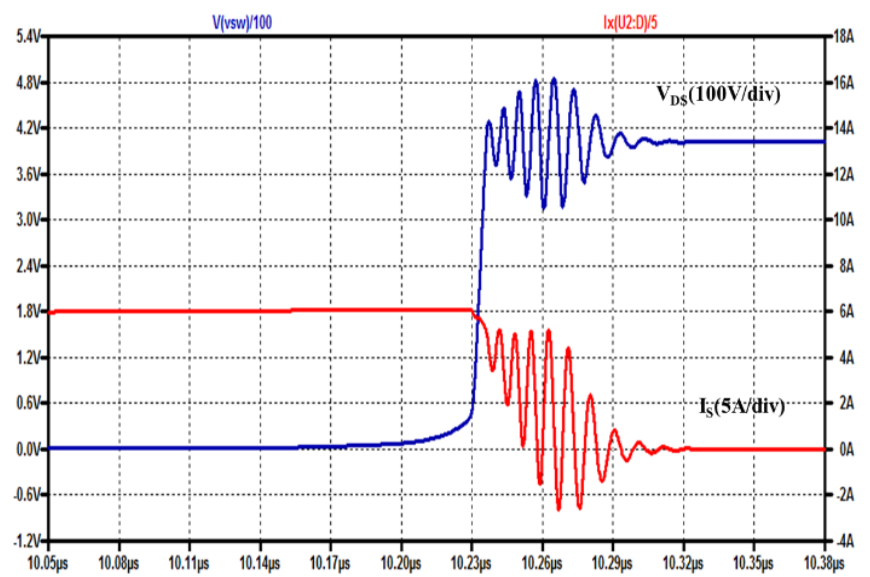

(c)

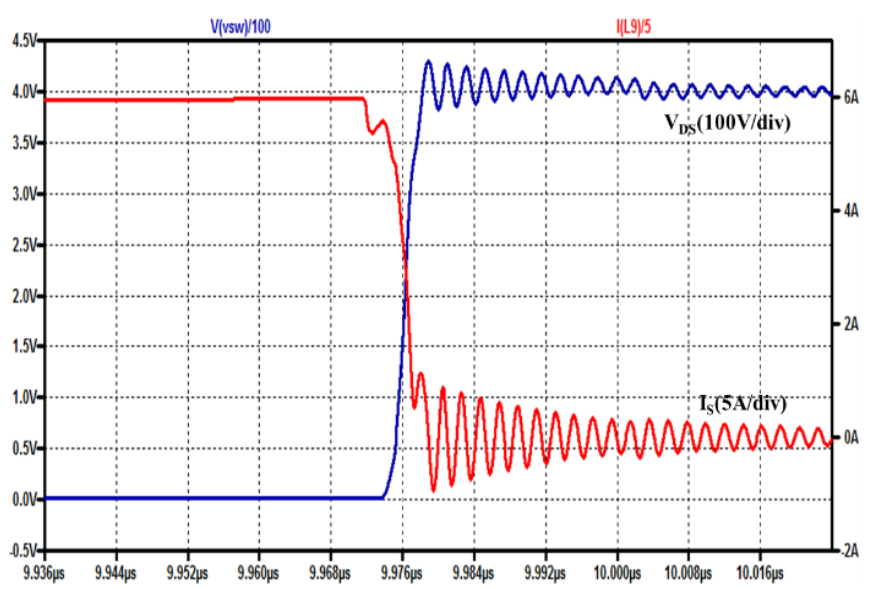

(d)

Fig. 3.3 The turn-on and turn-off waveforms of Si MOSFET and GaN HEMT at $400 \mathrm{~V}$ and $30 \mathrm{~A}$ : (a) Si MOSFET Turn-on; (b) GaN HEMT Turn-on; (c) Si MOSFET Turn-off; (d) GaN HEMT Turn-off.

Table 3.1 Switching characteristics.

\begin{tabular}{ccccc}
\hline & \multicolumn{2}{c}{ Turn-on } & \multicolumn{2}{c}{ Turn-off } \\
\cline { 2 - 5 } dv/dt $(\mathbf{K V} / \boldsymbol{\mu} \mathbf{s})$ & 6 & GaN & Si & GaN \\
\cline { 2 - 5 } di/dt $(\mathbf{K A} / \boldsymbol{\mu} \mathbf{s})$ & 0.63 & 9.6 & 4.9 & 15.8 \\
\hline \hline
\end{tabular}

The switching losses can be obtained by measuring the voltage and the current at different operating conditions. Thus, the switching energy losses can be obtained by integrating the product of the collected voltages and currents. Fig. 3.4 shows the turn-on and turn-off energy losses of Si MOSFET and GaN HEMT. Table 3.2 presents the values 
of the turn-on and turn-off switching energy losses shown in Fig. 3.4. It can be noticed that the Si MOSFET turn-on switching energy loss is more than five times that of the GaN HEMT. The most attractive characteristic of GaN HEMTs is their significantly low turn-off energy loss, which is almost constant over the current range of the system. Conversely, the turn-off energy loss of the Si MOSFET increases linearly with the current. It can be seen from Fig. 3.4 and Table 3.2 that the switching energy loss of the Si MOSFET at $20 \mathrm{~A}(105.96 \mu \mathrm{J})$ is more than seven times that of GaN HEMT at $20 \mathrm{~A}(14.1$ $\mu \mathrm{J})$, and Si MOSFET at $40 \mathrm{~A}(1045.6 \mu \mathrm{J})$ is more than 30 times that of GaN HEMT at the same current $(14.8 \mu \mathrm{J})$.

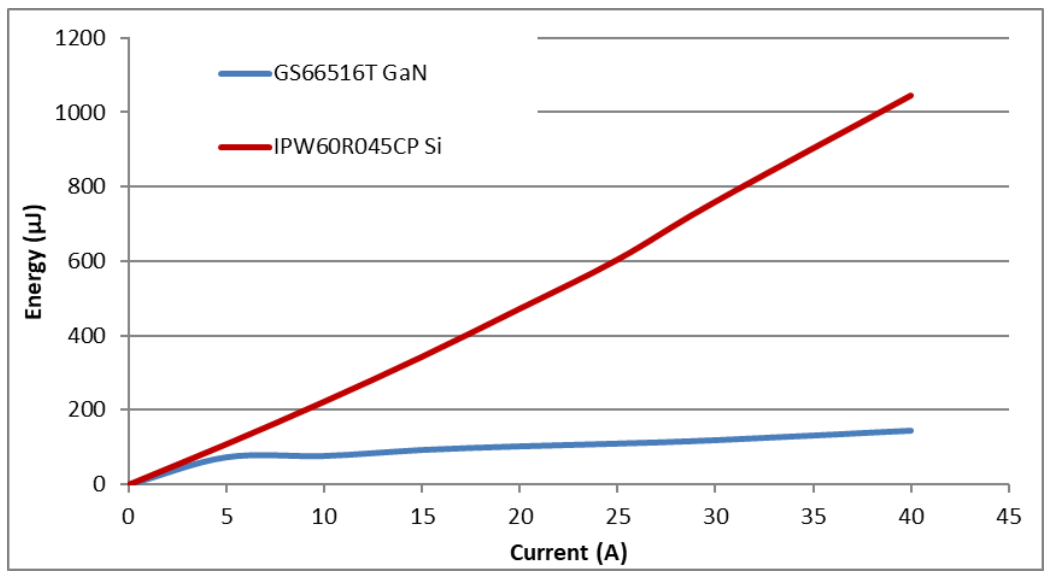

(a)

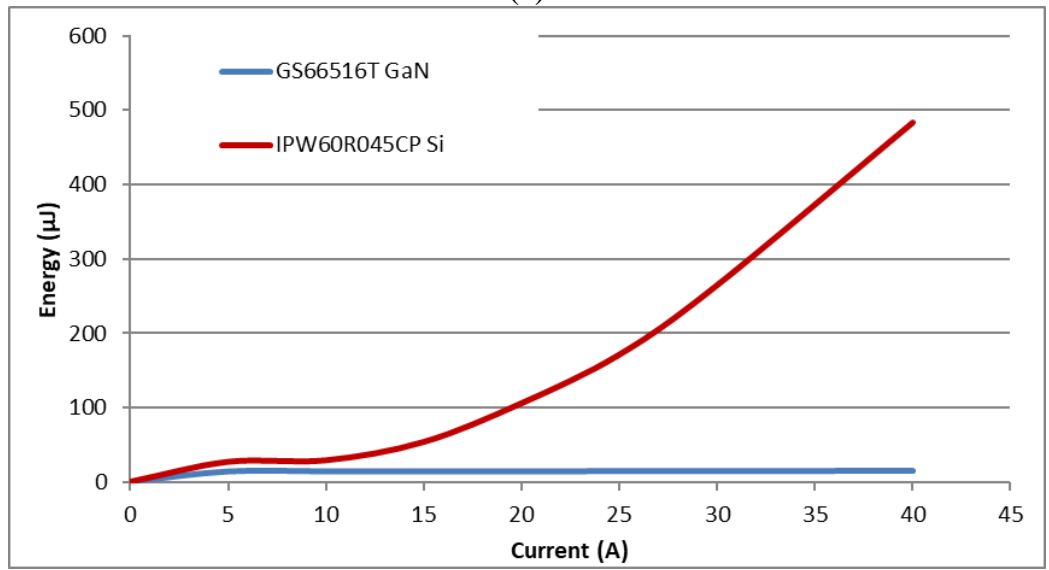

(b)

Fig. 3.4 Turn-on and Turn-off switching energy losses of Si MOSFET and GaN HEMT: (a) Turn-On; (b) Turn-Off. 
Table 3.2 Switching energy losses.

\begin{tabular}{ccccc}
\hline \hline Current (A) & \multicolumn{2}{c}{ Si MOSFET } & \multicolumn{2}{c}{ GaN HEMT } \\
\cline { 2 - 5 } & $\mathbf{E}_{\mathbf{o n}}(\boldsymbol{\mu} \mathbf{J})$ & $\mathbf{E}_{\mathbf{o f f}}(\boldsymbol{\mu} \mathbf{J})$ & $\mathbf{E}_{\mathbf{o n}}(\boldsymbol{\mu J})$ & $\mathbf{E}_{\text {off }}(\boldsymbol{\mu} \mathbf{J})$ \\
\cline { 2 - 5 } 0 & 0 & 0 & 0 & 0 \\
5 & 109.16 & 26.86 & 73.1 & 14 \\
10 & 223.17 & 28.92 & 76.5 & 14.1 \\
15 & 343.9 & 53.59 & 92.3 & 14.2 \\
20 & 472.86 & 105.69 & 102 & 14.1 \\
25 & 604.8 & 170.94 & 109 & 14.5 \\
30 & 760.32 & 264.29 & 118.3 & 14.6 \\
40 & 1045.6 & 482.79 & 143.2 & 14.8 \\
\hline \hline
\end{tabular}

\subsection{Conclusion}

In this chapter, WBG materials-based power switching devices have been introduced. WBG power switching devices have superior characteristics, such as low gate charge and low on-state resistance compared to Si power switching devices. Thus, WBGbased power switching devices can operate at high switching frequencies which will reduces the overall system's weight and volume without adding more losses to the system. A double pulse test circuit was designed to evaluate the performance and loss profiles as well as provide an analysis of switching and conduction characteristics of $\mathrm{GaN}$ HEMTs in comparison to Si MOSFETs. It is noted that GaN HEMTs had lower conduction and switching losses compared to the Si MOSFETs. Si MOSFETs'switching energy loss was more than five times that of the GaN HEMTs. 


\section{Chapter Four: Wide Bandgap Power Devices in PV Inverters}

\subsection{Introduction}

WBG power switching devices have gained much interest in the power electronics society because of their superior switching and conduction performance compared to Si power devices. WGB power devices, such as $\mathrm{SiC}$ and $\mathrm{GaN}$ devices, are the latest advancements in power semiconductor technology, and they are considered to be a promising technology that can switch at high frequencies and achieve very high power density and very high efficiencies [56]. Application of WBG devices in renewable energy converters has been researched and has shown the potential benefits of these devices.

The benefits and potential performance enhancement of $\mathrm{SiC}$ applications in renewable energy converters have been widely discussed [57]-[59]. The designed PV inverter in [57]achieved $98.8 \%$ efficiency. By just replacing Si IGBTs with SiC, JFETs overall losses were reduced to half in the designed PV inverter [58]. The benefit of using SiC MOSFET in a transformer-less inverter in terms of efficiency and power losses has been explored in detail [59]. The use of GaN HEMT in renewable energy has also been discussed [60]-[62]. The higher performance of GaN HEMT in terms of energy efficiency has been described [60], [61]. GaN devices have been used in [62] to achieve $99.3 \%$ efficiency at $16 \mathrm{kHz}$ switching frequency and low output power. 


\subsection{Proposed GaN-Based Single-Phase Transformer-Less PV Grid-Tied Inverter}

In order to verify the benefits of replacing Si MOSFET with GaN HEMT in the PV inverter; the proposed topology in Fig. 2.16 was simulated and analyzed using cosimulation between the PSIM environment and the MATLAB/Simulink Platform. Table 4.1 shows the simulation specifications. Table 4.2 shows the switching power devices used in the simulation. The proposed topology power losses and efficiency were compared using two different power devices (Si MOSFET and GaN HEMT). Heatsink design and thermal analysis of the proposed inverter were simulated using COMSOL Multiphysics.

Table 4.1 Simulation parameters.

\begin{tabular}{cc}
\hline \hline Parameter & Value \\
\hline System Power & $5 \mathrm{KW}$ \\
Input Voltage & $400 \mathrm{~V}$ \\
Grid Voltage & $120 \mathrm{~V}$ \\
Grid Frequency & $60 \mathrm{~Hz}$ \\
Switching Frequency & $50 \mathrm{kHz}$ and $200 \mathrm{kHz}$ \\
Input Capacitance & $1 \mathrm{mF}$ \\
\hline \hline
\end{tabular}

Table 4.2 Switching devices parameters.

\begin{tabular}{ccc}
\hline \hline Parameter & IPW60R045CP & GS66516T \\
\hline V $_{\mathrm{DS}}(\mathrm{V})$ & 650 & 650 \\
$\mathrm{I}_{\mathrm{D}}(\mathrm{A})$ & 60 & 60 \\
$\mathrm{R}_{\mathrm{DS}}(\mathrm{m} \Omega)$ & 45 & 25 \\
$\mathrm{Q}_{\mathrm{G}}(\mathrm{nC})$ & 150 & 12.1 \\
$\mathrm{Q}_{\mathrm{GS}}(\mathrm{nC})$ & 34 & 4.4 \\
$\mathrm{Q}_{\mathrm{GD}}(\mathrm{nC})$ & 51 & 3.4 \\
$\mathrm{C}_{\text {iss }}(\mathrm{pF})$ & 6800 & 520 \\
$\mathrm{C}_{\text {oss }}(\mathrm{pF})$ & 320 & 130 \\
$\mathrm{C}_{\text {rss }}(\mathrm{pF})$ & - & 4 \\
\hline \hline
\end{tabular}


The most important benefit of replacing the Si MOSFET with GaN HEMT for the proposed inverter is the reduction in overall loss by more than $60 \%$ at $50 \mathrm{kHz}$ and more than that at $200 \mathrm{kHz}$ as shown in Fig. $4.1 \mathrm{a}$ and b. The significantly low power losses of GaN HEMTs can help improve the efficiency of the overall system and reduce thermal stress. Moreover, GaN HEMTs can operate at high switching frequencies with lower power losses, which will consequently reduce the total volume of the system [63].

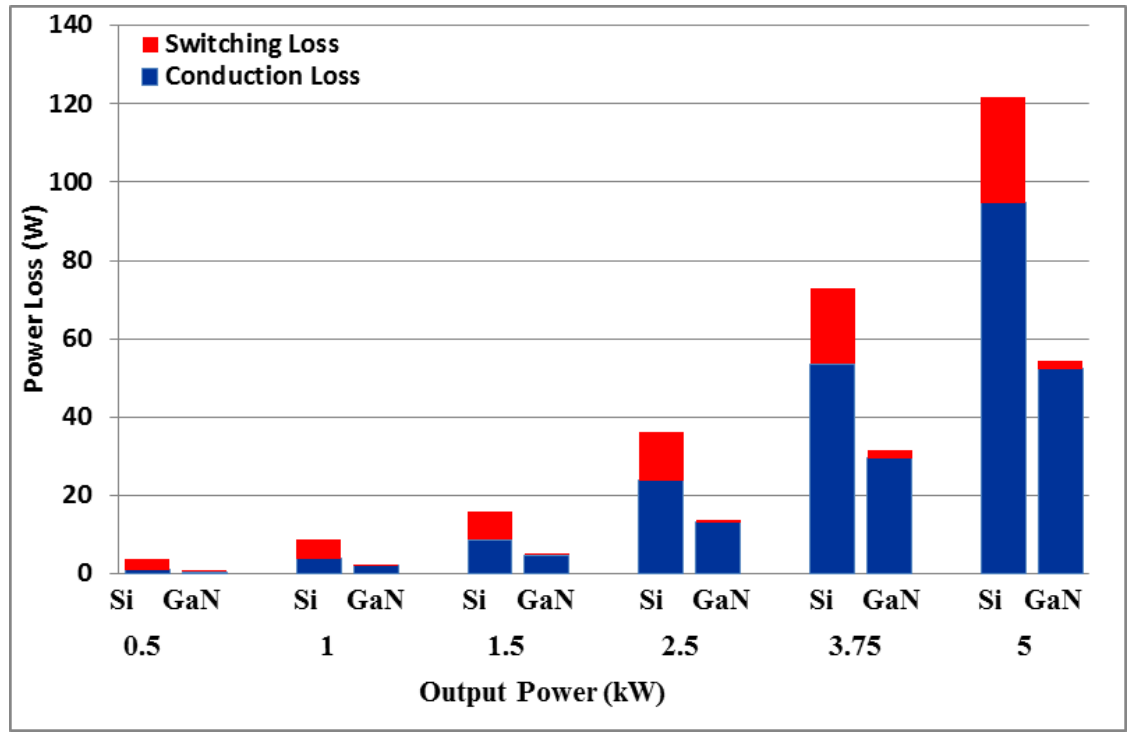

(a)

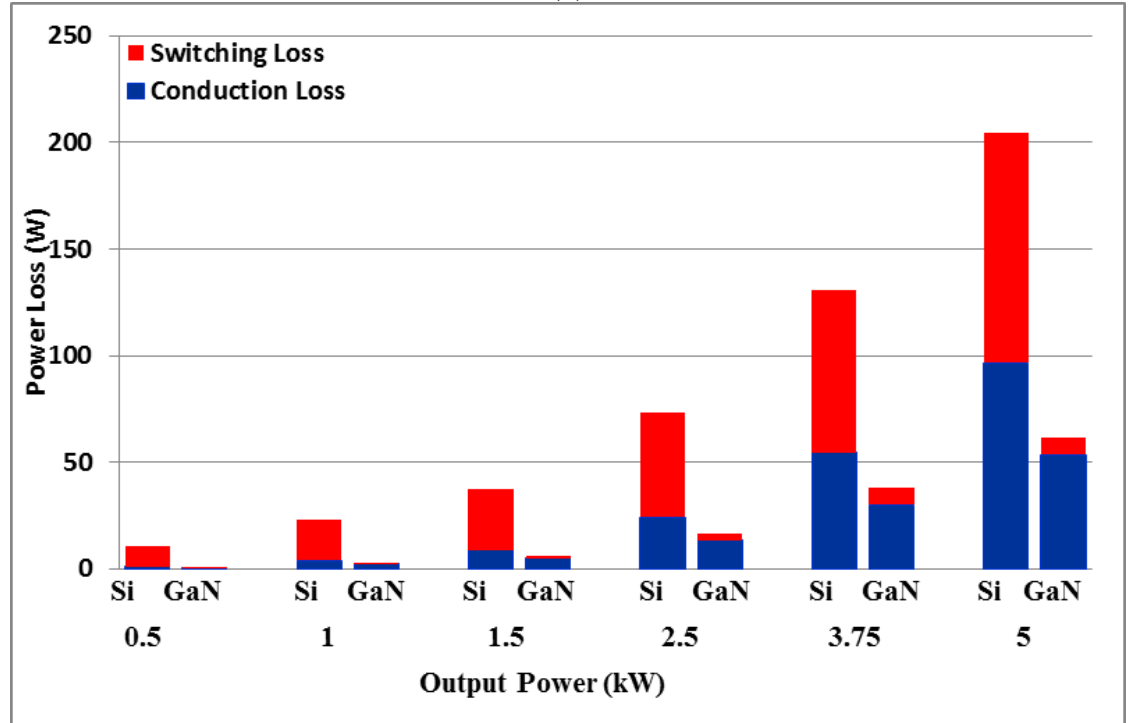

(b)

Fig. 4.1 Power losses of Si MOSFET and GaN HEMT: (a) at $50 \mathrm{kHz}$; (b) at $200 \mathrm{kHz}$. 


\subsubsection{Efficiency Improvement}

The overall efficiency of the system is directly affected by the switching device power losses. Fig. 4.2 shows the efficiency of the proposed topology with Si MOSFETs and GaN HEMTs at different levels of rated power and different switching frequencies. The figure shows the efficiency improvement using GaN HEMTs with more than $2 \%$ of improvement at $50 \mathrm{kHz}$ and more than $3 \%$ of improvement at $200 \mathrm{kHz}$. Hence, these results verify the superior performance of the $\mathrm{GaN}$ switching devices over their $\mathrm{Si}$ counterparts.

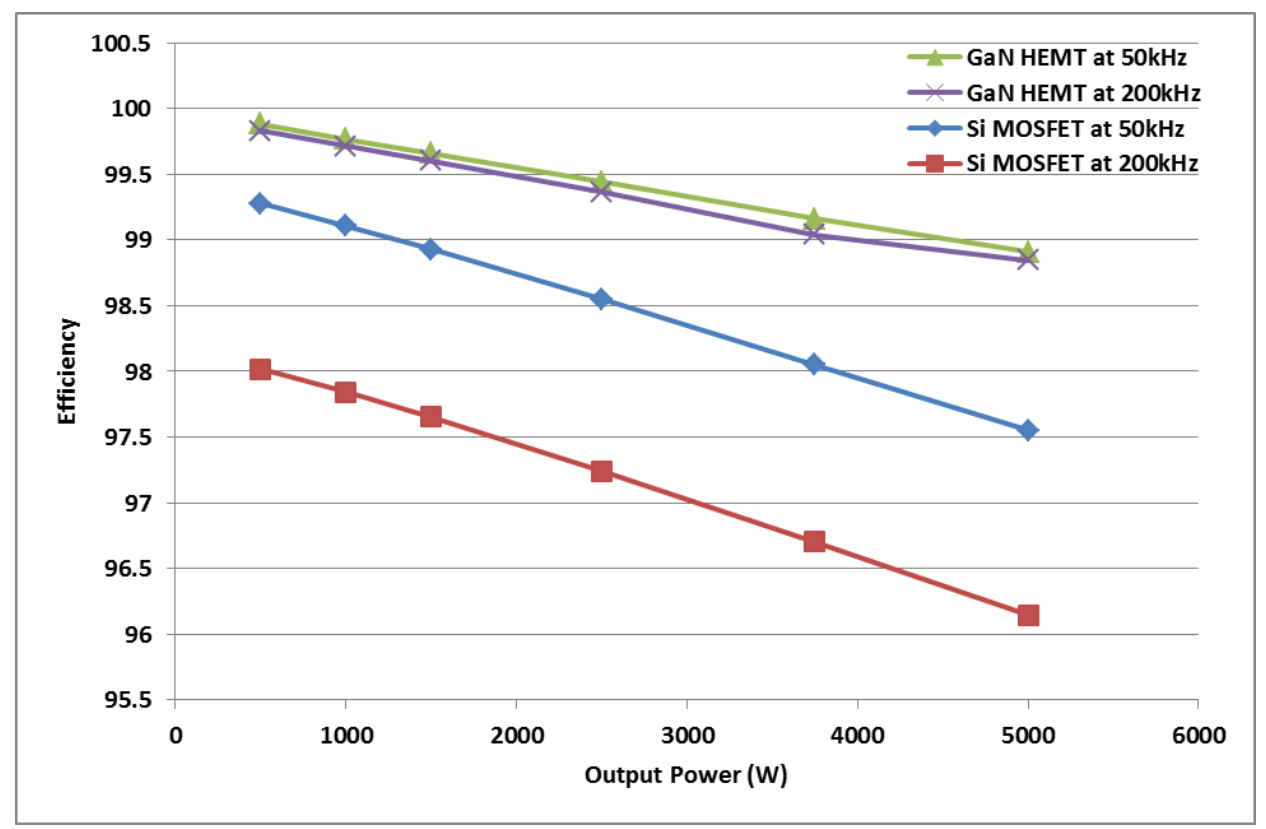

Fig. 4.2 Efficiency comparison of Si MOSFET and GaN HEMT at different switching frequency.

\subsubsection{Passive Component Reduction}

Switching the inverter at high switching frequencies can significantly reduce the passive component size. Thus, by using the previously presented semiconductor loss model, the switching frequency of the inverter that is equipped with GaN HEMT has been increased until the losses of the GaN HEMT are almost equal to the losses of $\mathrm{Si}$ 
MOSFET. Fig. 4.3 shows the results of this process for an output power of $5 \mathrm{~kW}$; as can be seen from the figure, the switching frequency has been increased to $500 \mathrm{kHz}$ for $\mathrm{GaN}$ HEMT to reach the balance point where its losses are equal to Si MOSFET losses at 50 $\mathrm{kHz}$. Thus, to reach the point where both devices dissipate the same power, the $\mathrm{GaN}$ HEMT switching frequency increased to 10 times the switching frequency of the $\mathrm{Si}$ MOSFET. This high switching frequency reduces the filter inductance size significantly since the inductance size is inversely proportional to the switching frequency [64]:

$$
\mathrm{L}_{\mathrm{f}}=\frac{\mathrm{V}_{\mathrm{DC}}}{4 \times \mathrm{f}_{\mathrm{SW}} \times 0.2 \times \mathrm{I}_{\mathrm{L} \_ \text {max }}}
$$

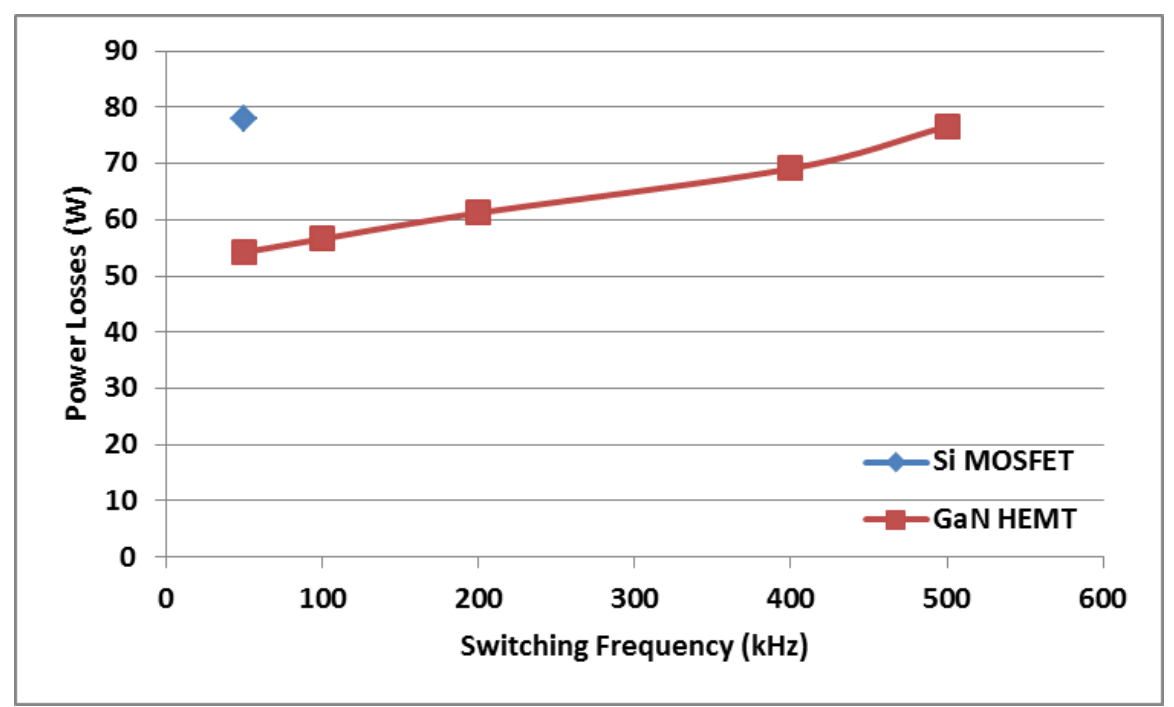

Fig. 4.3 The balance point where GaN HEMT losses at $500 \mathrm{kHz}$ is equal to Si MOSFET losses at 50 $\mathrm{kHz}$.

The inductor current ripple was chosen to be $20 \%$ of the maximum output current. Fig. 4.4 shows the effect of increasing the switching frequency on the inductance size. As can be seen from the figure, increasing the switching frequency reduced the inductance size from 600 to $40 \mu \mathrm{H}$, which is almost $93 \%$ of reduction in inductor value. Fig. 4.5 shows the effect of increasing the switching frequency on the magnetic core volume. The magnetic core volume has been reduced from initially 237 to $43.1 \mathrm{~cm}^{3}$, which is around 
an $82 \%$ reduction in core volume. Accordingly, this will result in a reduction of the inductor weight as demonstrated in Fig. 4.6. The inductor weight was reduced from 618 to $120 \mathrm{~g}$, which is more than an $80 \%$ reduction in weight.

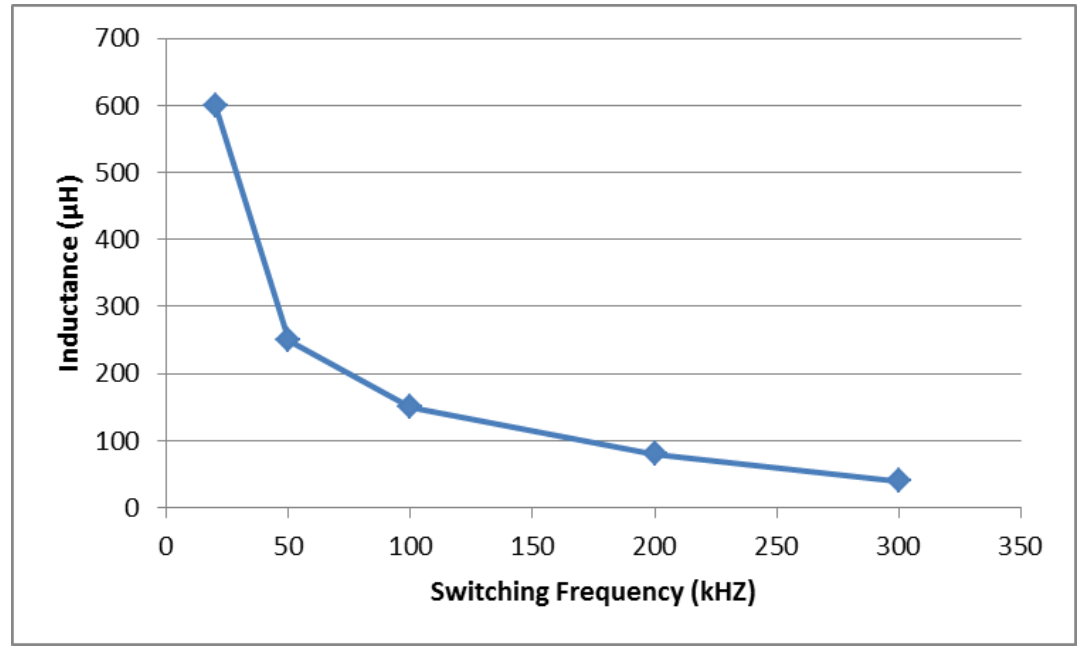

Fig. 4.4 The effect of increasing the switching frequency on inductance size.

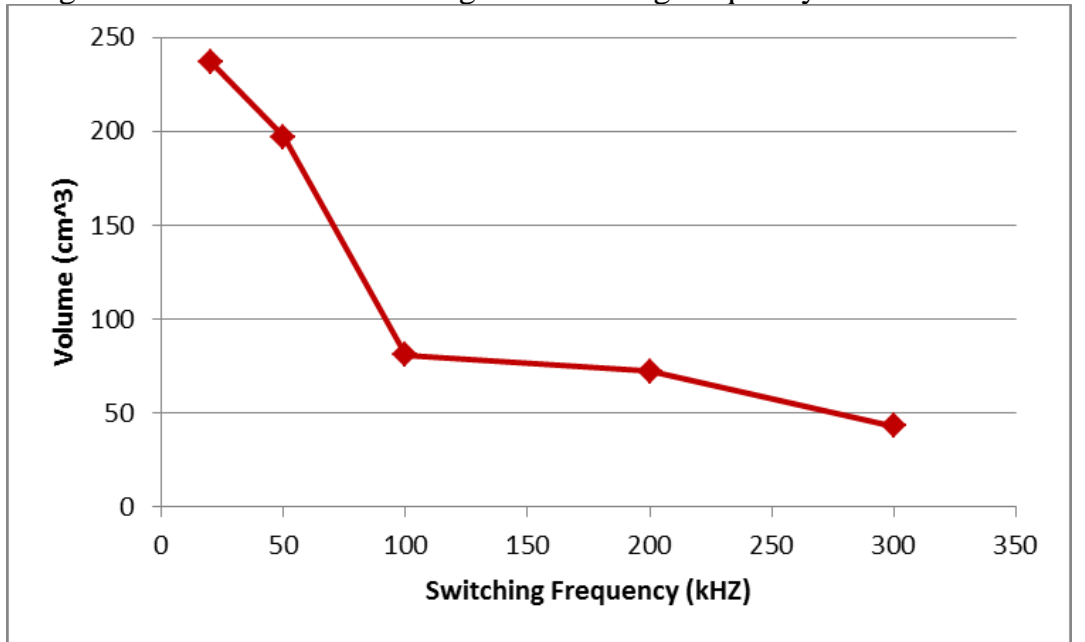

Fig. 4.5 The effect of increasing the switching frequency on magnetic core volume. 


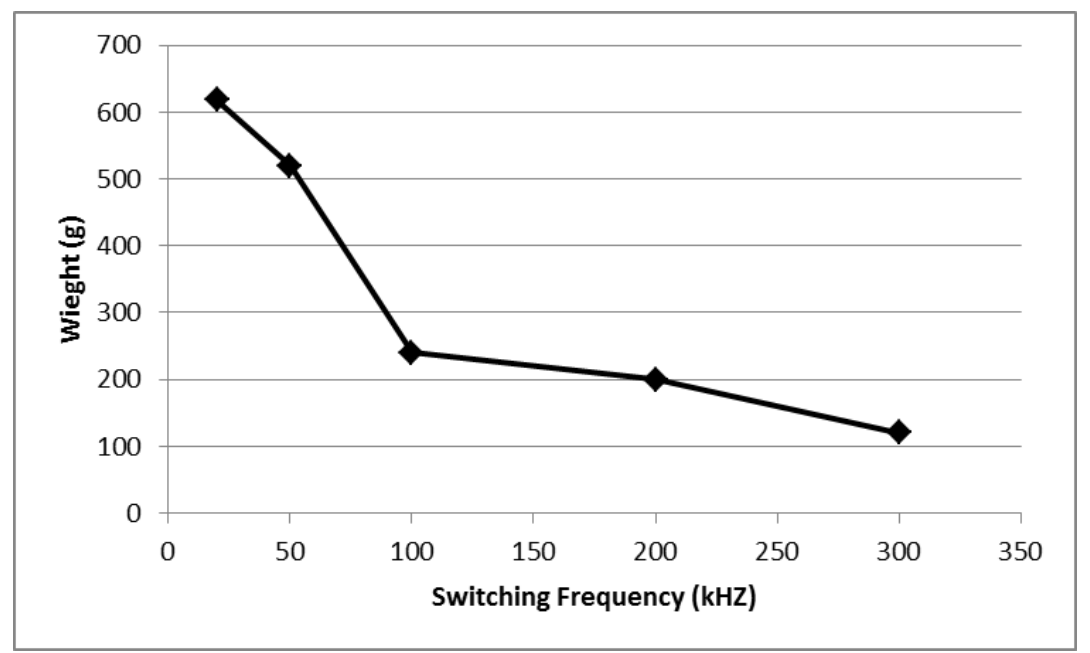

Fig. 4.6 The effect of increasing the switching frequency on the inductor weight.

\subsubsection{Improvement in Power Rating}

As mentioned previously, GaN HEMTs' most important benefit is their low power loss, which improves efficiency and can be used to improve the power rating of the proposed system. Improving the power rating can be done by increasing the output power of the system using the same heatsink that has been designed for Si MOSFETs. Fig. 4.7 presents this concept. As shown in the figure, the output power increased from $2500 \mathrm{~W}$ using Si MOSFET to $3750 \mathrm{~W}$ using GaN HEMT with the same power losses at $50 \mathrm{kHz}$ switching frequency. Thus, the GaN HEMT-based inverter achieves more than a $60 \%$ increase in power rating without any additional cooling. 


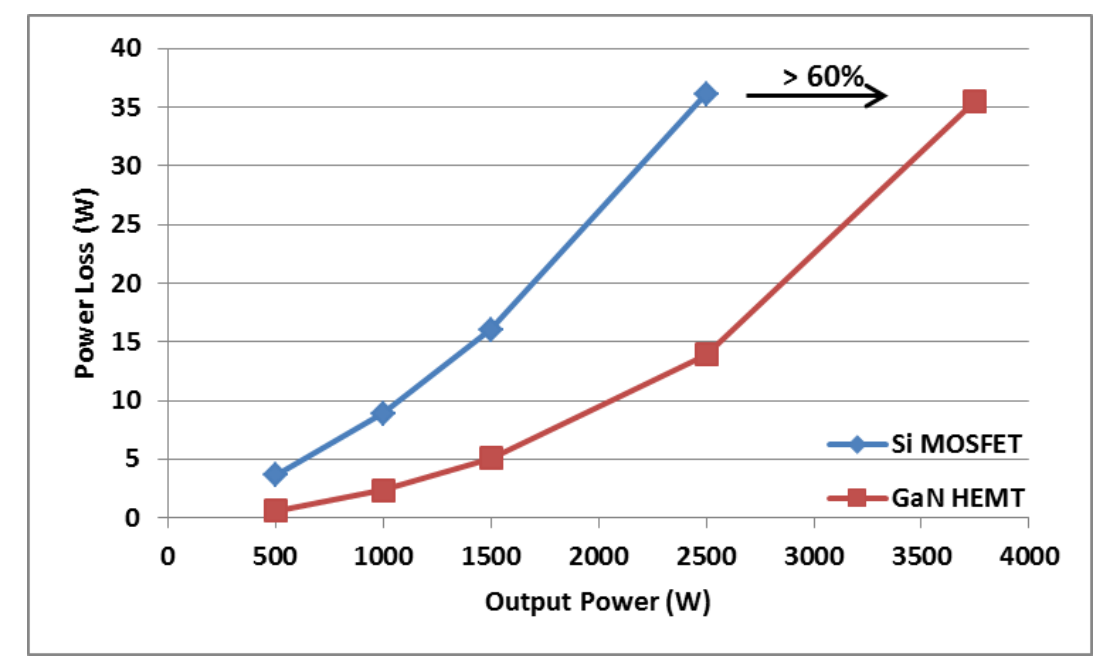

Fig. 4.7 Power rating improvement, output power increase with same power losses.

\subsection{Thermal Design and Simulation Analysis}

\subsubsection{Model Outline}

Modelling and thermal performance analysis of heatsinks using simulation platforms have been reported by several researchers [65]-[69]. In this research, COMSOL Multiphysics was used to create two 3D models of a 6-pack MOSFET module with Silicon ( $\mathrm{Si}$ ) and $\mathrm{GaN}$ as their respective semiconductor materials.

To reduce the module's temperature and to compare the thermal performance of each semiconductor, heatsinks were added to the design. The Finite Element Analysis (FEA) method was used to solve the temperatures of the 3D structure. Body Corp's online tool AAVID Genie was used to verify the results and select the appropriate heatsink for each structure from their commercially available heatsinks, and then simulate it in COMSOL. The Joule heating generated by electric currents passing through each of the MOSFET modules was obtained from calculations made in PSIM, which acted as the heat sources for COMSOL. Thermal stresses and physical deformation are beyond the scope of this work. 


\subsubsection{Model Geometry}

The internal structure of the Si MOSFET module from the bottom to the top includes: a Copper $(\mathrm{Cu})$ Baseplate, a solder layer, a Copper layer, an Aluminum Nitride (AIN) layer and a Copper layer [70]. The module for GaN consists of all the layers as the Si module except for the diode and its corresponding solder layer. The dimensions of the MOSFETs for the GaN module were obtained from [55]. Fig. 4.8 shows the dimensioned view of the Si MOSFET, and GaN HEMT, respectively.

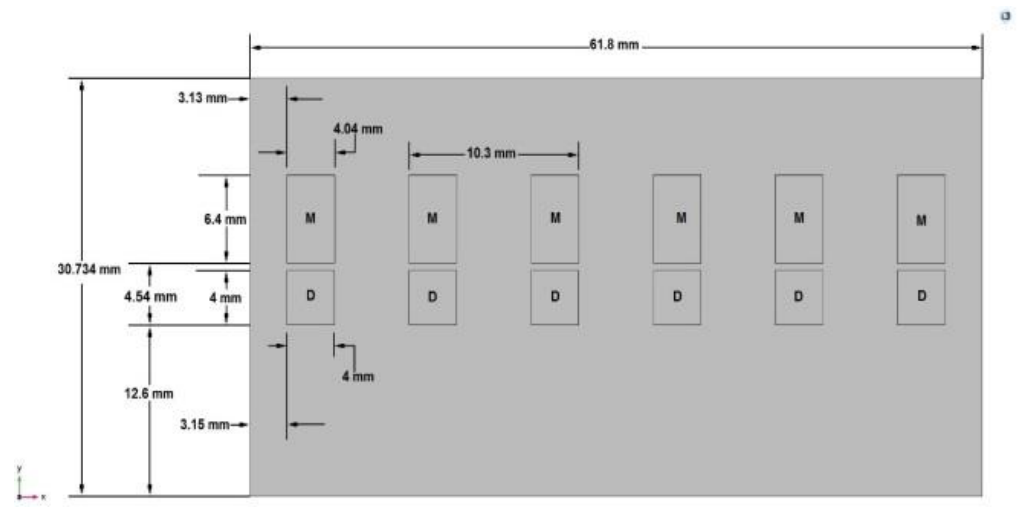

(a)

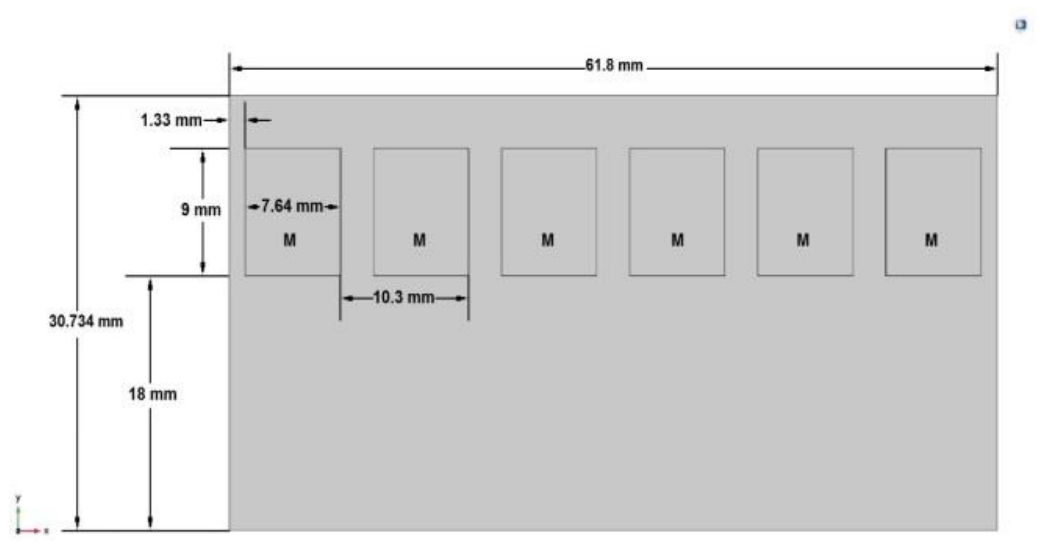

(b)

Fig. 4.8 xy-plane view of MOSFET modules: (a) for $\mathrm{Si}$; (b) for $\mathrm{GaN}$. 


\subsubsection{Model Simulation and Results}

Figs. 4.9 and 4.10 show the temperature profiles for the Si and GaN models with the heatsinks. The temperatures displayed on the legends are in degrees Celsius. The temperature profiles for the two models with the heatsink show similar distribution of temperatures. The Si and GaN models have higher temperatures on the heatsink uniform around all the MOSFETs, but the range of temperatures for the heatsinks are much lower in the GaN model than the Si model.

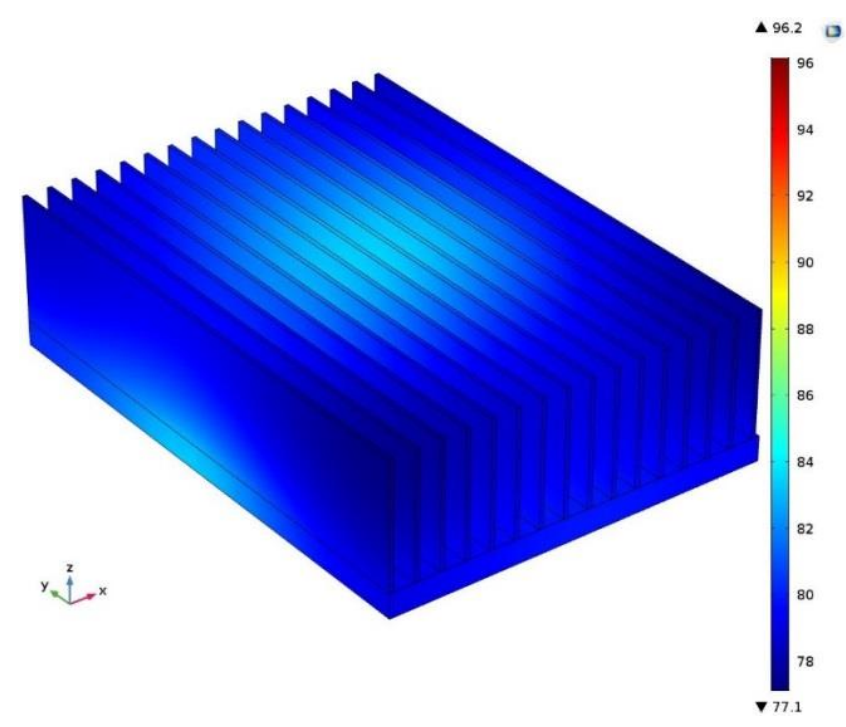

Fig. 4.9 Temperature profile of Si model with heatsink visible.

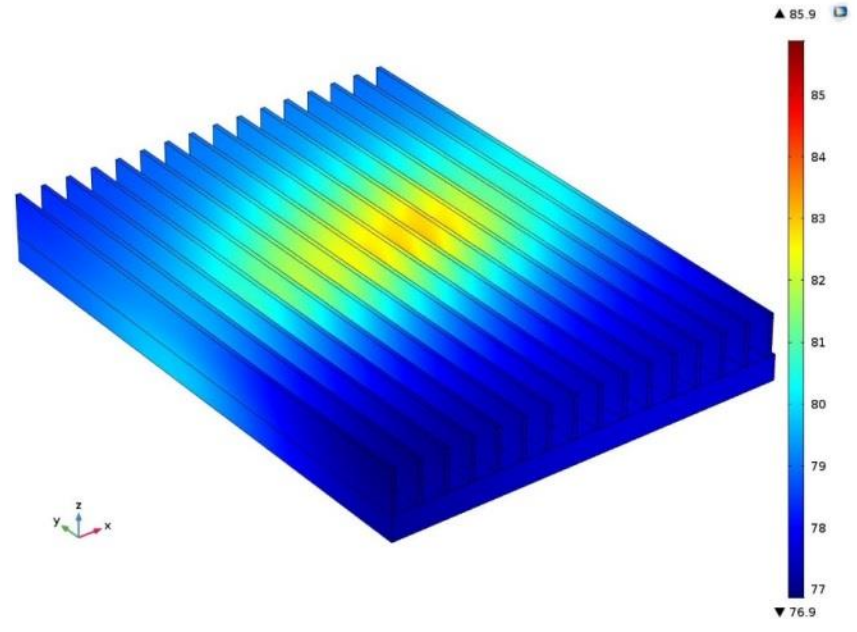

Fig. 4.10 Temperature profile of GaN model with heatsink visible. 
The maximum temperatures for the $\mathrm{Si}$ and $\mathrm{GaN}$ models were found to be $96.36^{\circ} \mathrm{C}$ and $85.91{ }^{\circ} \mathrm{C}$, respectively. The minimum temperatures were $77.14{ }^{\circ} \mathrm{C}$ and $76.87{ }^{\circ} \mathrm{C}$ for the Si and GaN models, respectively. The 3D model for Si MOSFETs had a volume of $183.8 \mathrm{~cm}^{3}$ and surface area of $1861 \mathrm{~cm}^{2}$ for the heatsink, while the GaN model had a volume of $125.6 \mathrm{~cm}^{3}$ and surface area of $826.3 \mathrm{~cm}^{2}$. Thus, using GaN HEMTs can achieve more than $55 \%$ reduction in heatsink surface area and more than $31 \%$ reduction in heatsink volume as shown in Fig. $4.11 \mathrm{a}$ and $\mathrm{b}$, respectively. As a result, the WBG (GaN) HEMT module requires a smaller heatsink for similar maximum temperatures. Using GaN HEMT will consequently reduce the overall system volume. The thermal modelling clearly demonstrates that the GaN module is more efficient than the Si module in terms of heatsink size and overall heat dissipation.

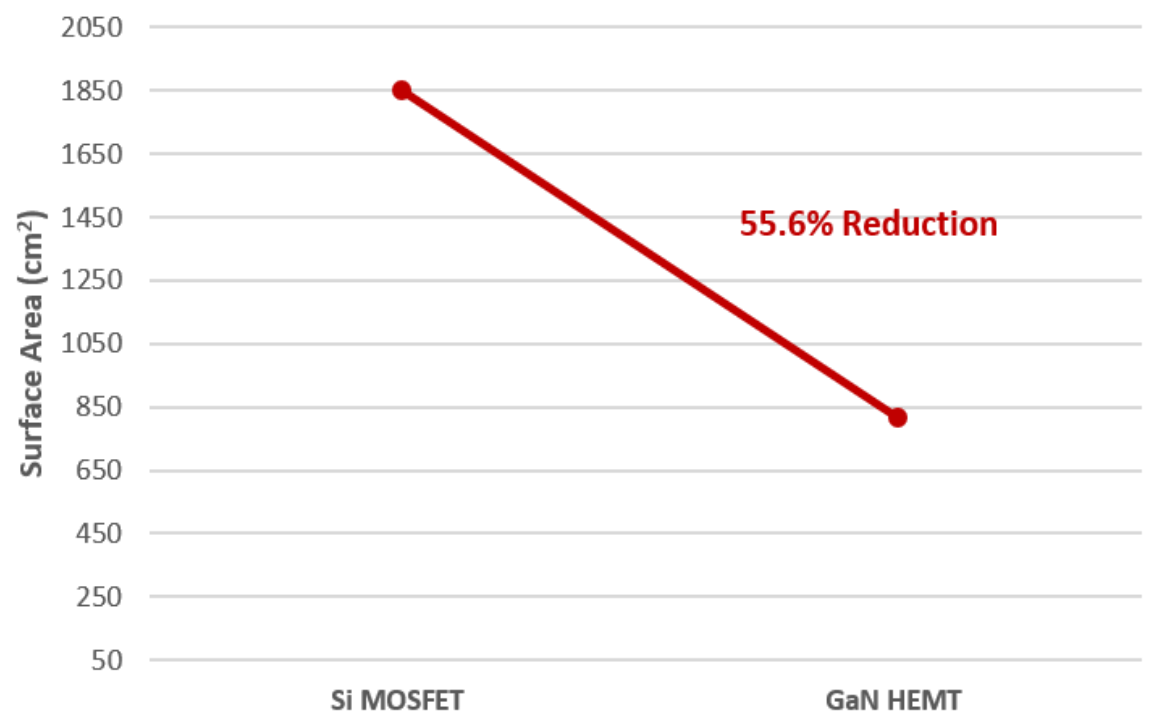

(a) 


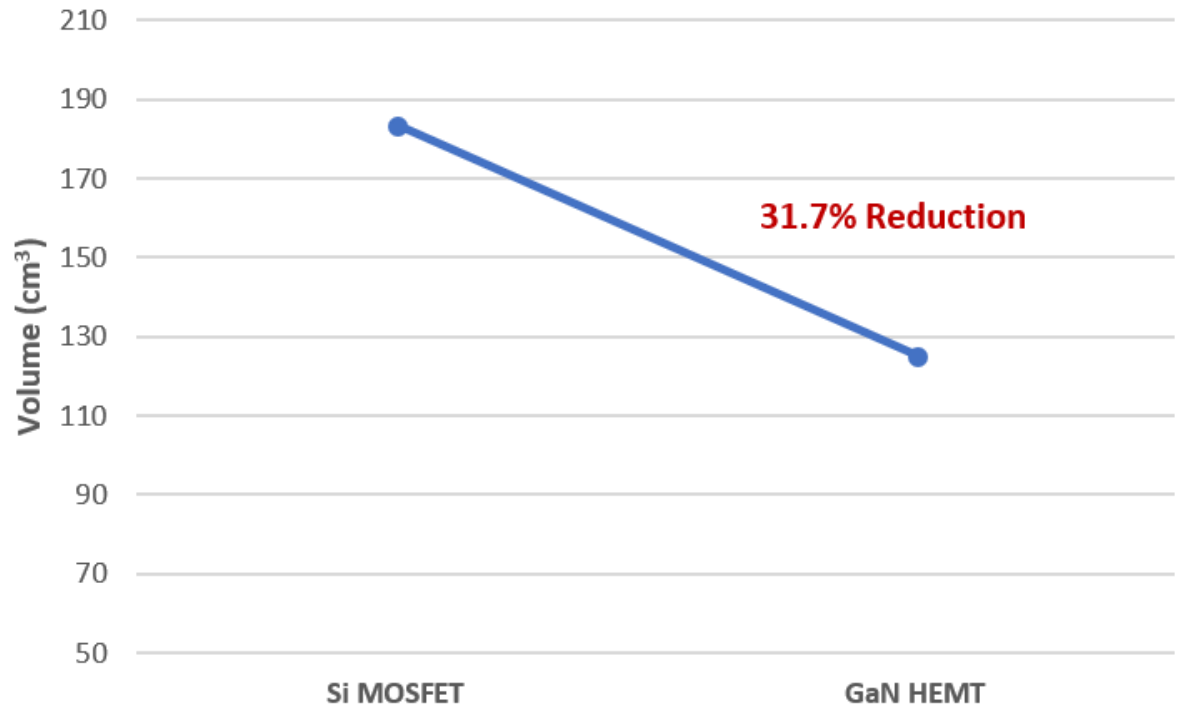

(b)

Fig. 4.11 Heat Sink Comparison between Si MOSFET and GaN HEMT: (a) Heatsink surface area. (b) Heatsink volume

\subsection{Conclusion}

In this chapter, an investigation of the benefits of using GaN HEMTs in a transformer-less PV inverter has been presented. The conduction losses, switching losses, and thermal analysis at different output powers and switching frequencies verified the benefits of replacing Si MOSFET with GaN HEMTs. The use of GaN HEMTs significantly reduced the overall semiconductor power losses of the proposed inverter by $60 \%$ when compared to Si MOSFETS under the same operation conditions (load and switching frequency). This loss reduction will increase the overall efficiency of the system by more than 3\%. Moreover, the GaN HEMT-based inverter operating at the same switching frequency as Si MOSFET-based inverter can provide more than a $60 \%$ increase in power rating while maintaining the same power losses. Furthermore, this loss reduction, when operating at the same switching frequency, allows a reduction of more 
than $30 \%$ in heat sink volume, which will consequently reduce the overall system volume and cost. Finally, the superior switching characteristics of GaN HEMTs allow the switching frequency to be increased to more than 10 times the switching frequency of the Si MOSFETs. This increase will, consequently, reduce the passive components weight and volume, which, eventually, will reduce the overall inverter cost. 


\section{Chapter Five: Improvement of Proposed Transformer-Less Inverter with}

\section{Reactive Power Capability}

\subsection{Introduction}

The significant increase of PV system installations in recent years will have a significant impact on the power grid [71]. Typically, in the distribution system, the power flow is unidirectional and as the line distance increases, the line voltage decreases, which affects the end consumer voltage. Therefore, in the existing grid system, the substation transformer side voltage is set to a higher voltage to maintain a reasonable voltage for long distance consumers from substation at high load conditions. With the huge increase of PV system installations, the power flow in the distribution system can be bidirectional and the huge active power fed to the grid can maintain high voltage with long line distance. However, in some cases, the voltage will exceed the upper threshold voltage. Limiting the PV power can solve this over voltage, but a more efficient solution is to use the PV inverter to regulate the voltage by absorbing reactive power.

Voltage Sags can occur for many reasons in distribution systems, such as sudden load change, and this sag can affect sensitive loads; therefore, sag mitigation is required to reduce its effect on the system. This improves power quality and grid stability and provides safe operation of loads. Reactive power control in PV inverters can help mitigate any voltage sag in the system to avoid any system interruption [72]-[74]. 
IEEE 1547a [19] and California's Electric Tariff Rule 21 [23] introduce the future roles of distribution energy resources (DR) and the future standards recommendations for PV inverters. According to IEEE 1547a [19], it is "required for the DR to actively participate to regulate the voltage by changes of real and reactive power". In [23], the recommended functionalities of the DR inverter are to "Provide reactive control through dynamic reactive power injection through autonomous responses to local voltage measurements, and to provide reactive power by a fixed power factor". Thus, it is required to have a reactive power capability in the future PV inverter.

\subsection{Reactive Power Capability of Current Transformer-less inverters}

The flow of bidirectional current is required in the inverter circuit to generate a reactive power. Existing transformer-less inverters, such as the H5 and H6 inverters, all use the complimentary phase-leg method shown in Fig. 5.1. To create a bidirectional current path, the current will flow either through the body diode of the switch or through the addition of extra fast recovery diodes. The most common switching devices used in inverter circuits are MOSFETs for low power, IGBTs for medium to high power and GTOs for high power applications.

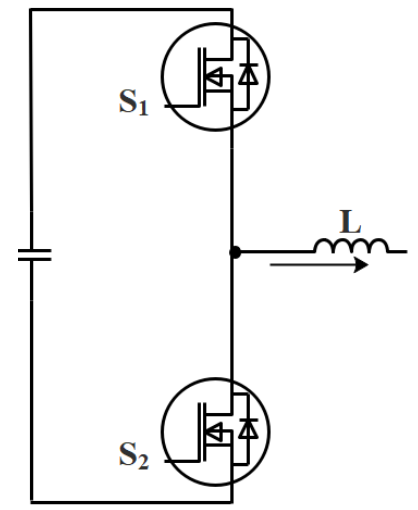

Fig. 5.1 Complimentary phase-leg method. 
In order to design inverters with low losses, switching devices with low switching losses are required and a good reverse recovery antiparallel diode must be used across each switching device. MOSFETs have excellent switching performance, but their antiparallel body diodes have poor reverse recovery behavior. The problem with MOSFET's body diode is that it can conduct current even when there is another current path. Also, any unexpected reverse recovery of this diode during MOSFET turn on and turn off will cause high frequency ringing and high switching losses which will cause higher stresses on the devices and electromagnetic interference (EMI). To solve this problem, MOSFET-based inverters usually use extra in series and freewheeling fast diodes, which increases the system cost, as well as the conduction losses in the system. Additionally, when designing highly efficient inverters with reactive power capability, the MOSFET's body diode will provide slow reverse recovery and cause high reverse recovery losses. Typically, IGBTs are used in inverter designs to overcome these problems. IGBTs tend to have higher switching losses than MOSFETs but need fewer diodes to provide good reverse recovery behavior. Thus, IGBTs will reduce the system cost compared to MOSFETs but will have lower efficiency at high switching frequencies.

GaN switches are promising technology with excellent switching performance that can operate at high switching frequency with high efficiency. This reduces the size and the volume of the system, which in return, will lower the system's overall cost. GaN HEMTs have a superior reverse recovery behavior compared to Si MOSFETs since they do not have a body diode, so there is zero reverse recovery charge. Therefore, GaN HEMTs will reduce the losses and provide lower EMI. These devices naturally have the 
capability of reverse conduction and depending on the gate voltage, they will provide different characteristics. Therefore, the gate drive of GaN HEMTs needs to be optimized to provide excellent reverse recovery behavior. The natural reverse conduction capability is an advantage because no antiparallel diodes are required compared to Si MOSFETs and IGBTs. These characteristics make the GaN HEMTs an excellent choice for future PV inverters.

In order to verify the superior reverse recovery of GaN HEMT compared to $\mathrm{Si}$ MOSFET's body diode, two simulations are done in PSpice using double pulse test circuits shown in Fig. 5.2 at $400 \mathrm{~V}$ and 2 A. Two devices are selected for the simulation Infineon $\mathrm{Si}$ MOSFET (CoolMOS) IPW60R045CP and GaNSystems GaN HEMT GS66516T. Table 5.1 shows the characteristics of each device. As can be seen from the table, the GaN HEMT has zero recovery charge and faster turn on and turn off times with low time delay. The test is done by first turning the bottom MOSFET (or HEMT) on; this charges the inductor current. Then, by turning the bottom MOSFET (or HEMT) off, the inductor current will have only one path to conduct through which is the top MOSFET body diode (or the top HEMT). Finally, by turning the bottom MOSFET (or HEMT) on again, a forced reversed recovery can occur on the top MOSFET body diode (or top HEMT). In this way, the reverse recover effect on the MOSFET body diode and the GaN HEMT can be studied and evaluated. 


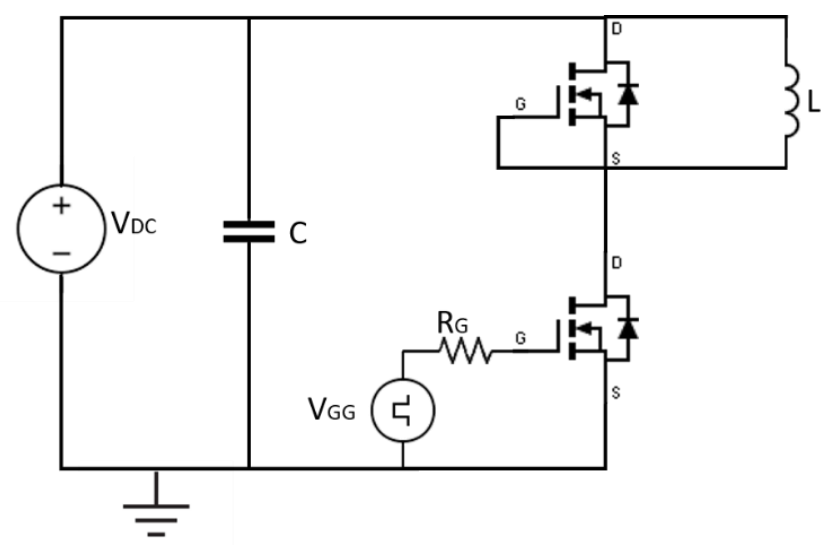

Fig. 5.2 Double pulse test circuit.

Table 5.1 Power switching devices characteristics

\begin{tabular}{ccc}
\hline Parameter & IPW60R045CP & GS66516T \\
\hline$V_{\mathrm{DS}}(\mathrm{V})$ & 650 & 650 \\
$\mathrm{I}_{\mathrm{D}}(\mathrm{A})$ & 60 & 60 \\
$\mathrm{R}_{\mathrm{DS}}(\mathrm{m} \Omega)$ & 45 & 25 \\
$\mathrm{Q}_{\mathrm{RR}}(\mu \mathrm{C})$ & 17 & 0 \\
$\mathrm{~T}_{\mathrm{R}}(\mathrm{ns})$ & 20 & 12.4 \\
$\mathrm{~T}_{\mathrm{R}}$ delay $(\mathrm{ns})$ & 30 & 4.6 \\
$\mathrm{~T}_{\mathrm{F}}(\mathrm{ns})$ & 10 & 22 \\
$\mathrm{~T}_{\mathrm{F}}$ delay $(\mathrm{ns})$ & 100 & 14.9 \\
\hline \hline
\end{tabular}

The Si MOSFET waveforms during this process are shown in Fig. 5.3. The peak reverse recovery current is 41.89 A under 2 A load current conditions. Both Top and Bottom MOSFETs gate voltages exhibit higher voltages than intended gate voltages of 10 $\mathrm{V}$, which will lead to false turn on and turn off in the MOSFETs. Consequently, MOSFET failure is inevitable. On the other hand, GaN HEMTs show an excellent reverse recovery behavior. The GaN HEMT waveforms during this process are shown in Fig. 5.4. The peak reverse recovery current is less than 8 A under the same 2 A load current. The gate voltages are stable, and the false turn on and turn off are avoided. 
Therefore, shoot through failure is prevented by the superior reverse recovery performance of GaN HEMTs.

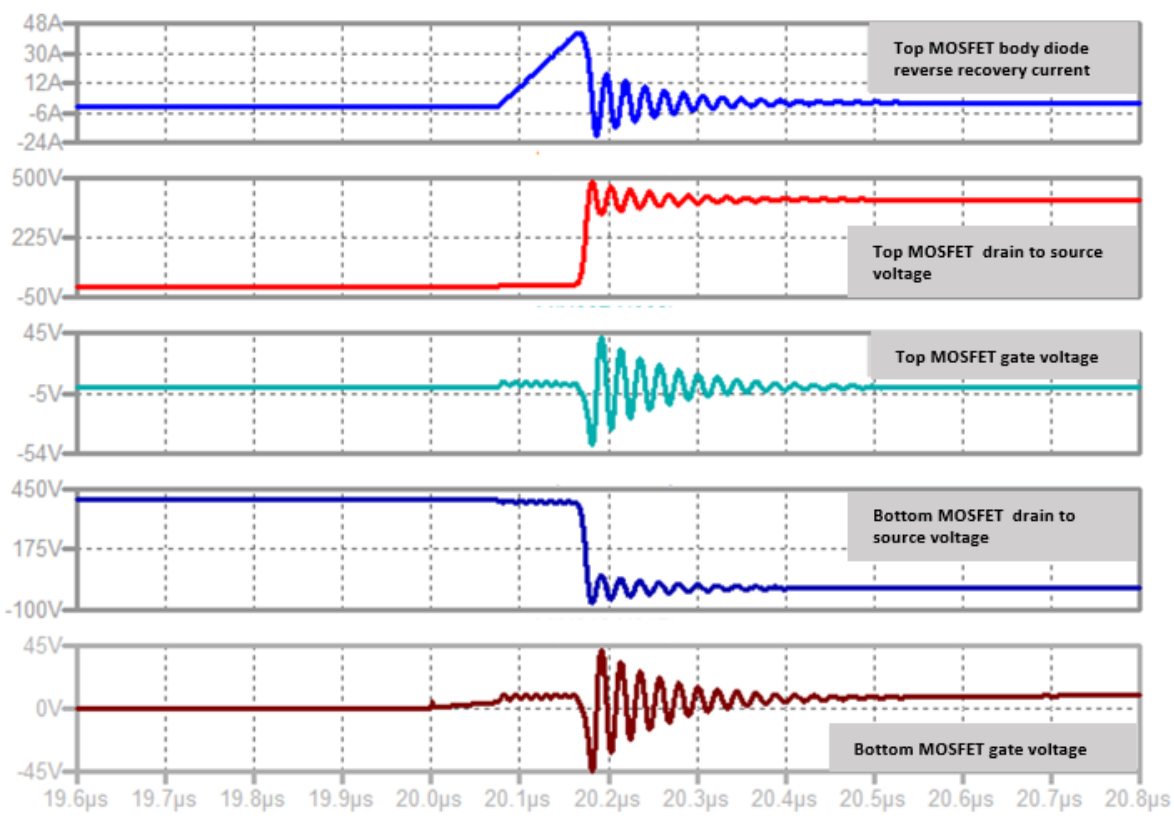

Fig. 5.3 Diode reverse recovery waveforms of Si MOSFET.
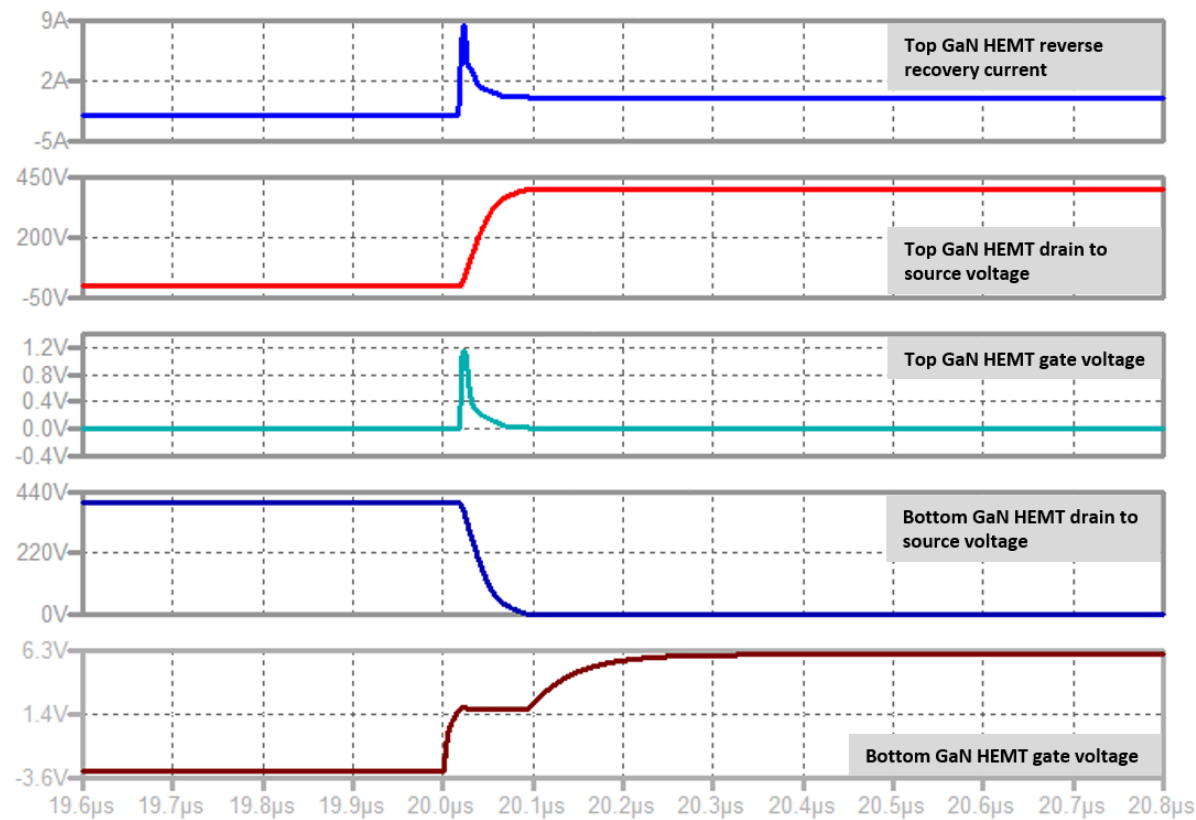

Fig. 5.4 Reverse recovery waveforms of GaN HEMT. 


\subsection{Proposed GaN-Based Single-Phase Transformer-Less PV Grid-Tied Inverter with Reactive Power Capability}

The proposed transformer-less inverter in section 2.3 and the enhanced GaN HEMT-based inverter in chapter 4 is working and tested for unity power factor operation. The proposed topology can generate unipolar output voltage $\left(+\mathrm{V}_{\mathrm{DC}}, 0,-\mathrm{V}_{\mathrm{DC}}\right)$ and constant CMV using conventional PWM during the positive power region. During the negative power region grid voltage and current have opposite polarity and four modes of operation are needed. When grid voltage is negative and grid current is positive, the current freewheels through the antiparallel diode of S2 and S6 as shown in Fig. 5.5 (in GaN HEMT case its reverse conduction capability). $\mathrm{V}_{\mathrm{AB}}=-\mathrm{V}_{\mathrm{DC}}$, and the Common Mode voltage $\mathrm{V}_{\mathrm{CM}}=\left(\mathrm{V}_{\mathrm{AN}}+\mathrm{V}_{\mathrm{BN}}\right) / 2=\left(0+\mathrm{V}_{\mathrm{DC}}\right) / 2=\mathrm{V}_{\mathrm{DC}} / 2$. When grid voltage is positive and grid current is negative, the current freewheels through the antiparallel diode of S4 and $\mathrm{S} 5$ as shown in Fig. 5.6 (in GaN HEMT's case its reverse conduction capability). $\mathrm{V}_{\mathrm{AB}}=$ $+\mathrm{V}_{\mathrm{DC}}$, and the Common Mode voltage $\mathrm{V}_{\mathrm{CM}}=\left(\mathrm{V}_{\mathrm{AN}}+\mathrm{V}_{\mathrm{BN}}\right) / 2=\left(\mathrm{V}_{\mathrm{DC}}+0\right) / 2=\mathrm{V}_{\mathrm{DC}} / 2$. However, there is no current path to generate zero state voltage. Therefore, the conventional PWM used earlier is not suitable for reactive power generation. Thus, the PWM or the switching states of the proposed topology need to be modified to provide a current path for the zero-state voltage during the negative power region. 


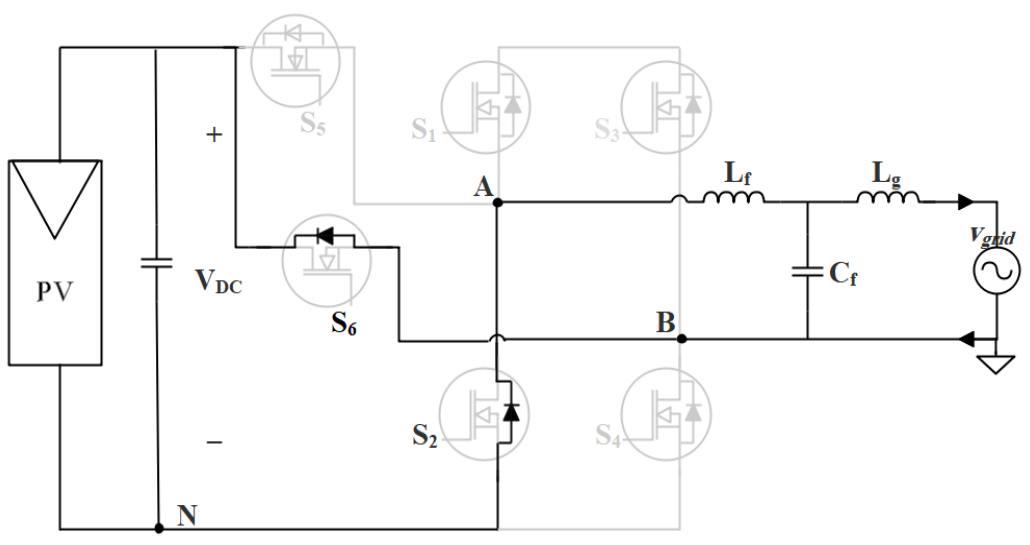

Fig. 5.5 Active state mode negative state voltage in negative power region.

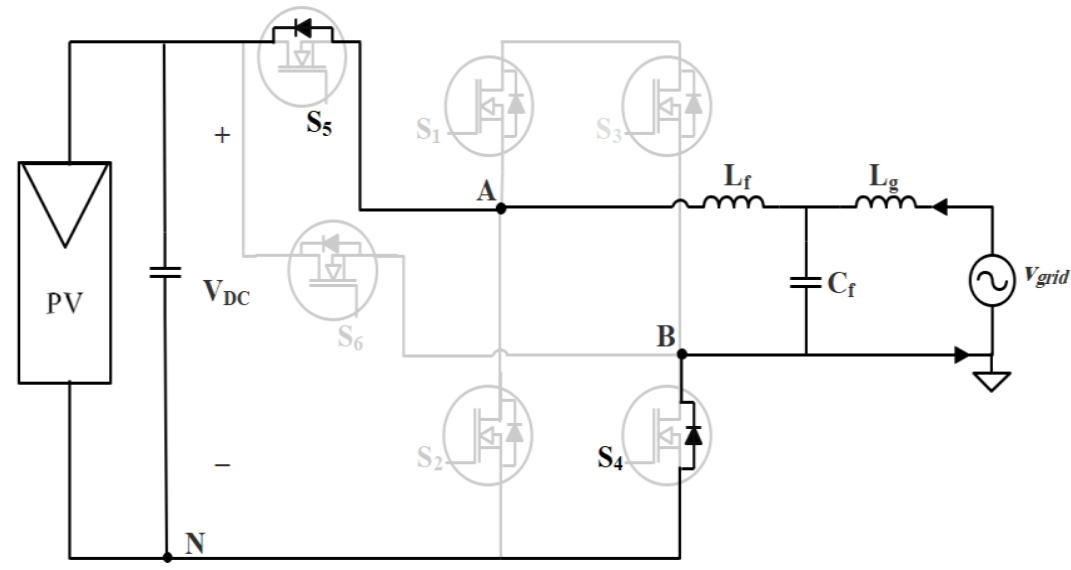

Fig. 5.6 Active state mode positive state voltage in negative power region.

\subsubsection{Modified PWM for Reactive Power Generation}

As mentioned previously, conventional PWM is not suitable for reactive power generation. Therefore, the PWM signals need to be modified to generate zero voltage during the negative power region. Modified PWM, shown in Fig. 5.7, creates a new current path to generate the zero voltage in the negative power region. As shown in the figure, there are four regions of operation. Region I and region II are the positive power regions where grid voltage and current have the same polarity. Region III and region IV are the negative power regions where grid voltage and current have opposite polarity. 
Operation principles for region I and region II (the positive power region) are the same as conventional PWM and they are discussed in detail in section 2.3.

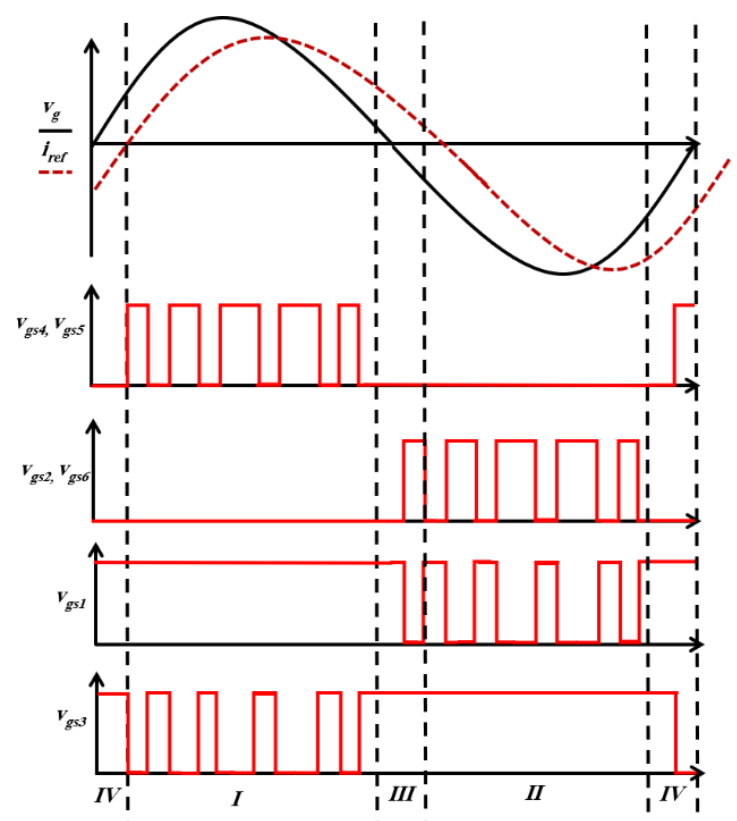

Fig. 5.7 Non-unity power factor PWM signals.

There are four modes of operation in the negative power region. Region III, when grid voltage is negative and grid current is positive, has two modes of operation.

In Mode 1, S2, S6 and S3 are turned ON. The current during this mode is freewheeling through the antiparallel diode of S2 and of S6 (in GaN HEMT case its reverse conduction capability), as shown in Fig. 5.5. $\mathrm{V}_{\mathrm{AB}}=-\mathrm{V}_{\mathrm{DC}}$, and $\mathrm{V}_{\mathrm{CM}}=\left(\mathrm{V}_{\mathrm{AN}}+\right.$ $\left.\mathrm{V}_{\mathrm{BN}}\right) / 2=\left(0+\mathrm{V}_{\mathrm{DC}}\right) / 2=\mathrm{V}_{\mathrm{DC}} / 2$.

In Mode 2, S1 and S3 are turned ON while all other switches are turned OFF. S1 in the conventional PWM is turned OFF in this state but with the modified PWM, it is complimentary commutating to S2 and S6 to create a new current path for zero state in region III. The current during this mode flows through S1 and the anti-paralleled diode of $\mathrm{S} 3$, as shown in Fig. 5.8. $\mathrm{V}_{\mathrm{AB}}=0$, and $\mathrm{V}_{\mathrm{CM}}=\mathrm{V}_{\mathrm{DC}} / 2$. 
Region IV, when grid voltage is positive and grid current is negative, has two modes of operation.

In Mode 3, S1, S4 and S5 are turned ON. The current during this mode is freewheeling through the antiparallel diode of S4 and S5 (in GaN HEMT case its reverse conduction capability), as shown in Fig. 5.6. $\mathrm{V}_{\mathrm{AB}}=+\mathrm{V}_{\mathrm{DC}}$, and the Common Mode voltage $\mathrm{V}_{\mathrm{CM}}=\left(\mathrm{V}_{\mathrm{AN}}+\mathrm{V}_{\mathrm{BN}}\right) / 2=\left(\mathrm{V}_{\mathrm{DC}}+0\right) / 2=\mathrm{V}_{\mathrm{DC}} / 2$.

In Mode 4, S1 and S3 are turned ON while all other switches are turned OFF. S3 in the conventional PWM is turned OFF in this state, but with the modified PWM, it is complimentary, commutating to S4 and S5 to create a new current path for zero state in region IV. The current during this mode flows through S3 and the anti-paralleled diode of $\mathrm{S} 1$, as shown in Fig. 5.9. $\mathrm{V}_{\mathrm{AB}}=0$, and $\mathrm{V}_{\mathrm{CM}}=\mathrm{V}_{\mathrm{DC}} / 2$.

Applying the modified PWM, zero states can be achieved in the negative power region for the proposed inverter in section 2.3. As a result, reactive power can be generated while maintaining constant CMV and low leakage current.

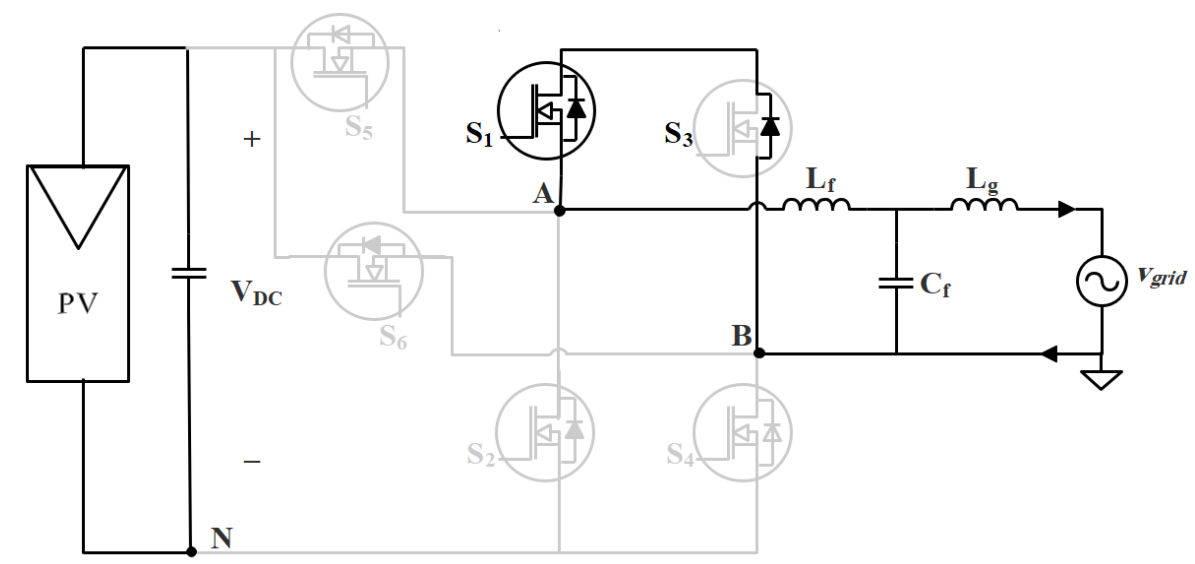

Fig. 5.8 Negative zero state voltage mode in negative power region. 


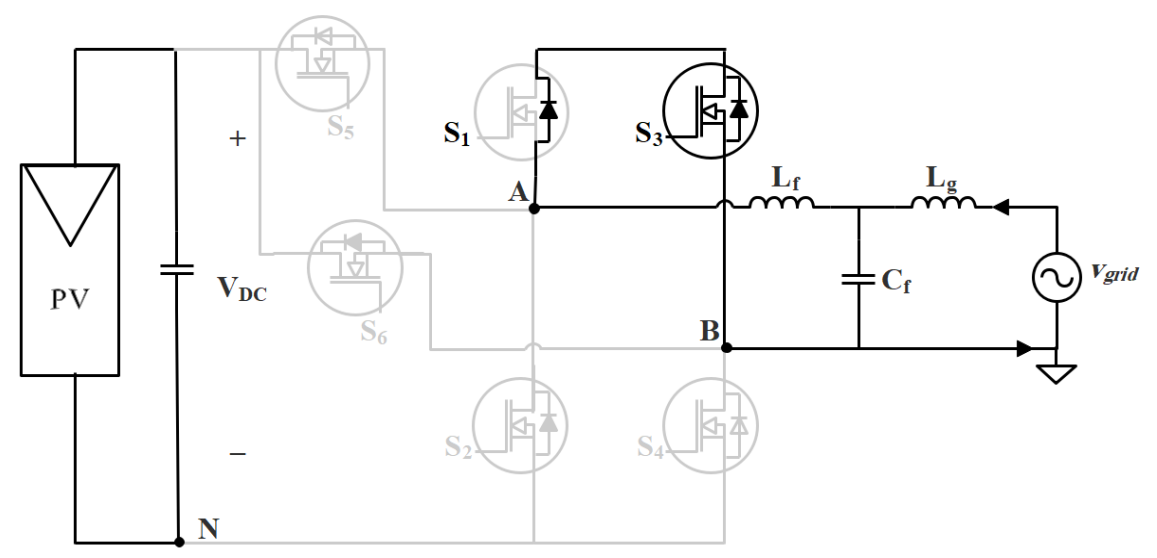

Fig. 5.9 Positive zero state voltage mode in negative power region.

\subsubsection{Simulation Results}

To validate the theoretical analysis of the proposed inverter reactive power capability with the modified PWM, a simulation is carried out using co-simulation between PSIM environment and MATLAB/Simulink Platform. Table 5.2 lists the simulation parameters. GaN HEMT (GS66516T) is used in the simulation as the power switching device.

Table 5.2 Simulation Parameters

\begin{tabular}{cc}
\hline \hline Parameter & Value \\
\hline System Power & $5 \mathrm{KW}$ \\
Input Voltage & $400 \mathrm{~V}$ \\
Grid Voltage & $120 \mathrm{~V}$ \\
Grid Frequency & $60 \mathrm{~Hz}$ \\
Switching Frequency & $200 \mathrm{kHz}$ \\
Input Capacitance & $1 \mathrm{mF}$ \\
\hline \hline
\end{tabular}

Fig. 5.10 shows the proposed inverter simulated waveforms with the modified PWM for unity power factor. Fig. 5.11 and Fig. 5.12 show the proposed inverter simulated waveforms with the modified PWM for non-unity power factor, lagging PF and leading PF, respectively. Thus, prove the modified PWM can allow the proposed 
inverter to operate with both unity and non-unity power factors. Fig 5.13 and 5.14 show the change from unity PF to lagging PF and from unity PF to leading PF, respectively. As can be noticed from the figures, the modified PWM is working properly during the transition period either from unity PF to lagging PF or from unity PF to leading PF.

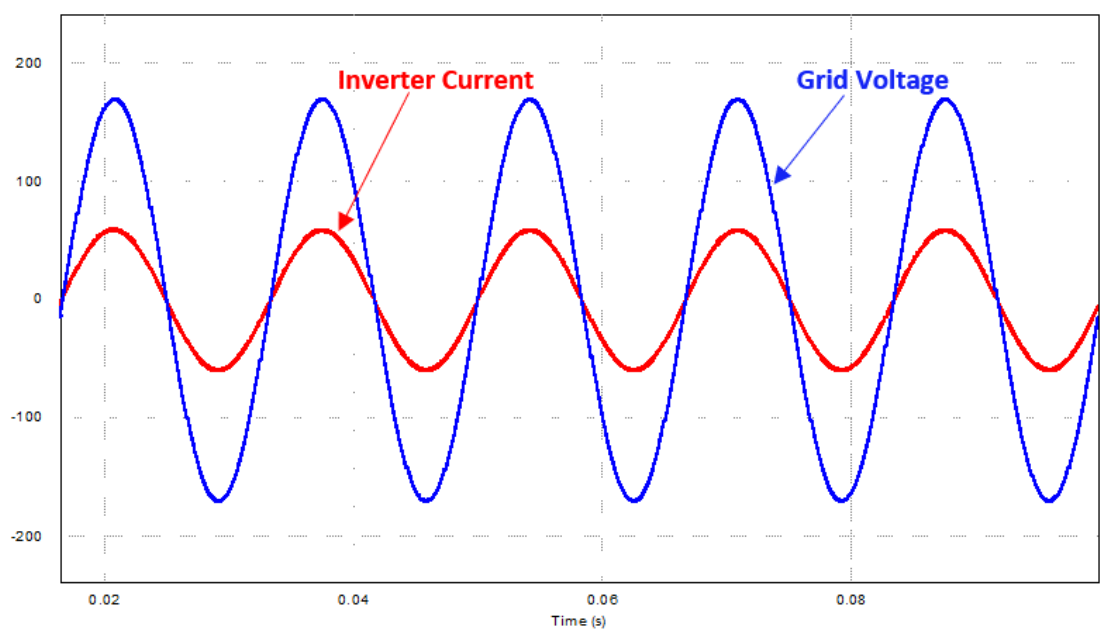

Fig. 5.10 Proposed inverter with modified PWM under unity power factor.

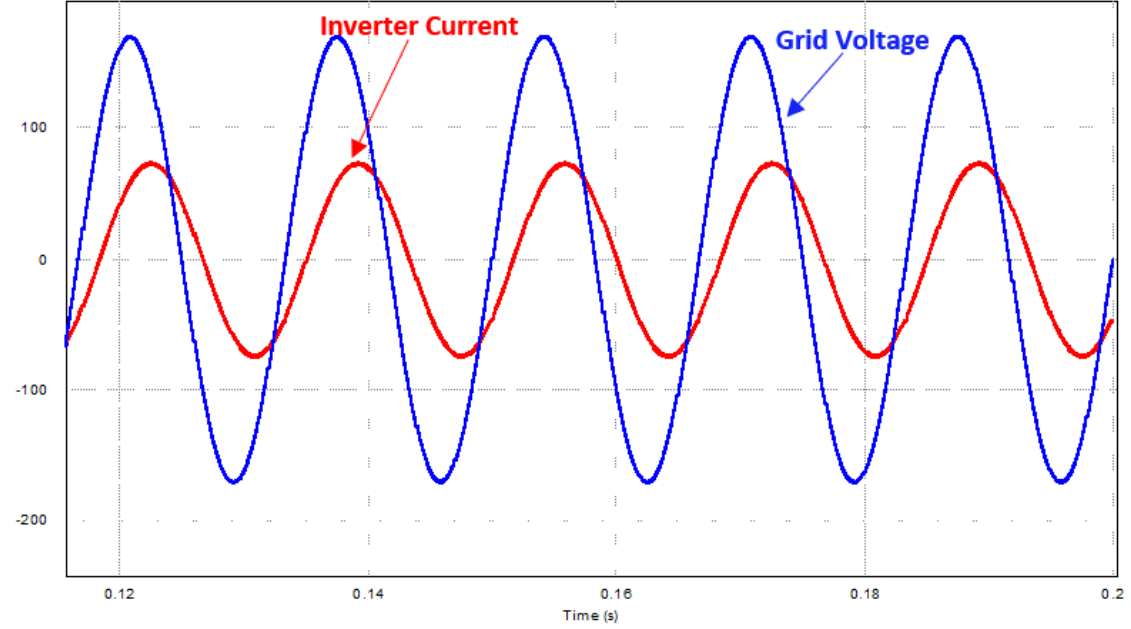

Fig. 5.11 Proposed inverter with modified PWM under lagging power factor. 


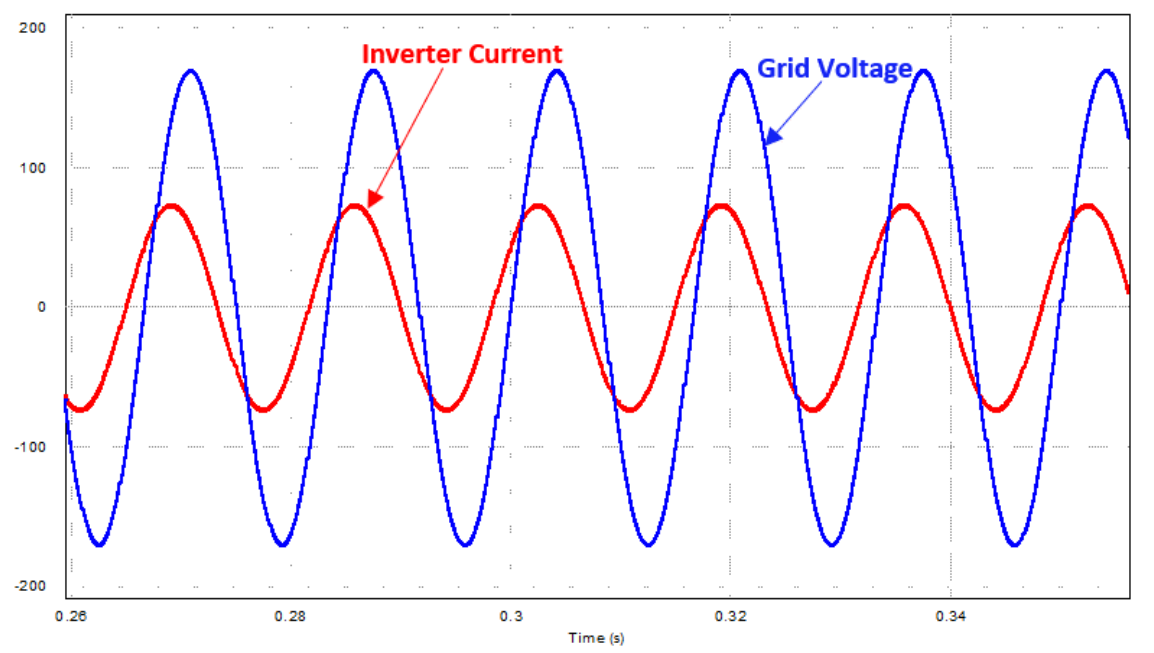

Fig. 5.12 Proposed inverter with modified PWM under leading power factor.

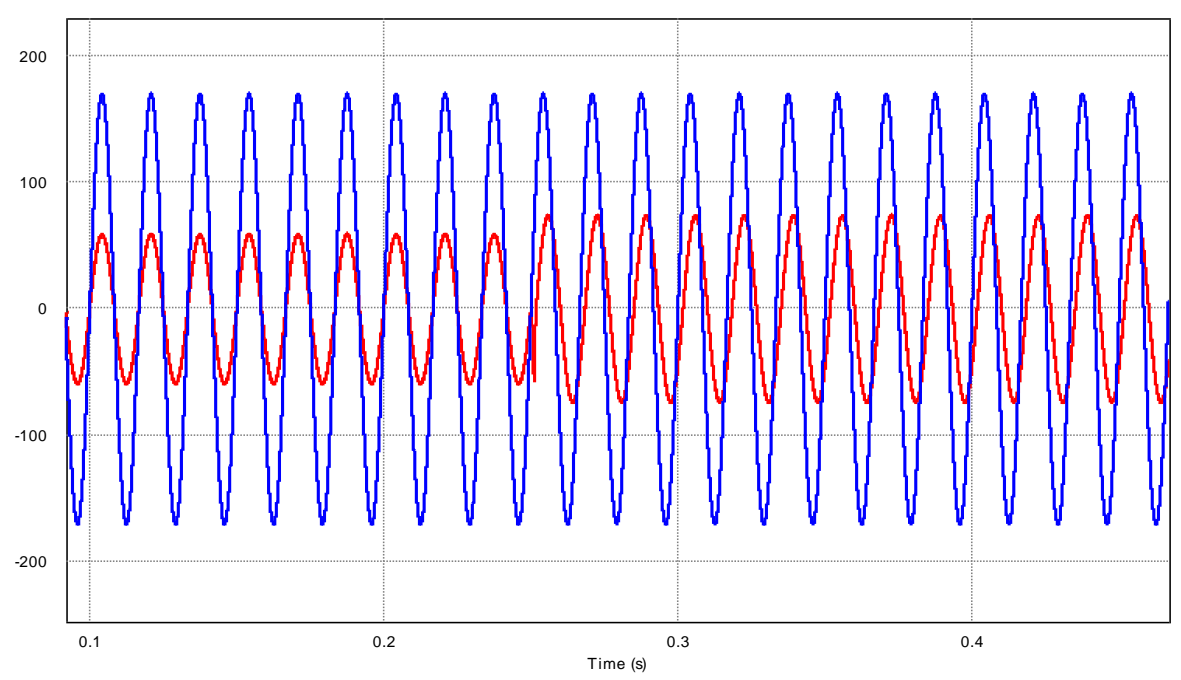

Fig. 5.13 Transition from unity power factor to lagging power factor. 


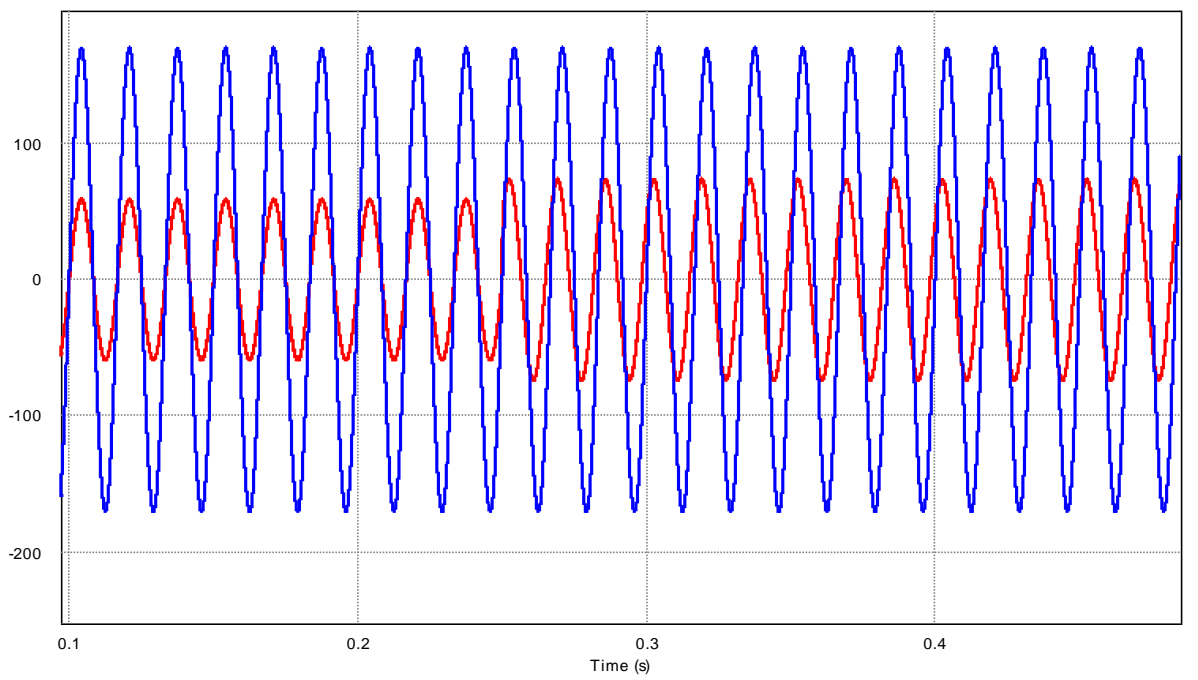

Fig. 5.14 Transition from unity power factor to leading power factor.

Fig. 5.15 shows the leakage current of the inverter with the modified PWM. The leakage current is still low with RMS of $10.6 \mathrm{~mA}$, and it is almost the same as the proposed inverter with conventional PWM in section 2.3. Therefore, with the modified modulation technique, the proposed inverter in section 2.3 is suitable for transformer-less and reactive power applications without adding additional components or modifying the inverter structure.

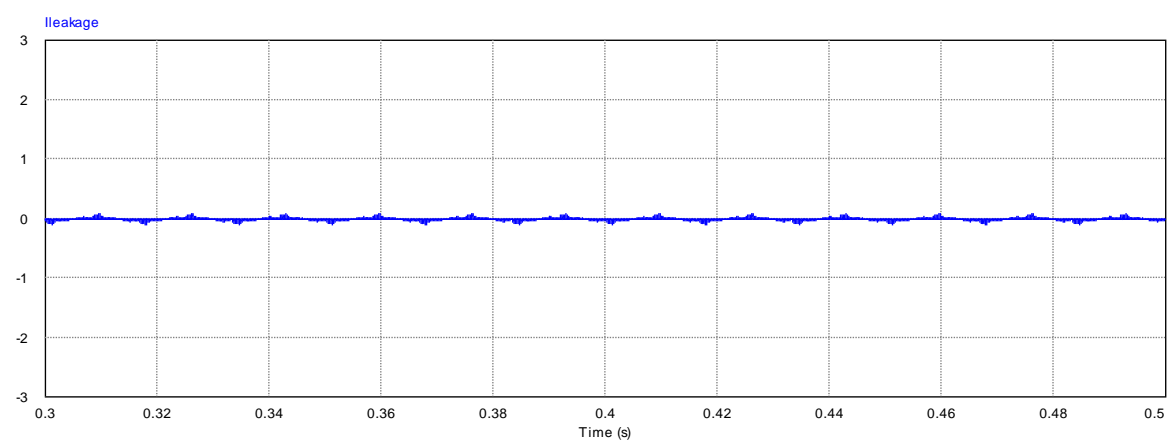

Fig. 5.15 Leakage current of proposed inverter with modified PWM.

The efficiency curve of the proposed inverter with conventional PWM and the modified PWM at different load powers is presented in Fig. 5.16. The inverter with the 
modified PWM has slightly lower efficiency than the inverter with conventional PWM due to the increase of switch count. The calculated efficiencies according to equation (2.15), the CEC standard for conventional and modified PWMs, are 99.23\% and 98.80\%, respectively. Regardless of the increase of switch count, the modified PWM provides the system with reactive power capability without adding additional components or modifying the inverter structure. This provides a simple and cost-effective PV inverter.

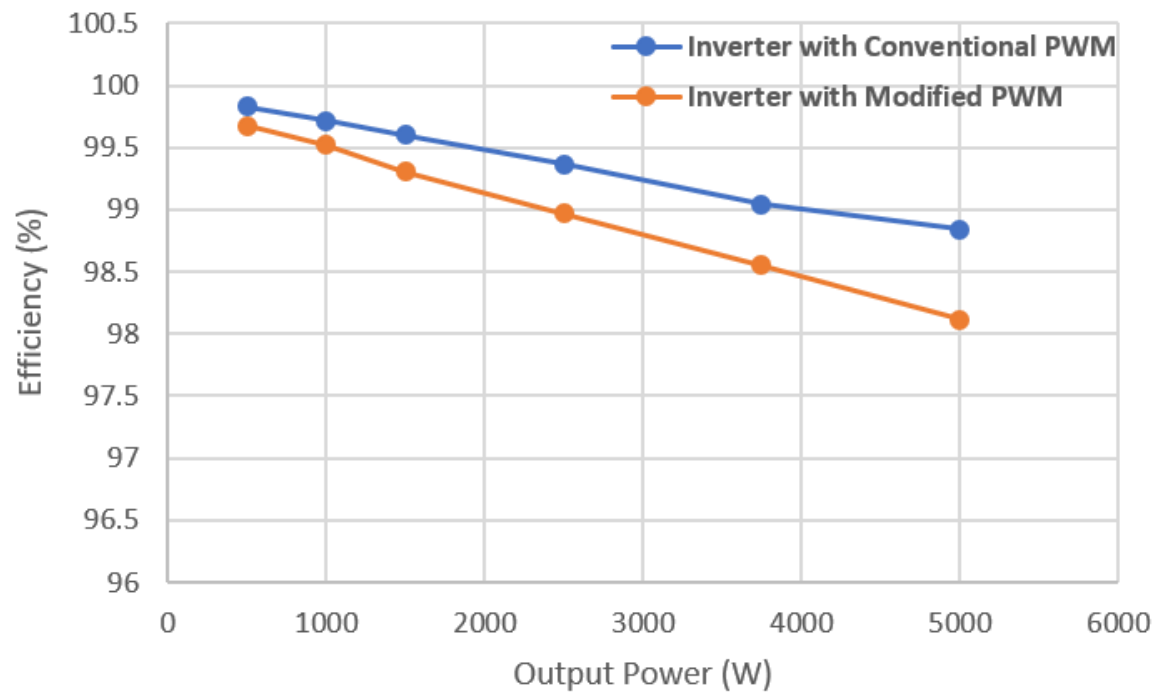

Fig. 5.16 Efficiency comparison of proposed inverter with conventional and proposed PWM.

\subsection{Conclusion}

In this chapter, a high efficiency single-phase transformer-less inverter with reactive power capability has been proposed. The flow of bidirectional current is required in the inverter circuit to generate a reactive power. Thus, to create a bidirectional current path, the current will flow either through the body diode of the switch or through the addition of extra fast recovery diodes. MOSFET's body diode has poor reverse recovery behavior, which leads to high frequency ringing and high switching losses that will cause 
higher stresses on the power devices. Also, adding fast recovery diodes to create a path for bidirectional current flow reduces the system's efficiency and increases the cost and size of the system. On the other hand, GaN HEMTs naturally have the capability of reverse conduction and no antiparallel diodes are required compared to Si MOSFETs and IGBTs. Gan HEMTs provide excellent reverse recovery behavior, which makes it an excellent choice for future PV inverters. Furthermore, a modified PWM has been proposed to create a new current path and help achieve zero states in the negative power region. As a result, reactive power can be generated while maintaining constant CMV and low leakage current. It should be noted that the inverter with the modified PWM has slightly lower efficiency than the inverter with conventional PWM due to the increase of switch count. The efficiency has been reduced from $99.23 \%$ using conventional PWM to 98.80\% using modified PWM. However, the use of GaN HEMTs with its superior reverse recovery performance and the modified PWM provides the system with reactive power capability without adding additional components or modifying the inverter structure. Thus, the proposed inverter provides a simple and cost-effective next generation PV inverter. 


\section{Multifunctional Control Strategy for PV Grid-Tied Inverter to Support the \\ Grid}

\subsection{Introduction}

Due to the intermittent nature of solar energy, the rapid increase of PV system installation into the electric network will affect the reliability and the quality of the power system. The increasing penetration of PV power will weaken the whole power system due to the injection of fluctuation PV power. Thus, grid codes have been updated and new regulations have been introduced to control PV energy integration with the electric grid.

Typically, during grid faults it is required that PV systems trigger an antiislanding protection in order to stop delivering power to local loads. However, due to the rapid increase in PV installation, its impact on the grid cannot be ignored even for small residential PV systems [75]-[78]. If all grid-connected PV systems switched suddenly to islanding mode of operation, the grid would face more severe problems than any initial grid fault. Therefore, many countries have updated their grid codes to solve gridconnected PV system potential problems. Future PV Systems will be required to provide additional services, such as Low Voltage Ride-Through capability (LVRT) [79]-[84], active power control [85]-[87], and reactive power compensation [88]-[92]. The German grid code requires that under grid faults, any Distributed Generation system including PV 
systems must have low voltage ride through capability when connected to medium or high voltage networks [93]. In the updated Italian grid code, any distributed generation system with more than $6 \mathrm{KW}$ nominal power must have voltage ride through capability under grid faults [94]. In IEEE 1547a [19] it is required that the DR support the grid during voltage recovery by controlling the active and reactive power. In California's Electric Tariff Rule 21 [23], it is recommended that the DR inverter provide reactive power and participate in voltage regulation. Therefore, future PV systems must provide advanced control functions to support the grid.

To fully benefit from solar PV energy and take advantage of the increasing number of grid-tied PV systems, a simple and flexible control strategy should be developed to provide PV inverters with advanced functions that will support the grid. A control system is developed in this chapter to provide the PV inverter with advanced functions, and this control system has the flexibility to change from one mode to another according to the grid requirements or the customer demands. The proposed control strategy is based on $d-q$ synchronous frame controller, which is simple yet has the ability to provide the proper power references that will be used in the inner control systems. Moreover, this control strategy can provide the PV inverter with multiple operation modes to achieve multiple advanced functions.

\subsection{Grid-Tied Single-Phase Transformer-Less Inverter Control}

Single-phase grid-tied transformer-less PV systems are the common configuration for low power applications (mainly residential applications up to 5kW). Fig. 6.1 shows the complete configuration of the control system. To maximize the power and extract 
more energy from the PV system, maximum power point tracking (MPPT) control is implemented [95]. The main control components are the phase locked loop (PLL), the Orthogonal System Generator (OSG), PI controllers, the sag detection unit and the power calculation algorithm. The power calculation algorithm is constructed by controlling the active and reactive power using $d-q$ components. Using Park Transformation, the inverter current is transformed into $\mathrm{I}_{d}$ and $\mathrm{I}_{q}$ in reference to the grid voltage rotating $d$ - $q$ reference frame [96]-[98]. $\mathrm{I}_{d}$ is the active power component and $\mathrm{I}_{q}$ is the reactive power component. After the transformation, two PI regulators are used, and the PI outputs are transformed back into $\alpha-\beta$ reference frame to provide the inverter modulation signals as shown in Fig. 6.1.

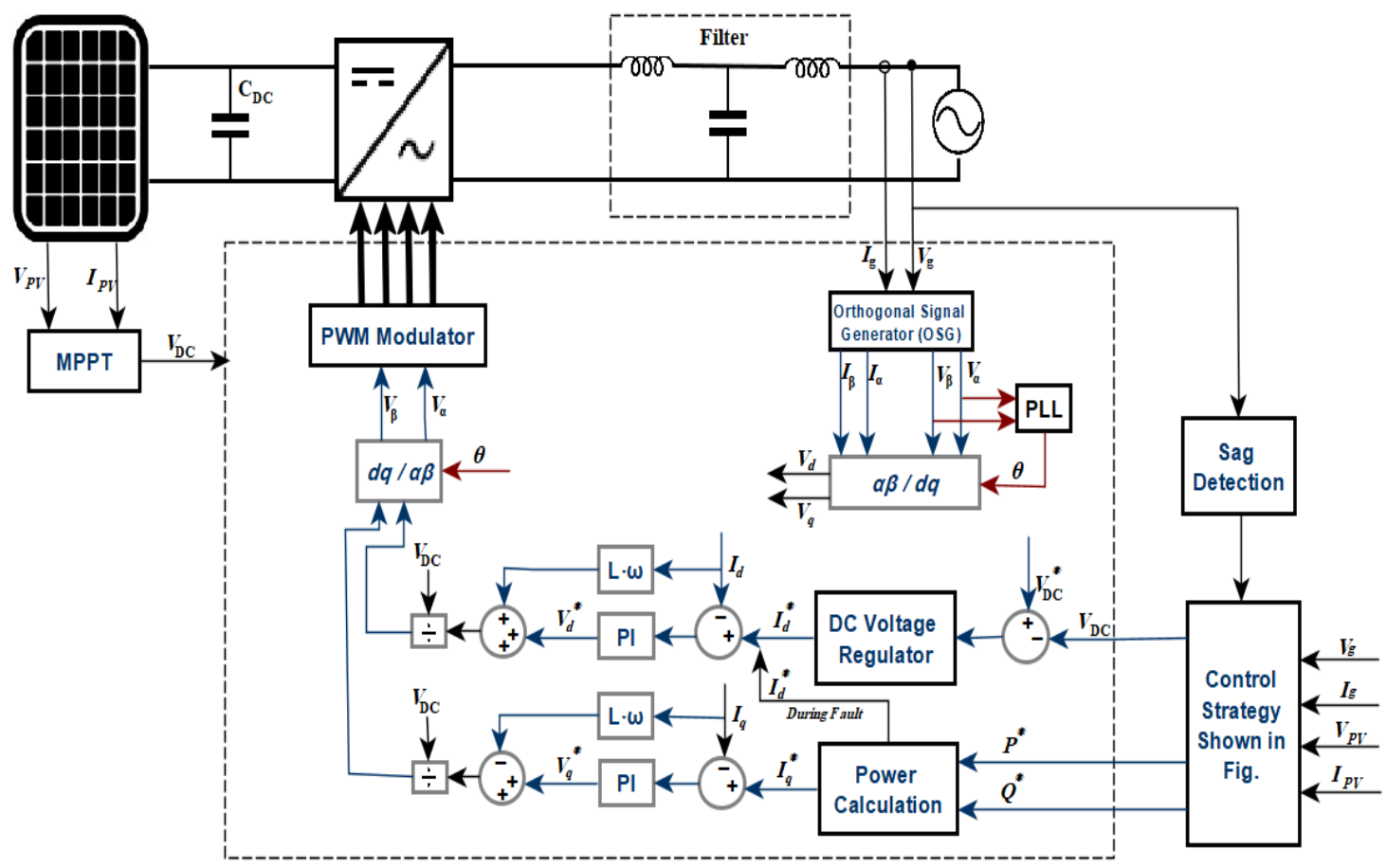

Fig. 6.1 Single Phase Transformer-less Inverter configuration with synchronous rotating frame control $(d-q$ control) 
The $d-q$ transformation is originally used in three phase systems. Using linear transformation, it can be directly implanted from abc space (time varying signals) to $d-q$ space [97]-[99]. This transformation also can be achieved by first transforming the abc vector to $\alpha-\beta$ space using $\alpha-\beta$ stationary frame, and after that transforming $\alpha-\beta$ to $d-q$ space using $d-q$ synchronous frame [100], [101]. In this theory, it is required to have two orthogonal components to obtain $d-q$ components, and this is a problem in single-phase systems where there is only one phase signal.

Several methods have been developed to generate the other orthogonal component to apply the $d-q$ transformation in single-phase systems. [102] Proposes using the current of output filter capacitor which is $90^{\circ}$ out of phase with the output voltage as the orthogonal component. Another approach to obtain the orthogonal component is to delay the original signal by $1 / 4$ period of time [103]. If a current signal is considered, to be transformed to the $d-q$ rotating frame using the time delay method, we can obtain an imaginary current signal, which is the time delayed version of the original real current signal. As a result, the real current signal will be the $\alpha$ component and the imaginary signal will be the $\beta$ component. Fig. 6.2 illustrates this process. 


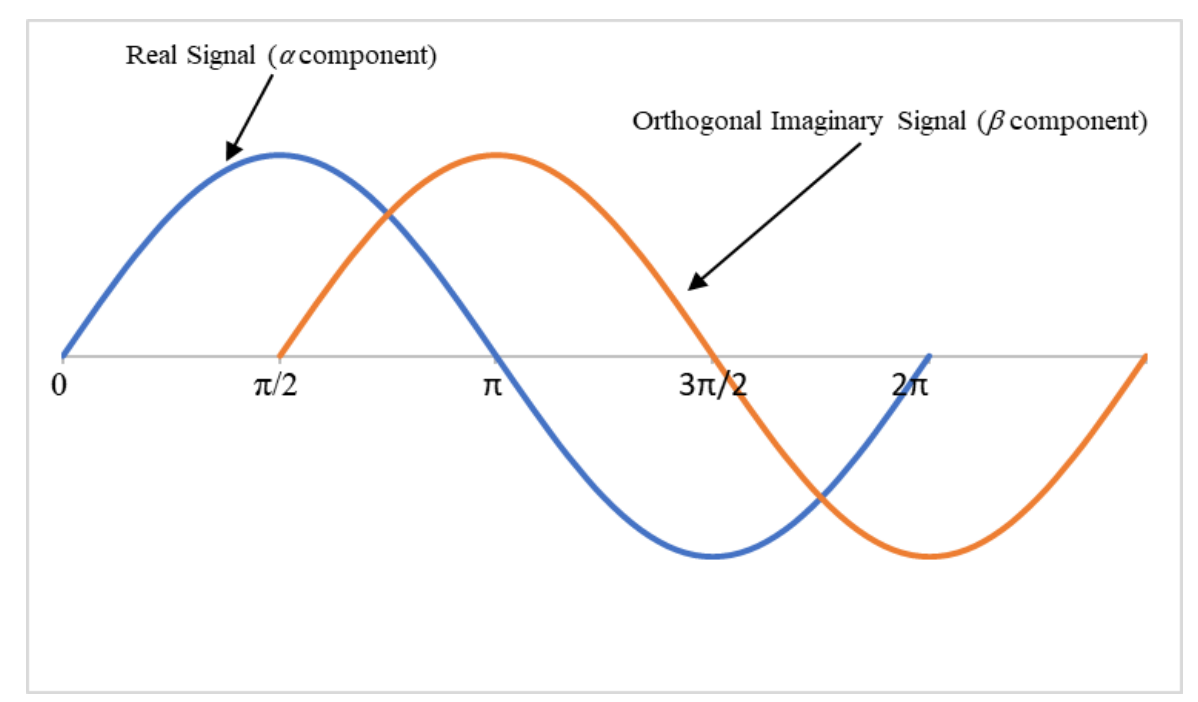

Fig. 6.2 Real $(\alpha)$ and imaginary ( $\beta$ ) signals.

Mathematical foundations of sine versions of these current signals are as follows:

$$
\begin{aligned}
& \mathrm{i}_{\mathrm{r}}=\mathrm{i}_{\alpha}=A \sin (\omega \mathrm{t}+\varphi) \\
& \mathrm{i}_{\mathrm{i}}=\mathrm{i}_{\beta}=A \sin \left(\omega \mathrm{t}+\varphi-\frac{\pi}{2}\right)=-A \cos (\omega \mathrm{t}+\varphi)
\end{aligned}
$$

The DC values in the $d-q$ rotating frame are obtained using linear transformation given in:

$$
\left[\begin{array}{l}
i_{d} \\
i_{q}
\end{array}\right]=\left[\begin{array}{cc}
\sin \omega t & -\cos \omega t \\
\cos \omega t & \sin \omega t
\end{array}\right]\left[\begin{array}{l}
i_{\alpha} \\
i_{\beta}
\end{array}\right]
$$

Transforming equations (6.1) and (6.2) using linear transformation in (6.3) gives $i_{d}$ and $i_{q}$ values as in:

$$
\begin{aligned}
& \mathrm{i}_{\mathrm{d}}=\mathrm{A} \sin (\omega \mathrm{t}+\varphi) \sin (\omega \mathrm{t})-\mathrm{A} \sin \left(\omega \mathrm{t}+\varphi-\frac{\pi}{2}\right) \cos (\omega \mathrm{t})=\mathrm{A} \cos (\varphi) \\
& \mathrm{i}_{\mathrm{q}}=\mathrm{A} \sin (\omega \mathrm{t}+\varphi) \cos (\omega \mathrm{t})+\mathrm{A} \sin \left(\omega \mathrm{t}+\varphi-\frac{\pi}{2}\right) \sin (\omega \mathrm{t})=A \sin (\varphi)
\end{aligned}
$$

These signals are constant $\mathrm{DC}$ values obtained from the original $\mathrm{AC}$ signals at fundamental frequency in the rotating $d-q$ frame. 
Finally, Inverse linear transformation is applied in order to transform back the $d$ - $q$ signals to the $\alpha-\beta$ signals:

$$
\left[\begin{array}{l}
i_{\alpha} \\
i_{\beta}
\end{array}\right]=\left[\begin{array}{cc}
\sin \omega t & \cos \omega t \\
\cos \omega t & -\sin \omega t
\end{array}\right]\left[\begin{array}{l}
i_{d} \\
i_{q}
\end{array}\right]
$$

\subsubsection{5 kW PV Array Design}

The Canadian Solar CS60P-180P PV module was used in this study and modeled using PSIM. PSIM provides a PV panel physical model and most of the parameters were obtained from the PV panel's datasheet. CS60P-180P PV panel specifications are shown in Table 6.1. To design a 5kW PV array, a number of series and parallel connections of PV modules have been performed. In this study, fourteen PV modules are connected in series to increase the output voltage and two modules are connected in parallel to increase output current to provide a $5 \mathrm{~kW}$ PV array. Thus, the PV output power is $(14 \times 2 \times 180=$ $5.04 \mathrm{~kW})$.

Table 6.1 Electrical Specification of CS60P-180P

\begin{tabular}{cc}
\hline \hline Parameter & Value \\
\hline Maximum Power $\left(\mathrm{P}_{\max }\right)$ & $180 \mathrm{~W}$ \\
Voltage at maximum power point $\left(\mathrm{V}_{\mathrm{mp}}\right)$ & $28.7 \mathrm{~V}$ \\
Current at maximum power point $\left(\mathrm{I}_{\mathrm{mp}}\right)$ & $6.26 \mathrm{~A}$ \\
Open circuit voltage $\left(\mathrm{V}_{\mathrm{oc}}\right)$ & $35.9 \mathrm{~V}$ \\
Short circuit current $\left(\mathrm{I}_{\mathrm{sc}}\right)$ & $6.98 \mathrm{~A}$ \\
\hline \hline
\end{tabular}

\subsubsection{Maximum Power Point Tracking (MPPT)}

MPPT is a control technique that allows the extraction of the maximum possible power from a PV system. MPPT enforces the PV system to always work at the maximum power by finding and tracking the maximum power point even when there is a sudden change in power due to the changes on solar irradiance and temperature. MPPT 
algorithms have been widely discussed and studied [104]-[110]. MPPT techniques are usually applied for DC/DC converters but recently, they have been applied directly to inverters for the purpose of increasing the overall system efficiency. Single-stage (DC/AC) PV systems will reduce the cost of the system and increase efficiency but will increase the control complexity compared to two-stage (DC/AC/DC) PV systems. However, in single-stage (DC/AC) PV systems, the PV voltage and current suffers from low frequency voltage and current ripples because of the sinusoidal power that is fed to the grid. Therefore, to reduce the ripples in PV voltage and current and to prevent the MPPT Algorithm from making wrong decisions, in single-stage systems, the average values of the PV voltage and current are used in the MPPT algorithm. The most common MPPT methods that are used in PV systems are Perturb and Observe (P\&O) MPPT, Incremental conductance (IC) MPPT and Constant Voltage (CV) MPPT.

\subsubsection{P\&O MPPT}

Perturb and Observe (P\&O) MPPT is a simple and low-cost algorithm that is widely used in research studies and commercial products. The P\&O MPPT works by measuring the derivative power and voltage $(\mathrm{dP}$ and $\mathrm{dV})$ of the PV source to find the operating point movement. Fig. 6.3 shows the power curve for different solar irradiance and the P\&O MPPT implementation. Based on the operating point, the MPPT will measure $\mathrm{dP}$ and $\mathrm{dV}$ of the $\mathrm{PV}$ panel and if $\mathrm{dP} / \mathrm{dV}$ is positive, the reference voltage will be increased and if $\mathrm{dP} / \mathrm{dV}$ is negative the reference voltage will be decreased. This process is repeated until the maximum power point is reached, that is, when $\mathrm{dP} / \mathrm{dV}=0$. Fig. 6.4 shows the flowchart of the P\&O MPPT algorithm and the detailed process. P\&O MPPT 
is a simple algorithm and requires fewer sensors compared to other MPPT algorithms. Therefore, it is a fast, easy implementation and cost-effective MPPT algorithm. However, its simplicity can be a disadvantage and lead to a decrease in efficiency in complex PV systems.

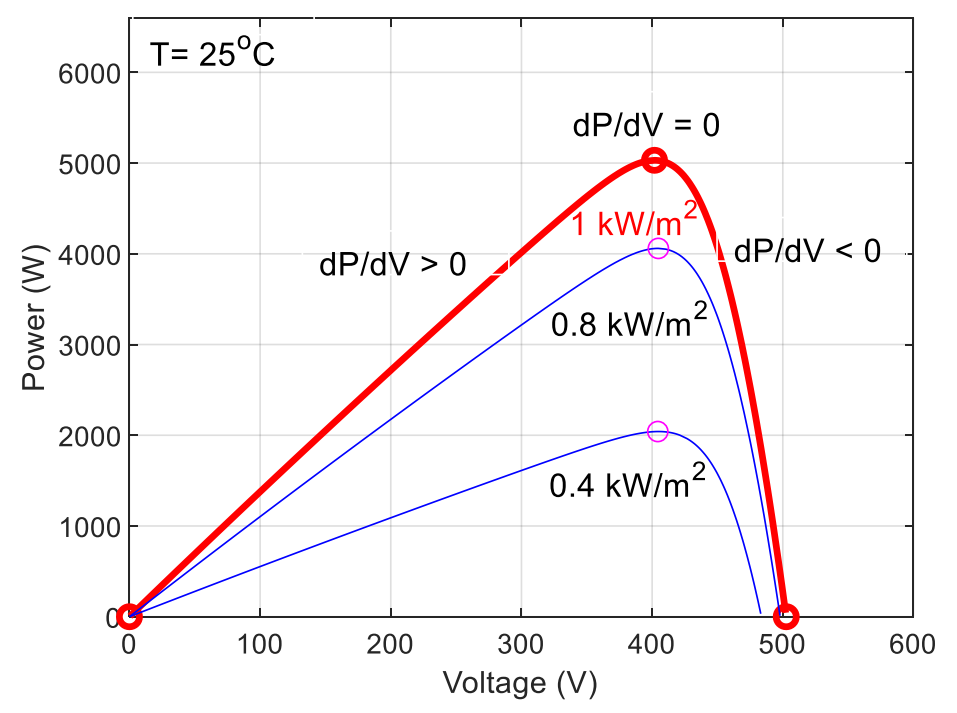

Fig. 6.3 Maximum power point variation for different solar irradiance. 


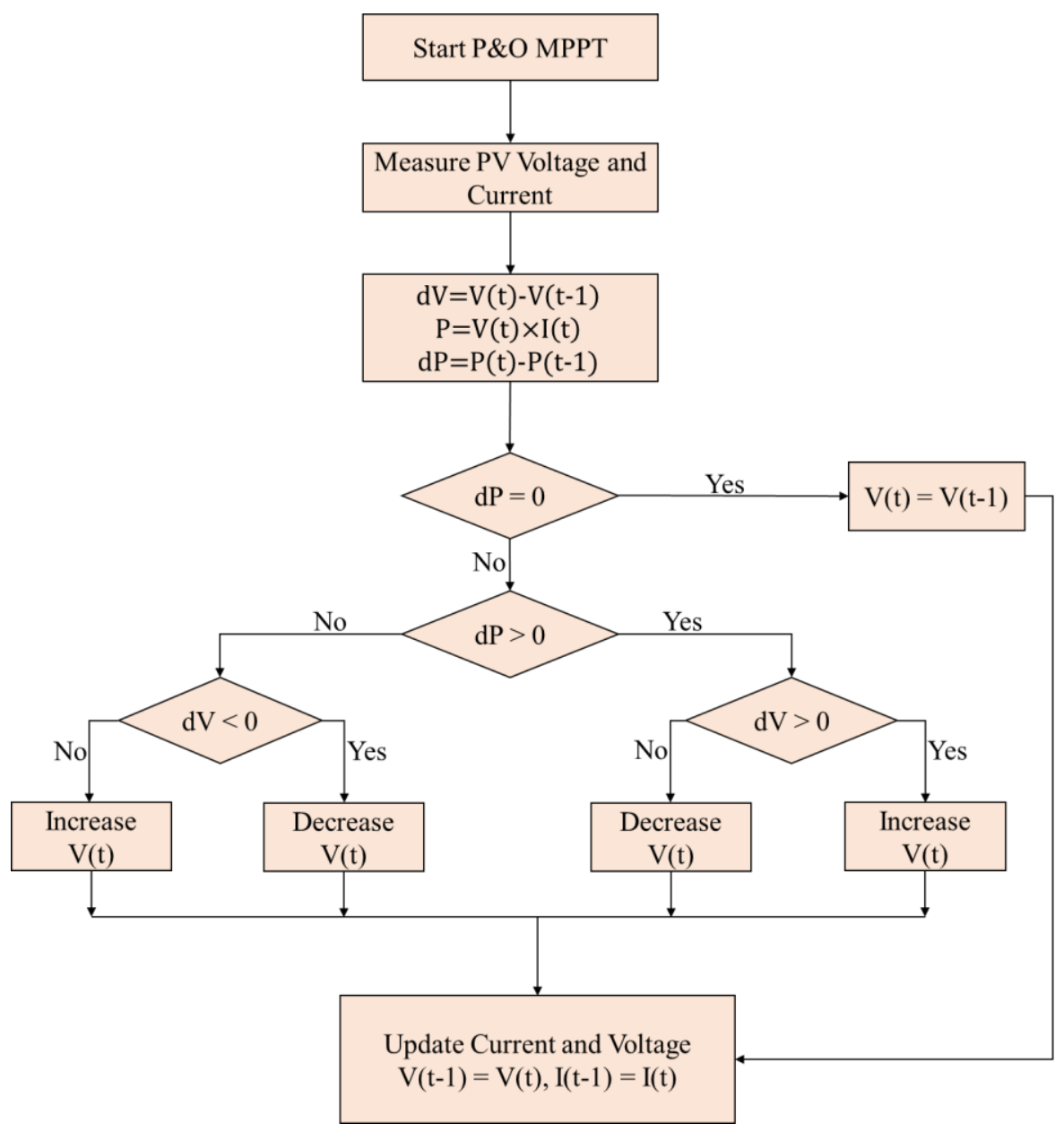

Fig. 6.4 P\&O MPPT algorithm flowchart.

\subsubsection{Incremental Conductance MPPT}

IC MPPT depends on the slope of PV power curve, and the maximum power point is achieved if the slope equals zero $(\mathrm{dP} / \mathrm{dV}=0)$ as shown in Fig. 6.3. If the slope is positive $(\mathrm{dP} / \mathrm{dV}>0)$ that means that the operation point is on the left side of MPP, and if it is negative $(\mathrm{dP} / \mathrm{dV}<0)$ that means the operation point is on the right side of the MPP. Since the PV power is a product of the PV voltage and current, $\mathrm{dP} / \mathrm{dV}$ can be expressed as:

$$
\frac{d P}{d V}=\frac{d(I V)}{d V}=I+V \frac{d I}{d V}
$$


Therefore, the maximum power point is reached when $\mathrm{d} I / \mathrm{d} V=-I / V$, if $\mathrm{d} I / \mathrm{d} V>-I / V$, the operation point is on the left side of MPP, and if $\mathrm{d} I / \mathrm{d} V<-I / V$ the operation point is on the right side of the MPP. Based on these equations, the algorithm starts by measuring the change in PV panel voltage and current and then calculates the incremental conductance $(\Delta I / \Delta V)$ and $I / V$. Based on the sign of the relative relation between the current and the voltage, the reference voltage will either increase or decrease. This process is repeated until the maximum power point is reached. IC MPPT has better efficiency and accuracy compared to P\&O MPPT; however, the implementation of IC MPPT is more complex than $\mathrm{P} \& \mathrm{O}$ MPPT. Also, it requires more sensors, which will increase the cost of system. Fig. 6.5 shows the flowchart of the IC MPPT algorithm and the detailed process. 


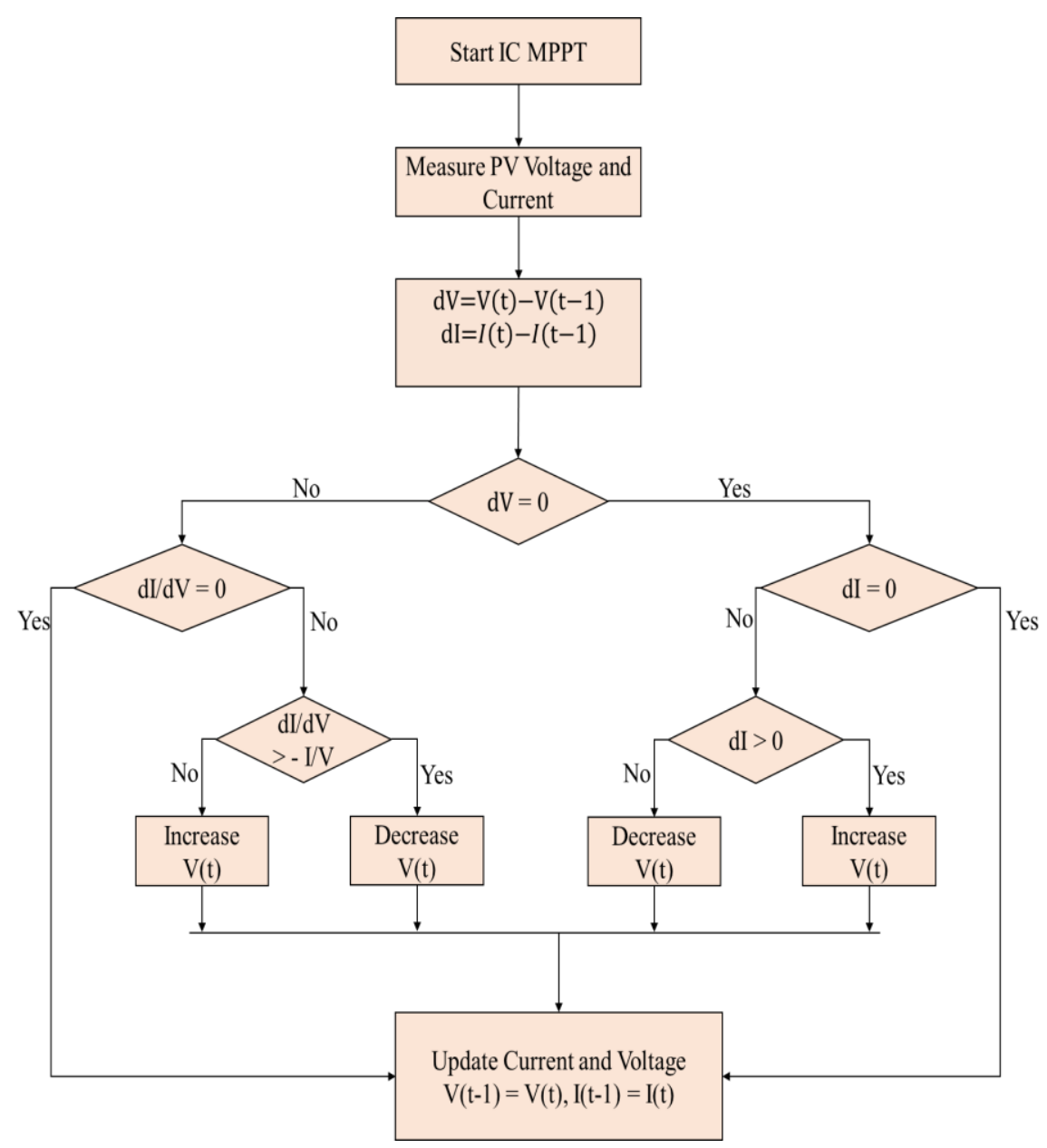

Fig. 6.5 IC MPPT algorithm flowchart.

\subsubsection{Constant Voltage MPPT}

The CV MPPT algorithm depends on the relation between the PV panel voltage at MPP ( $\left.V_{M P P}\right)$ and the open circuit voltage ( $\left.V_{O C}\right)$. The $V_{O C}$ is measured experimentally by disconnecting the PV panel temporarily, and the ratio of VMPP and VOC is usually a preset value in the range of $76 \%-80 \%$. After that, the voltage at MPP (VMPP) is calculated based on this operation. This method is simple and has fast response; the change in solar irradiance and temperature will have little effect in this method. However, it has lower 
efficiency than the $\mathrm{P} \& \mathrm{O}$ and IC algorithms and disconnecting and reconnecting the PV panel from the load to measure the open circuit voltage increases the energy losses on the system.

\subsubsection{P\&O MPPT Simulation in The Proposed Control System}

Choosing the MPPT algorithm always has a tradeoff between efficiency, complexity and cost. For the purpose of simplicity and reducing the cost of MPPT implementation; in this study, the P\&O MPPT algorithm is applied in the inverter control to track the PV's maximum power.

The proposed inverter using P\&O MPPT was simulated using PSIM and MATLAB/Simulink platforms. Fig. 6.6 and Fig. 6.7 show the change in solar irradiance from $1 \mathrm{~kW} / \mathrm{m}^{2}$ to $0.4 \mathrm{~kW} / \mathrm{m}^{2}$ and the tracking of maximum PV power for the change in solar irradiance with reduced ripples, respectively.

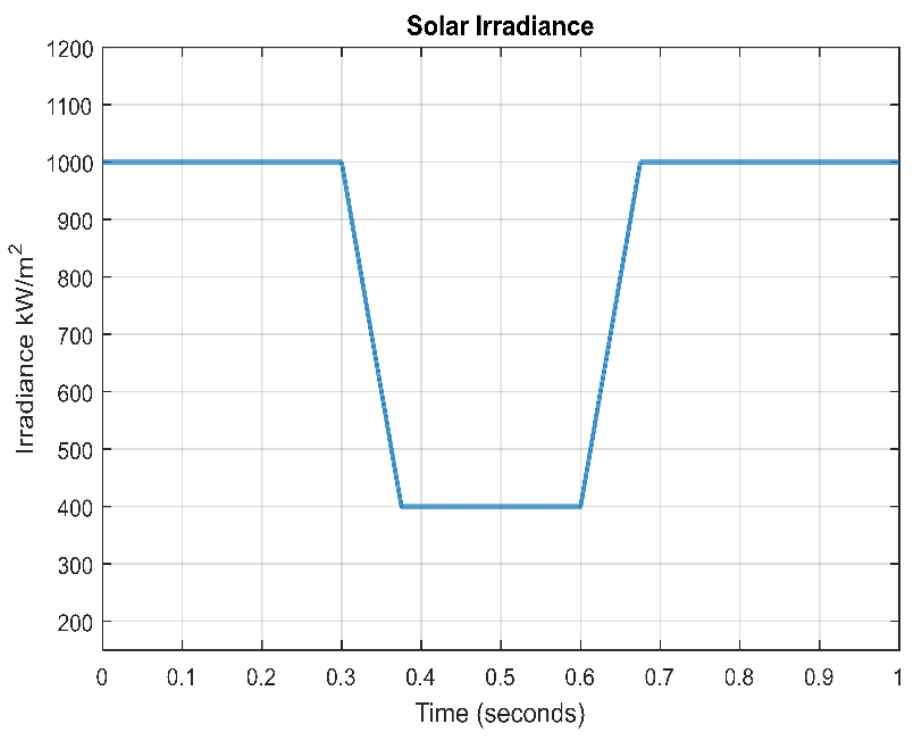

Fig. 6.6 Solar irradiance variation. 


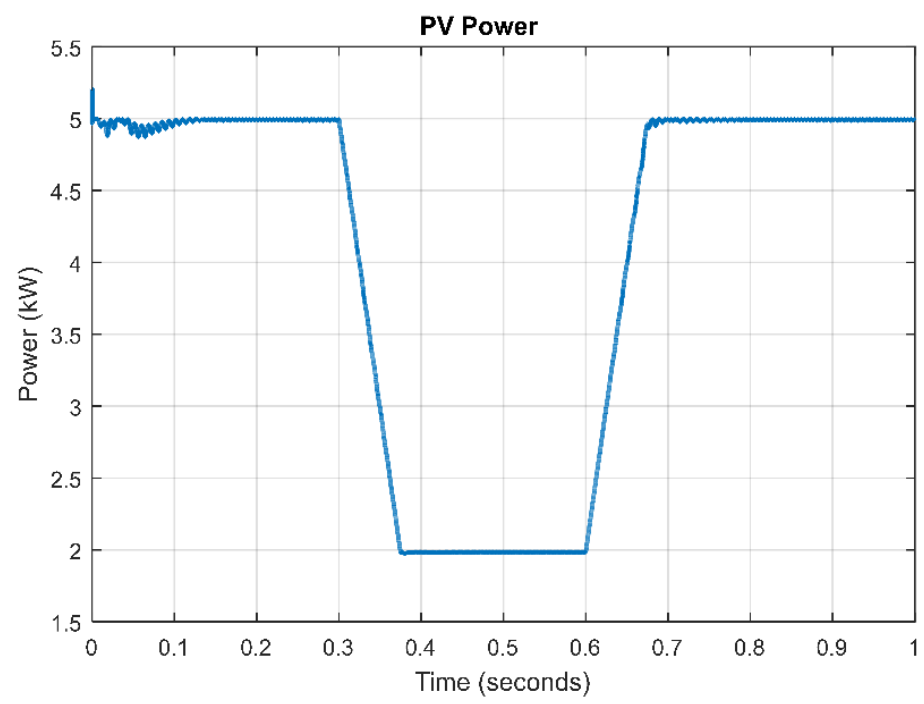

Fig. 6.7 PV output power under change in irradiance.

\subsubsection{PLL}

For power devices that feed power to the grid, phase angle information of the grid is critical for their operation. To find the phase angle of the grid voltage $\theta$, PLL is required. PLL is a closed loop system that controls its output phase to minimize the phase error between the output signal and the reference signal. The phase angle of the grid voltage $\theta$ is important to implement linear transformations in equation (6.3) and inverse linear transformation in equation (6.6) to transform the signals from $\alpha-\beta$ stationary frame to synchronized $d-q$ rotating frame and vice versa.

\subsubsection{Power Calculation Algorithms}

After the transformation, the voltages and the currents of the grid $\left(\mathrm{v}_{d}, \mathrm{v}_{q}\right),\left(\mathrm{i}_{d}, \mathrm{i}_{q}\right)$ are measured and the active and reactive power are calculated by:

$$
\begin{aligned}
& P=i_{d} \cdot v_{d}+i_{q} \cdot v_{q} \\
& Q=i_{d} \cdot v_{q}-i_{q} \cdot v_{d}
\end{aligned}
$$

The currents in a $d-q$ rotating reference frame can be expressed as: 


$$
\left[\begin{array}{l}
\mathrm{i}_{\mathrm{d}} \\
\mathrm{i}_{\mathrm{q}}
\end{array}\right]=\frac{1}{\mathrm{v}_{\mathrm{d}}^{2}+\mathrm{v}_{\mathrm{q}}^{2}}\left[\begin{array}{cc}
\mathrm{v}_{\mathrm{d}} & \mathrm{v}_{\mathrm{q}} \\
\mathrm{v}_{\mathrm{q}} & -\mathrm{v}_{\mathrm{d}}
\end{array}\right]\left[\begin{array}{l}
\mathrm{P} \\
\mathrm{Q}
\end{array}\right]
$$

Two control loops regulated by PI controllers are used in this control system to regulate the error in the $d$ component and $q$ component of the current. The designed control is based on vector control of power to feed the grid with active power and to control the inverter to generate or absorb any reactive power demand.

\subsubsection{Control Strategy}

To get the full benefits of a solar PV system in a cost-effective approach, a control strategy should be designed with advanced functions. The proposed control strategy has three modes of operation: normal operation mode, Low Voltage Ride Through mode (LVRT), and low solar irradiance mode. These three operations can mitigate any voltage fluctuations in the system and provide a stable grid operation. The reactive power consumption or generation that is needed to mitigate voltage sags will be provided by the PV inverter. The maximum reactive power capacity of the PV inverter is:

$$
\mathrm{Q}_{\max }=\sqrt{\left(\mathrm{S}_{\max }\right)^{2}-\left(\mathrm{P}_{\mathrm{PV}}\right)^{2}}
$$

where $\mathrm{S}_{\max }$ is the maximum apparent power of the PV inverter, and PPV is the PV system output power. In the proposed control strategy, the reactive power upper limit is $\mathrm{Q}_{\max }$., and the generation or consumption of reactive power cannot exceed this upper limit. If the apparent power exceeds $S_{\max }$ at any point, the over-current protection will be triggered, and the inverter will be disconnected.

After performing the $d-q$ transformation of the grid current in the control system, the delivered active and reactive power to the grid can be calculated as follows:

$$
\mathrm{P}=\frac{1}{2} \mathrm{v}_{\mathrm{d}} \mathrm{i}_{\mathrm{d}}
$$




$$
\mathrm{Q}=-\frac{1}{2} \mathrm{v}_{\mathrm{q}} \mathrm{i}_{\mathrm{q}}
$$

\subsubsection{Normal operation mode}

The normal range of grid voltage is when grid voltage deviation is $-10 \%$ to $+10 \%$ from the nominal voltage defined in ANSI C84.1-2016 [111] which is 120V. Thus, normal operation mode occurs when grid voltage is between 0.90 p.u-1.1 p.u, and there are no fluctuations in load conditions and weather for the PV system. In this mode, the system is operating in MPPT mode to deliver the maximum energy that can be extracted from the system to the grid. The PV system during this mode is stable and supplies active power to the grid. Additionally, there is no exchange of reactive power, so the reactive power reference in this mode is 0 .

The active and reactive power during normal operation mode can be expressed as:

$$
\begin{aligned}
& \mathrm{P}=\frac{1}{2} \mathrm{Vi}_{\mathrm{d}} \approx \mathrm{P}_{\mathrm{MPP}} \\
& \mathrm{Q}=-\frac{1}{2} \mathrm{Vi}_{\mathrm{q}}=0
\end{aligned}
$$

where $\mathrm{V}$ is the grid voltage amplitude, and $i_{d}$, and $i_{q}$ are the $d$ and $q$ components of grid current. $P_{M P P}$ is the PV system tracked maximum active power.

\subsubsection{LVRT mode}

For renewable energy systems, LVRT requirements were first introduced to wind power systems because many countries worldwide were using wind systems as a source of power, which results in high penetration of wind power. International grid standards require that the same level of performance and reliability of conventional generation systems should be achieved by wind systems. In general, many grid codes require that wind systems achieve two main requirements during grid disturbance and faults: 1 . 
remain connected to the grid for a specific time during voltage fault (LVRT); 2. support the grid recovery during fault by generating or absorbing reactive power. Similar requirements have been extended and enforced for large-scale PV systems. As the penetration of PV systems increases rapidly, these requirements in the near future will be posed also for small PV systems (single-phase systems and residential systems). Some countries, such as Germany and Japan, have already initiated these requirements for low power rating PV systems (single-phase systems).

Fig. 6.8 shows LVRT requirements from various countries' grid codes during grid voltage faults. As shown in Fig. 6.3, the grid-tied DGs should remain connected to the grid for a specific period of time during voltage fault. Simultaneously, the system should support the grid recovery by injecting reactive current. Fig. 6.9 shows an example of the required reactive current to support the grid during voltage faults [93]. 

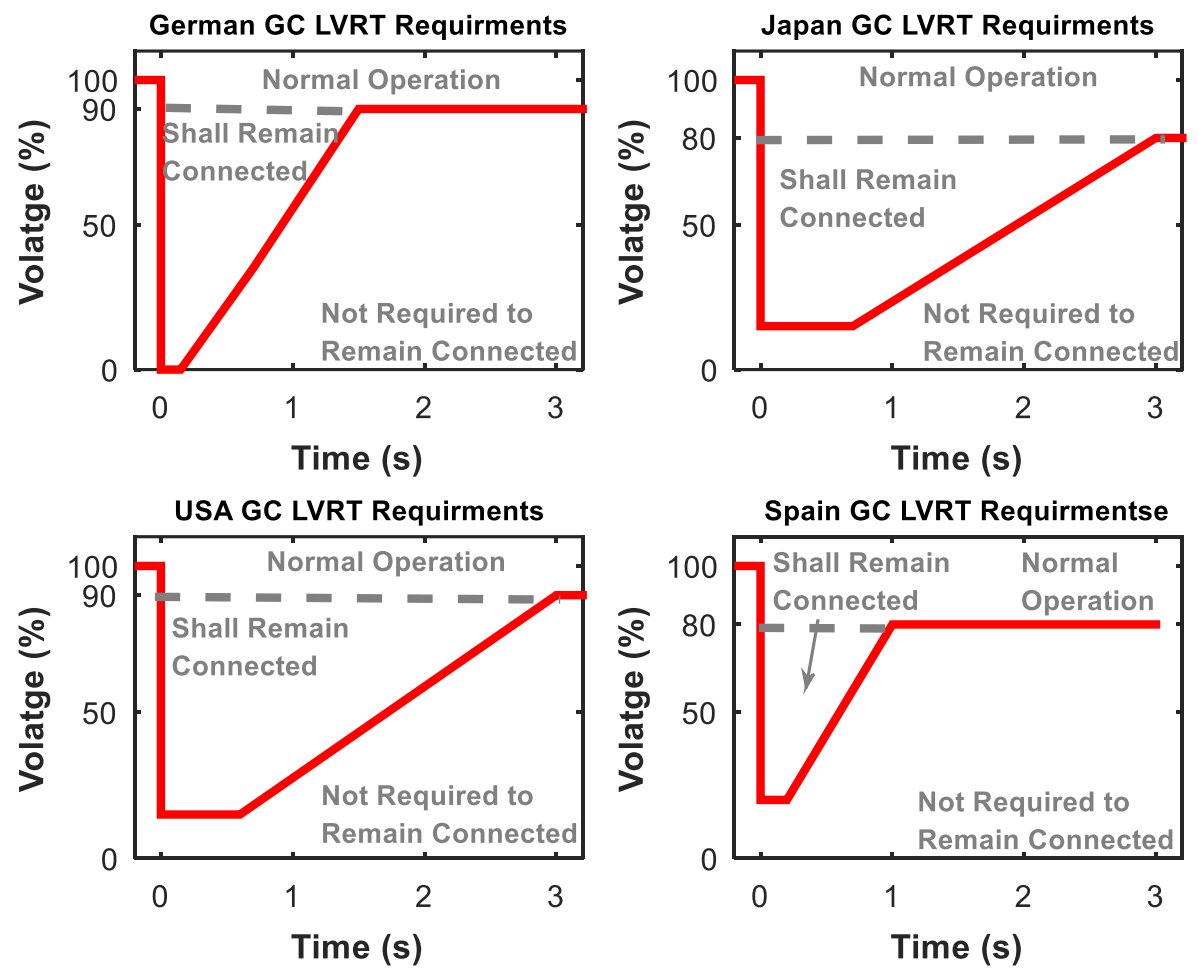

Fig. 6.8 LVRT requirements for distributed generation systems from various countries grid codes.

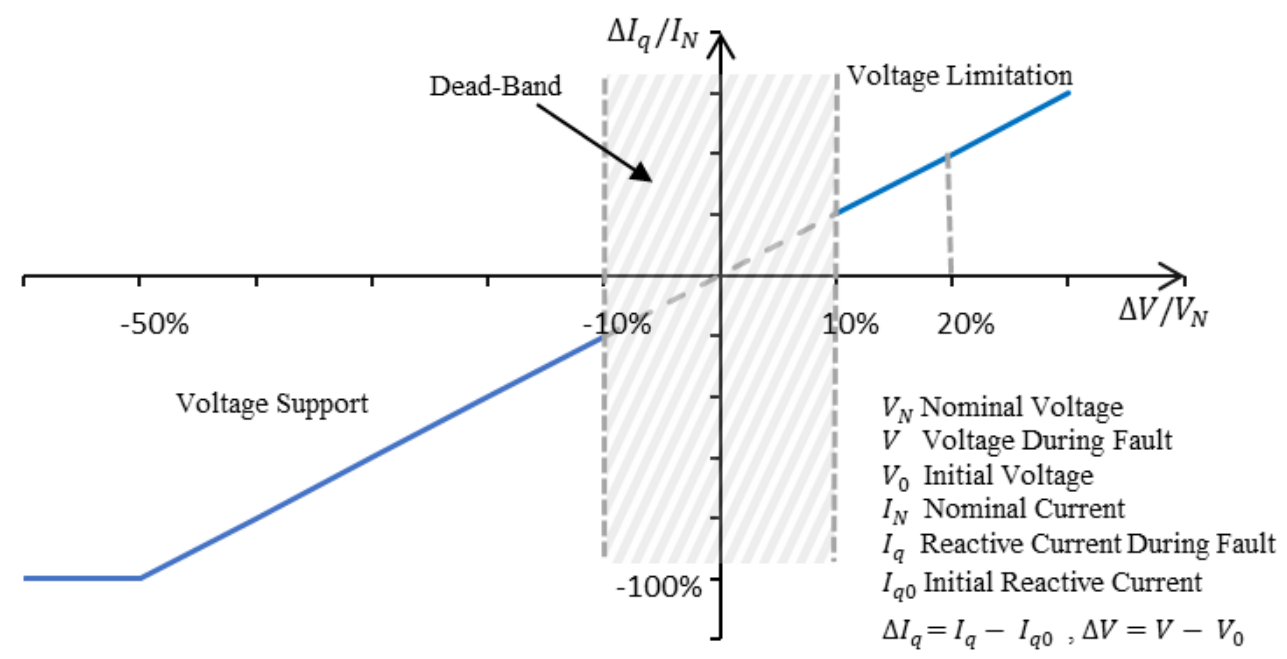

Fig. 6.9 Reactive current requirements to support the grid. 
As a result, future PV systems must perform advanced functions and meet the future grid codes requirements in case of grid fault which are: Remain connected to the grid during voltage fault and Support the grid recovery during fault by delivering reactive power. These requirements are implemented in the proposed control strategy shown in Fig. 6.1.

When grid voltage sag is detected, fault operation mode is activated, and the single-phase inverter should support the grid by injecting reactive power. The amount of reactive power needed to support the grid is dependent on the inverter rating and the depth of voltage sag. Also, when fault is detected, the control system will switch to nonMPPT operation to keep the inverter's apparent power within limits and not trigger overcurrent protection [112].

According to Fig. 6.8, the system is in normal operation when grid voltage is between 0.9 p.u and 1.1 p.u and no reactive current is injected. However, when grid voltage drops below 0.9 p.u, LVRT operation mode will be activated and the injected reactive current ratio $\left(\mathrm{I}_{\mathrm{qr}}\right)$ to the nominal current $\left(\mathrm{I}_{\mathrm{N}}\right)$ is defined as:

$$
\mathrm{I}_{\mathrm{qr}}=\left\{\begin{array}{lr}
0, & 0.9 \text { p.u } \leq \mathrm{V}<1.1 \text { p.u } \\
\mathrm{k} \cdot \frac{\mathrm{V}-\mathrm{V}_{0}}{\mathrm{~V}_{\mathrm{N}}}, & 0.5 \text { p.u }<\mathrm{V}<0.9 \text { p.u } \\
-1, & \mathrm{~V} \leq 0.5 \mathrm{p} . \mathrm{u}
\end{array}\right.
$$

where $\mathrm{V}$ is the amplitude of grid voltage during fault, $V_{0}$ is the initial grid voltage and $V_{N}$ the nominal grid voltage. The gain $\mathrm{k}$ is:

$$
\mathrm{k}=\frac{\Delta \mathrm{I}_{\mathrm{q}} / \mathrm{I}_{\mathrm{N}}}{\Delta \mathrm{V} / \mathrm{V}_{\mathrm{N}}} \geq 2 \mathrm{p} . \mathrm{u}
$$

Based on equation (6.15) the reference reactive current can be defined as:

$$
\mathrm{I}_{\mathrm{q}}^{*}=\mathrm{I}_{\mathrm{N}} \times \mathrm{I}_{\mathrm{qr}}
$$


where $\mathrm{I}_{\mathrm{N}}$ is limited by inverter maximum rating current Imax; $I_{N} \leq I_{\max }$. The active and reactive power references are given by:

$$
\begin{aligned}
& \mathrm{P}^{*}=\frac{1}{2} \mathrm{VI}_{\mathrm{d}} \approx \mathrm{P}_{\mathrm{PV}} \\
& \mathrm{Q}^{*}=\frac{1}{2} \mathrm{VI}_{\mathrm{q}}
\end{aligned}
$$

where $P$ PV is the PV power without MPPT control.

\subsubsection{Low Solar Irradiance operation mode}

Usually, PV inverter control strategies focus on day operations or only when there is active power and neglect the period at night or in severe weather conditions where there is no active power. During night and severe weather conditions in the day, the solar irradiance is almost $0 \mathrm{~kW} / \mathrm{m}^{2}$ and no active power is generated by the PV system; hence the PV inverter becomes idle. However, during this time, the PV inverter can generate reactive power and since the inverter structure is basically similar to the static VAR generator (SVG) which is currently used to compensate reactive power and mitigate voltage sags, it can be used as an SVG device to compensate reactive power for the grid [113], [114]. Therefore, by formulating a proper control mode, the PV inverter can provide reactive power compensation function for the grid during the period where the inverter is idle.

The proposed control strategy can provide reactive power from the PV system to the grid at night or at low solar irradiance. To perform this function, the PV system's output power lower limit $\mathrm{P}_{\min }$ needs to be defined (for example $\mathrm{P}_{\min }=5 \% \mathrm{P}_{\mathrm{MPP}}$ ) and the control system must monitor the active power of the PV system. When the condition PPV $\leq \mathrm{P}_{\min }$ is satisfied, the low solar irradiance mode is activated. The process that the control 
strategy uses to handle switching between the three operation modes is shown in Fig. 6.10.

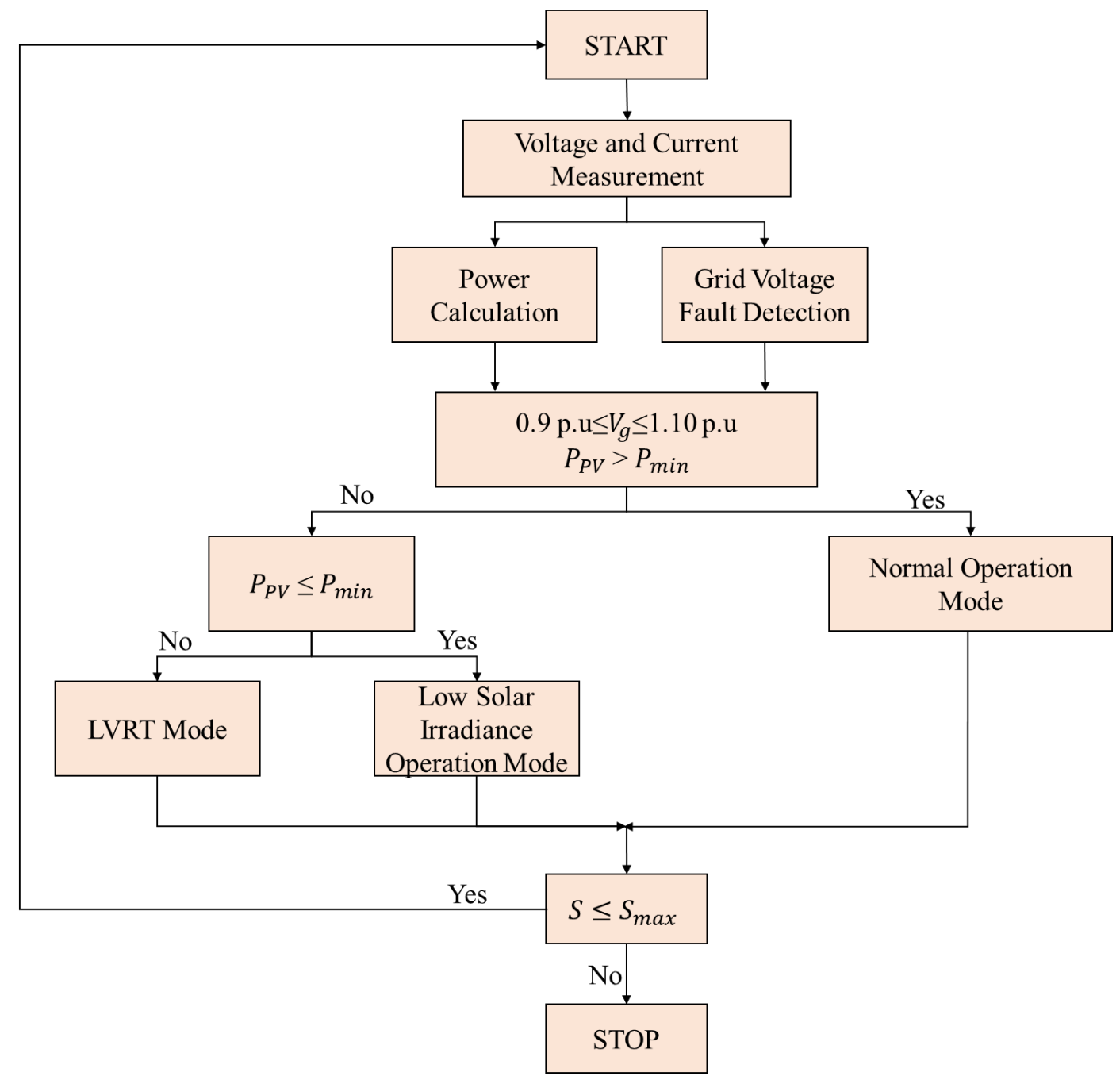

Fig. 6.10 Control flowchart of the multifunctional control strategy.

\subsection{Case Studies Simulation Results}

To verify the effectiveness of the proposed control system for a single-phase transformer-less PV inverter, several case studies have been carried out using PSIM and MATLAB/Simulink platforms. The system is designed and simulated using the same configuration in Fig. 6.1. The single-phase transformer-less inverter shown in Fig. 2.16 is 
used to test and verify the system. Maximum Power Point Tracking control (MPPT) is implemented. The P\&O MPPT method is used to track the PV maximum power. Table 6.2. shows the simulation parameters.

6.2 Simulation Parameters

\begin{tabular}{cc}
\hline \hline Parameter & Value \\
\hline PV Maximum Power & $5 \mathrm{KW}$ \\
Grid Voltage (RMS) & $120 \mathrm{~V}$ \\
Grid Frequency & $60 \mathrm{~Hz}$ \\
PV Voltage & $400 \mathrm{~V}$ \\
DC Link Capacitance & $1 \mathrm{mF}$ \\
Inverter Switching Frequency & $\mathrm{kHz}$ \\
\hline \hline
\end{tabular}

\subsubsection{Normal Operation Mode}

The normal operation mode with MPPT for the PV system is when the grid voltage is between 0.9 p.u and 1.1 p.u. During this mode, the PV system is controlled by MPPT to extract the maximum power. Fig. 6.11 shows the performance of the control system during normal mode. Fig. 6.11 (a) shows the active and reactive current $I_{d}$ and $I_{q}$ respectively; only active current is injected into the grid and the reactive current is 0 . Fig. 6.11 (b) shows the active and reactive power of the inverter; the inverter is capable of injecting maximum active power $(5 \mathrm{~kW})$ into the grid. Fig. 6.11 (c) shows the grid voltage and current. 


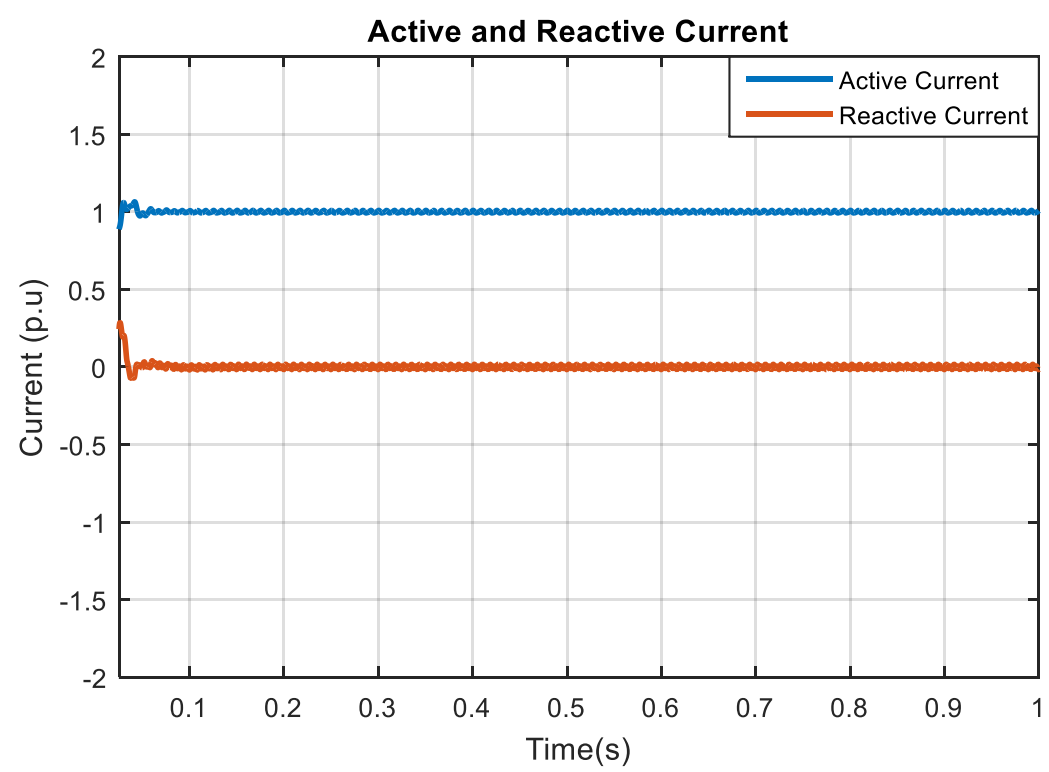

(a)

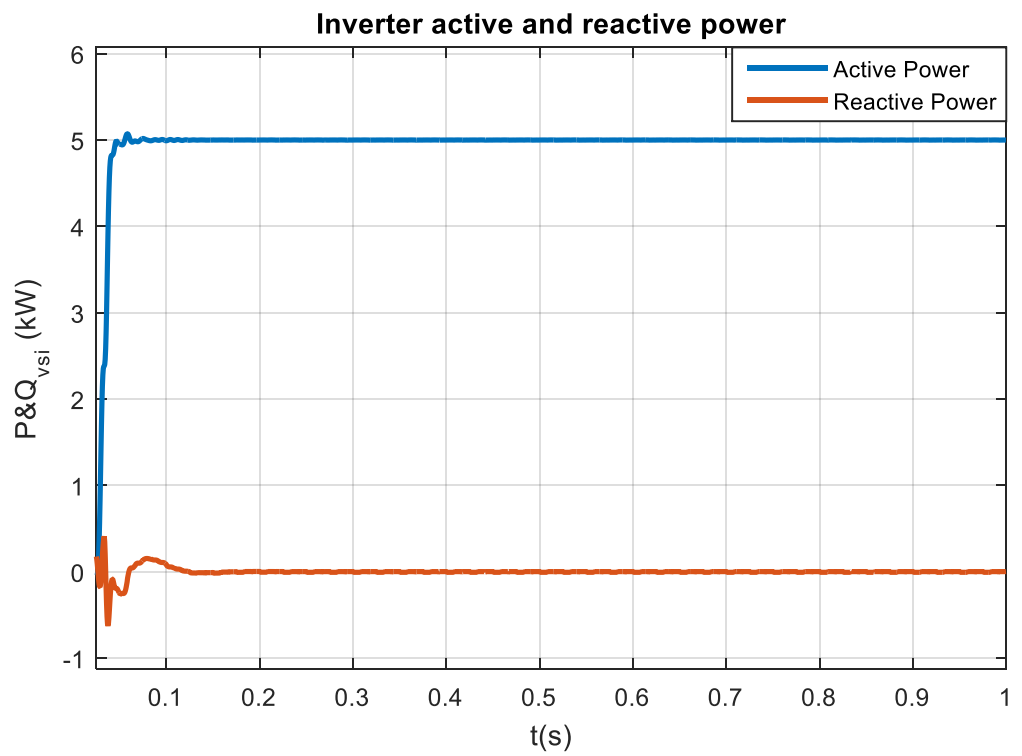

(b) 


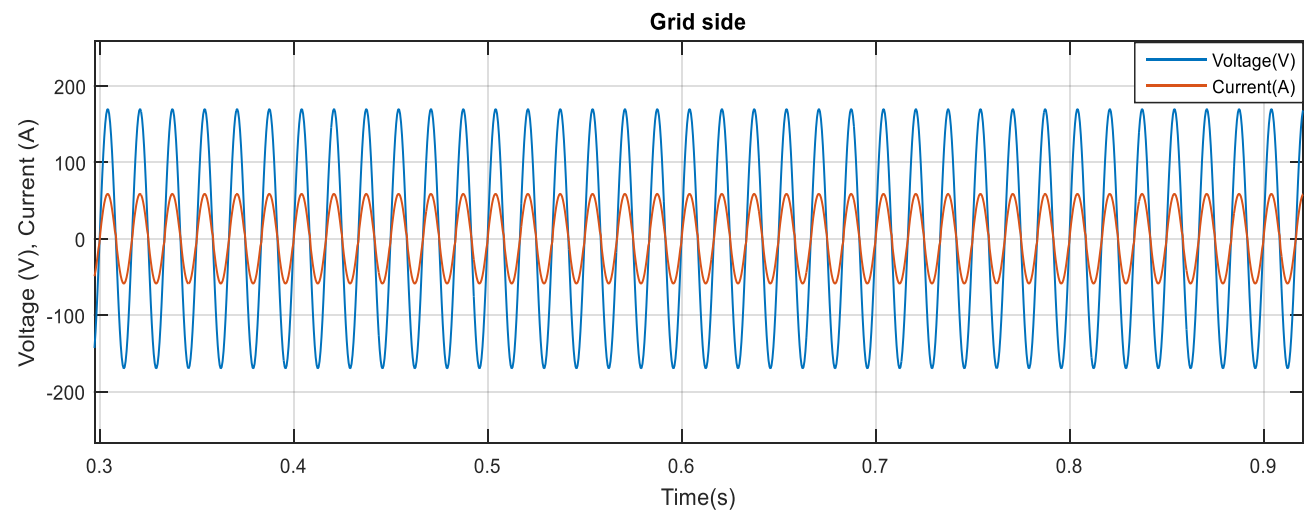

(c)

Fig. 6.11 The performance of the control system during normal mode: (a) active and reactive current, (b) Inverter active and reactive power, (c) Grid Voltage and current.

\subsubsection{LVRT Mode}

The control system switches to fault mode as soon as grid voltage fault is detected. After that, the system starts injecting the required reactive power based on Eq 6.18. and disables the MPPT control. Fig. 6.12. shows the performance of the control system when the PV inverter is subjected to grid voltage sag at $0.5 \mathrm{~s}$, and the voltage drops to 0.75 p.u. During the fault time, which lasts for $0.3 \mathrm{~s}$, the PV inverter provides the grid with reactive current of 0.5 p.u and active current of 0.866 p.u during the fault time as can be seen in Fig. 6.12 a. Fig. $6.12 \mathrm{~b}$ and c show the active and reactive power of the inverter and the grid voltage and current during the voltage sag, respectively. As can be seen form the figures, the reactive power provided by the PV inverter supports the grid voltage recovery and as soon as the fault is cleared, the system goes back to normal mode and provides PV maximum output power. 


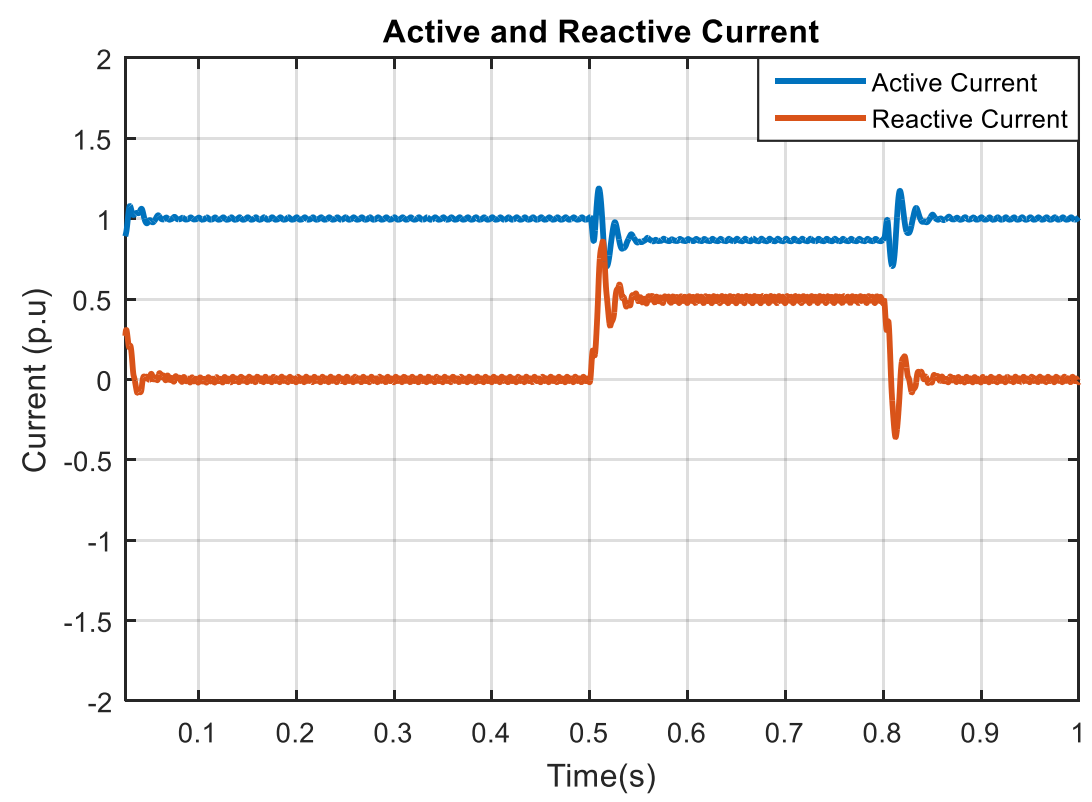

(a)

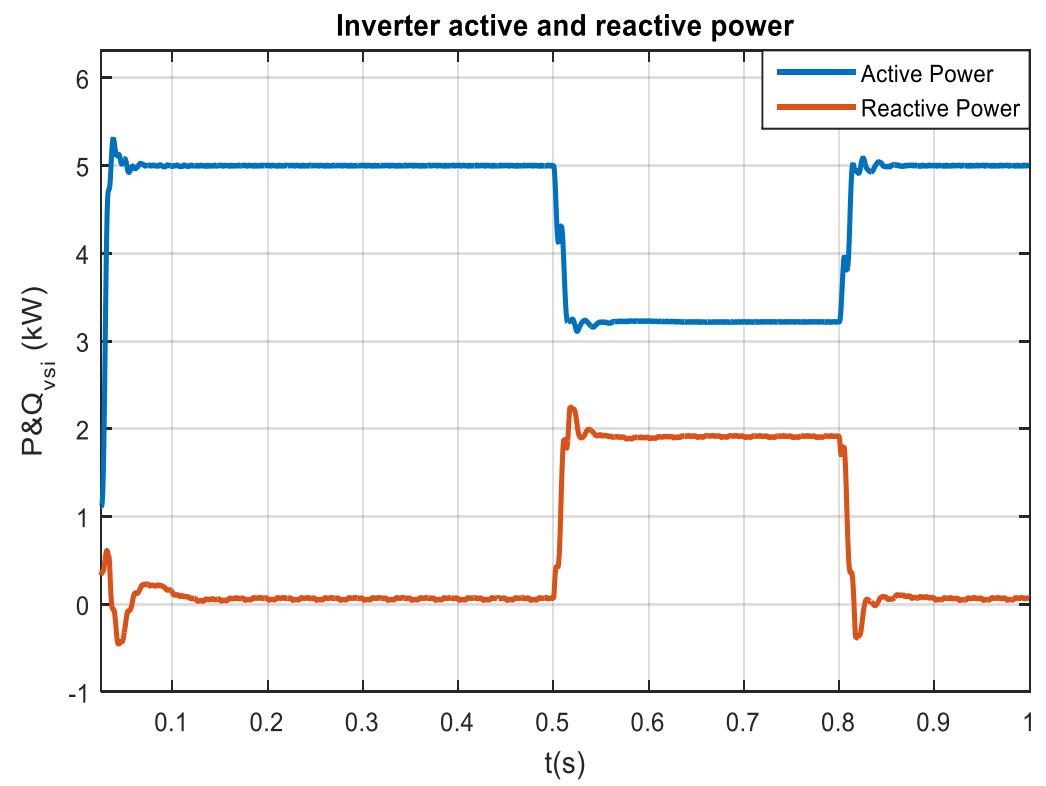

(b) 


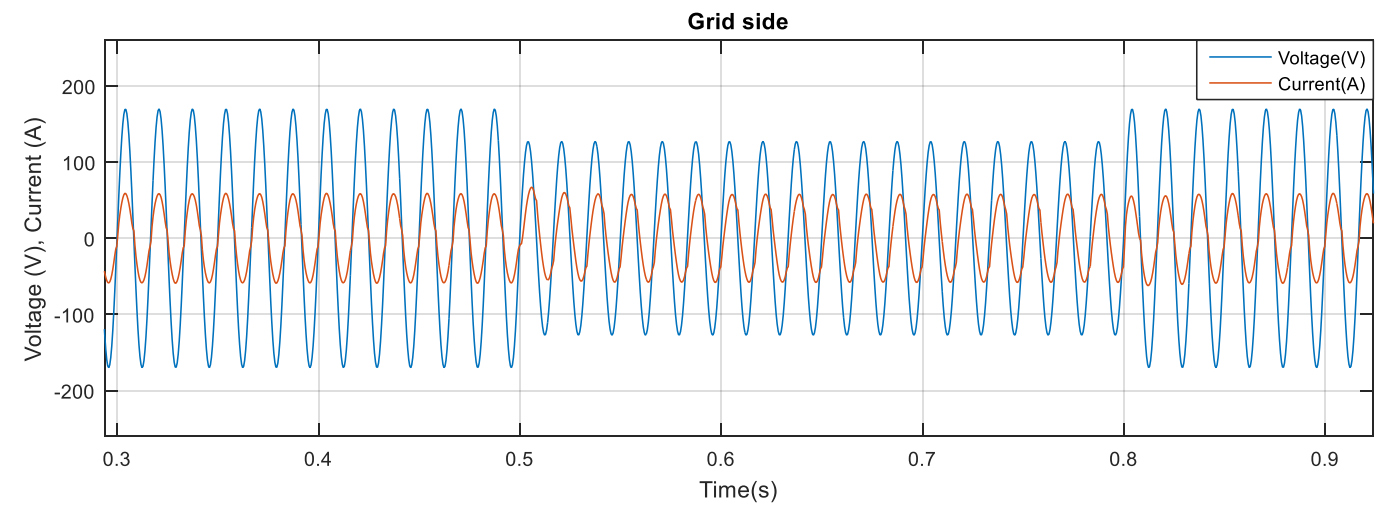

(c)

Fig. 6.12 The performance of the control system during LVRT mode during voltage sag when the voltage drops to 0.7 p.u: (a) active and reactive current, (b) Inverter active and reactive power, (c) Grid Voltage and current.

Fig. 6.13 shows the performance of the control system when the PV inverter is subjected to worst case of voltage sag (grid voltage $\leq 0.5 \mathrm{p} . \mathrm{u}$ ). The grid voltage drops to 0.3 p.u. In this case, it is required that the inverter stay connected and provide only reactive power to the grid. During the fault time, which lasts for $0.3 \mathrm{~s}$, the PV inverter provides the grid with reactive current of $1 \mathrm{p} . \mathrm{u}$ and active current of 0 as can be seen in Fig. $6.13 \mathrm{a}$; thus, no active power is delivered to the grid. Fig. $6.13 \mathrm{~b}$ and $\mathrm{c}$ show the active and reactive power of the inverter and the grid voltage and current during the voltage sag, respectively. As soon as the fault is cleared, the system goes back to normal mode and provides PV maximum output power. 


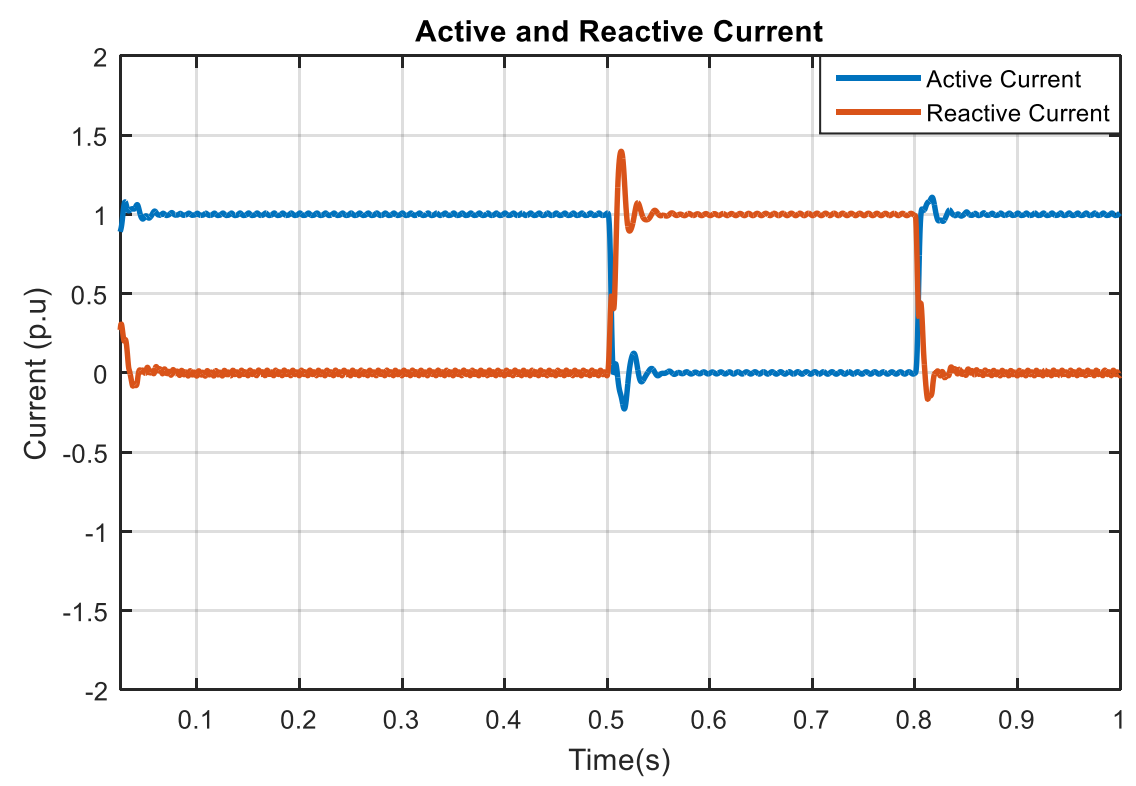

(a)

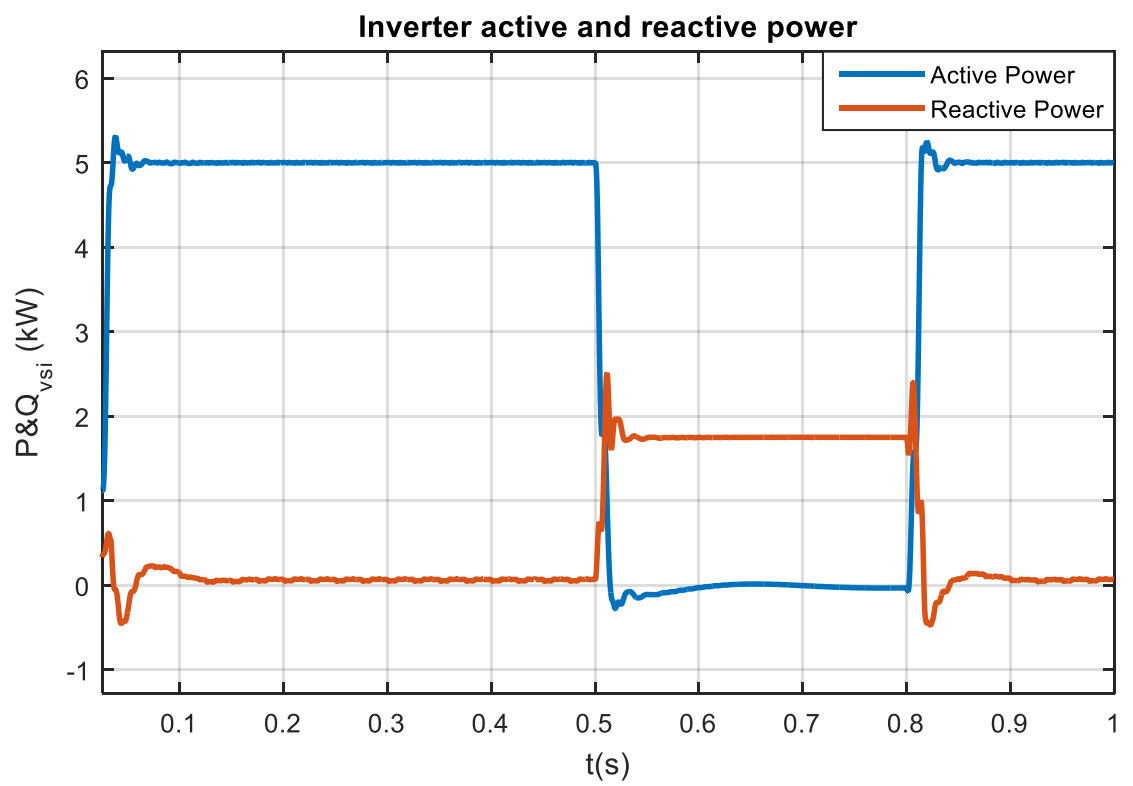

(b) 


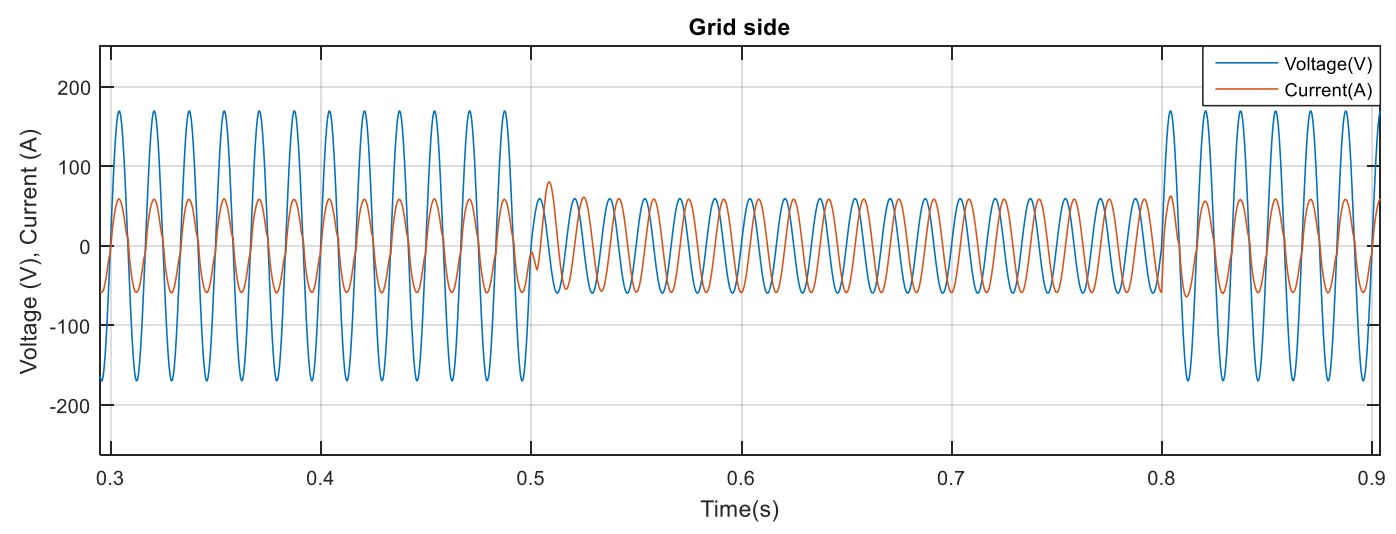

(c)

Fig. 6.13 The performance of the control system during LVRT mode during worst case of voltage sag when the voltage drops to 0.3 p.u: (a) active and reactive current, (b) Inverter active and reactive power, (c) Grid Voltage and current.

These results have proven the capability of single-phase transformer-less PV inverters employing the proposed control system to ride through faults. In addition, the results show that switching between different operation modes (LVRT-MPPT, MPPTLVRT) did not affect the stability of the system.

\subsubsection{Low Solar Irradiance Operation Mode}

Instead of disconnecting from the grid during the night or when the solar irradiance is 0 , the PV inverter can provide reactive power to the grid during this time. When the solar irradiance drops to 0 , which occurred at $0.5 \mathrm{~s}$, the control system activates the low solar irradiance operation mode to generate reactive power. Fig 6.14 shows the performance of the proposed control system for the PV inverter during low solar irradiance mode. When the irradiance is weak or almost zero at $0.5 \mathrm{~s}$ the inverter provides only reactive current to the grid as can be seen in Fig. 6.14 a. Fig. 6.14 b and c show the active and reactive power, grid voltage, and current during this mode, respectively. As can be seen from the figure, the PV inverter can provide reactive power to the grid during 
the time when there is no or weak active power at night or cloudy weather effectively using the proposed control strategy.

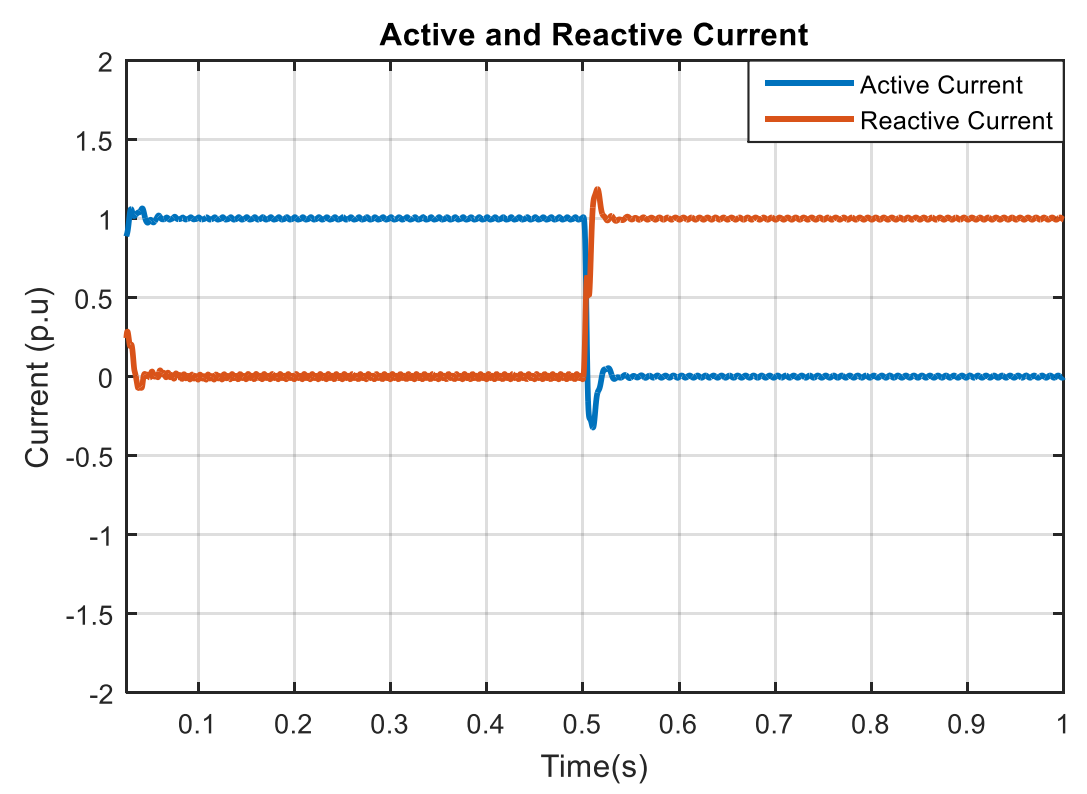

(a)

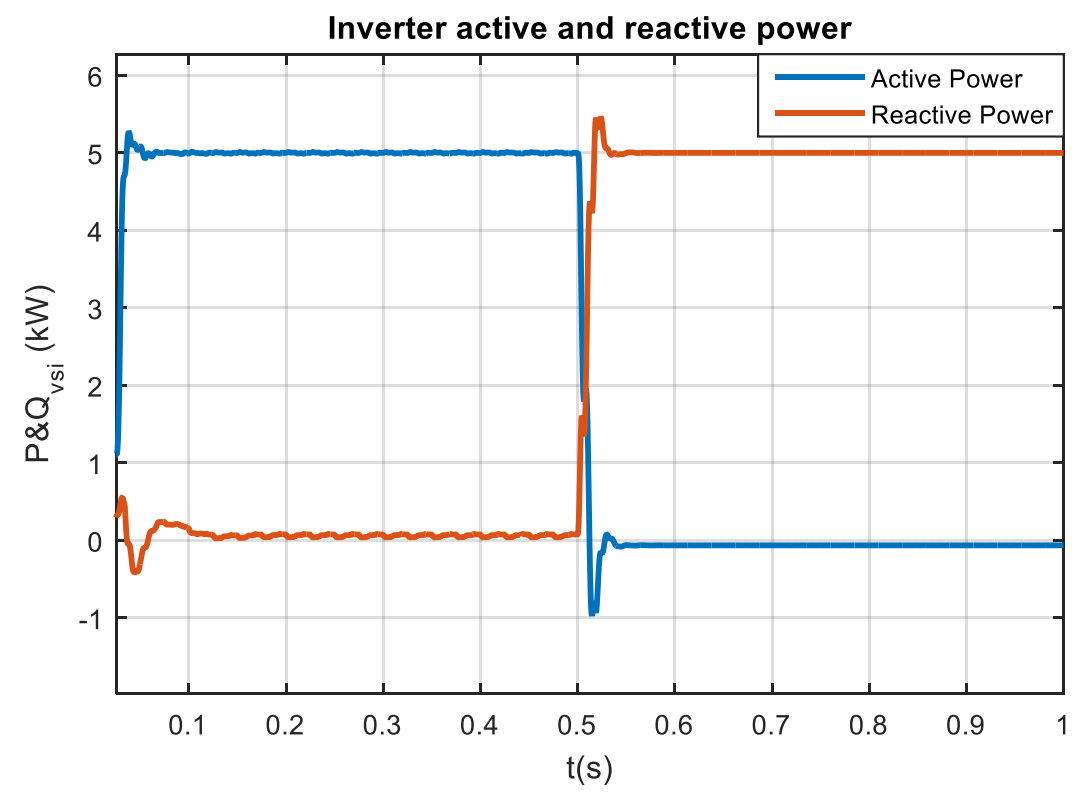

(b) 


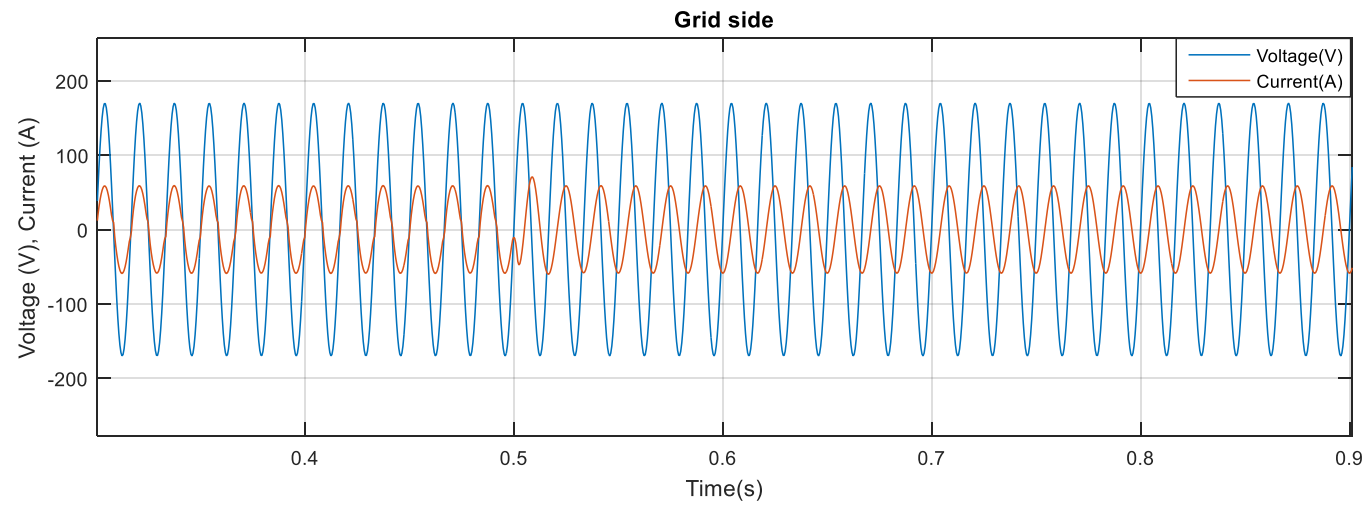

(c)

Fig. 6.14 The performance of the control system during low solar irradiance mode: (a) active and reactive current, (b) Inverter active and reactive power, (c) Grid Voltage and current.

\subsection{Conclusion}

This chapter has addressed the requirements for the next generation of PV inverters including the need for high efficiency, voltage regulation and fault ride through capability. To provide a reliable and stable integration of PV systems into the grid, a multifunctional control strategy has been presented and examined. Several case studies have been simulated and analyzed to examine the performance of the multifunctional control strategy. The results prove that the high efficiency transformer-less PV inverter with the proposed control strategy shows an excellent performance by keeping the inverter connected during grid faults (LVRT function) and provides reactive power to support the grid voltage recovery. Moreover, the control strategy can enable the inverter to be used as an SVG device to compensate reactive power for the grid when the PV inverter is idle during night or in severe weather conditions. 


\section{Conclusions and Future Works}

\subsection{Conclusions}

The limited supply of fossil fuel resources and the environmental issues they cause have led to the increased demand for clean and renewable energy resources worldwide. This demand has motivated research on renewable energy and power electronics technology, which is the key component in using renewable energy sources. State-of-the-art PV inverters and advanced power switching devices using WBG materials have achieved highly efficient, reduced volume and lower cost renewable energy systems.

This dissertation has presented a review of the advances on transformer-less inverters and proposes a new high efficiency transformer-less inverter. It has also explored and investigated the benefits of using WBG power switching devices on PV inverters. A comparison study of the proposed topology and multiple transformer-less inverters has been carried out in terms of the leakage current, power losses and efficiency. The results show that the proposed inverter achieves the lowest conduction losses and the highest efficiency among all presented topologies.

The impact of emerging GaN-based power devices on a single-phase transformerless inverter in terms of efficiency, high switching frequency capability, volume and 
cooling efforts has been investigated. This investigation has shown that using $\mathrm{GaN}$ HEMTs significantly reduced the overall semiconductor power losses of the proposed inverter by $60 \%$. This loss reduction increased the overall efficiency of the system by more than 3\%. Furthermore, this loss reduction when operating at the same switching frequency, allows a reduction of more than $30 \%$ in heatsink volume, which will consequently reduce the overall system's volume and cost. The superior switching characteristics of GaN HEMTs allow the switching frequency to be increased to more than 10 times the switching frequency of the Si MOSFETs. This increase reduces the inverter weight and volume while maintaining high system efficiency.

Because reactive power capability will be a requirement for next generation PV inverters, this work improves the proposed high efficiency GaN-based inverter by providing it with reactive power capability. Taking advantage of the natural reverse recovery of GaN HEMTs and proposing a modified PWM provided the proposed inverter with reactive power capability without adding additional components or modifying the inverter structure.

Besides providing high efficiency inverters, grid connection advanced functions will be essential requirements for next generation PV systems. To provide a reliable and stable integration of PV systems into the grid, a multifunctional control strategy has been proposed and investigated. The control strategy satisfies the grid requirements during grid faults by keeping the inverter connected and supporting the grid voltage by providing reactive power. Moreover, the control strategy allows the inverter to work as an SVG device to compensate for reactive power during severe weather conditions and nighttime. 


\subsection{Future Works}

To enhance the overall system performance, the following points are recommended for future work:

- High switching frequency has a huge impact on EMI filter design. Therefore, the effect of increasing switching frequency on EMI noise in GaN-based inverter needs to be investigated since an EMI filter has a significant impact on the inverter volume.

- Reactive power compensation can increase the thermal stress on power devices, which will reduce the lifetime of the power device. The impact of VAR at low solar irradiance mode of operation on the lifetime and maintenance cost of a PV system needs to be investigated. A detailed thermal analysis for different VAR levels is needed to assess the tradeoffs between reliability and cost savings of PV inverters with reactive power capability.

- Employing advanced functions on the PV inverters requires advanced monitoring and communication technologies. Thus, further investigation can be directed towards the communication methods between the distributed generation sources and the central dispatch. 


\section{References}

[1] REN21, “Renewables 2017: global status report,” 2017.

[2] F. Blaabjerg, K. Ma, and Y. Yang, "Power electronics - The key technology for Renewable Energy Systems," in 2014 Ninth International Conference on Ecological Vehicles and Renewable Energies (EVER), 2014, pp. 1-11.

[3] T. Kerekes, R. Teodorescu, P. Rodríguez, G. Vázquez, and E. Aldabas, “A New high-efficiency single-phase transformerless PV inverter topology," IEEE Trans. Ind. Electron., vol. 58, no. 1, pp. 184-191, 2011.

[4] D. Barater, G. Buticchi, A. S. Crinto, G. Franceschini, and E. Lorenzani, "Unipolar PWM strategy for transformerless PV grid-connected converters," IEEE Trans. Energy Convers., vol. 27, no. 4, pp. 835-843, 2012.

[5] B. Gu, J. Dominic, J. S. Lai, C. L. Chen, T. Labella, and B. Chen, "High reliability and efficiency single-phase transformerless inverter for grid-connected photovoltaic systems," IEEE Trans. Power Electron., vol. 28, no. 5, pp. 2235$2245,2013$.

[6] S. V. Araújo, P. Zacharias, and R. Mallwitz, "Highly efficient single-phase transformerless inverters for grid-connected photovoltaic systems," IEEE Trans. Ind. Electron., vol. 57, no. 9, pp. 3118-3128, 2010.

[7] B. Ji, J. Wang, and J. Zhao, "High-efficiency single-phase transformerless PV H6 inverter with hybrid modulation method," IEEE Trans. Ind. Electron., vol. 60, no. 
5, pp. 2104-2115, 2013.

[8] S. B. Kjaer, J. K. Pedersen, and F. Blaabjerg, "A review of single-phase gridconnected inverters for photovoltaic modules," IEEE Transactions on Industry Applications, vol. 41, no. 5. pp. 1292-1306, 2005.

[9] D. Barater, C. Concari, G. Buticchi, E. Gurpinar, D. De, and A. Castellazzi, "Performance Evaluation of a Three-Level ANPC Photovoltaic Grid-Connected Inverter With 650-V SiC Devices and Optimized PWM," IEEE Trans. Ind. Appl., vol. 52, no. 3, pp. 2475-2485, 2016.

[10] Y. Shi, L. Wang, R. Xie, Y. Shi, and H. Li, “A 60-kW 3-kW/kg Five-Level TType SiC PV Inverter with 99.2\% Peak Efficiency," IEEE Trans. Ind. Electron., vol. 64, no. 11, pp. 9144-9154, 2017.

[11] S. Saridakis, E. Koutroulis, and F. Blaabjerg, "Optimization of SiC-based H5 and conergy-NPC transformerless PV inverters," IEEE J. Emerg. Sel. Top. Power Electron., vol. 3, no. 2, pp. 555-567, 2015.

[12] F. M. Almasoudi, K. S. Alatawi, and M. Matin, "High efficiency three level transformerless inverter based on SiC MOSFETs for PV applications," in IEEE International Conference on Electro Information Technology, 2017, pp. 617-622.

[13] H. Xiao and S. Xie, "Leakage current analytical model and application in singlephase transformerless photovoltaic grid-connected inverter," IEEE Trans. Electromagn. Compat., vol. 52, no. 4, pp. 902-913, 2010.

[14] L. Wang, Y. Shi, Y. Shi, R. Xie, and H. Li, "Ground leakage current suppression in a $50 \mathrm{~kW}$ 5-level T-type transformerless PV inverter," in ECCE 2016 - IEEE 
Energy Conversion Congress and Exposition, Proceedings, 2016.

[15] S. A. Khan, Y. Guo, and J. Zhu, “A high efficiency transformerless PV gridConnected inverter with leakage current suppression," in Proceedings of 9th International Conference on Electrical and Computer Engineering, ICECE 2016, 2017, pp. 190-193.

[16] L. Ma, F. Tang, F. Zhou, X. Jin, and Y. Tong, "Leakage current analysis of a single-phase transformer-less PV inverter connected to the grid," in 2008 IEEE International Conference on Sustainable Energy Technologies, ICSET 2008, 2008, pp. $285-289$.

[17] P. Kakosimos, A. Sarigiannidis, M. Beniakar, and A. Kladas, "Investigation of transformerless topologies for renewable energy applications eliminating leakage currents," in 9th Mediterranean Conference on Power Generation, Transmission, Distribution and Energy Conversion, 2014, pp. 75-80.

[18] L. Zhang, K. Sun, Y. Xing, and M. Xing, "H6 transformerless full-bridge PV gridtied inverters," IEEE Trans. Power Electron., vol. 29, no. 3, pp. 1229-1238, 2014.

[19] IEEE Standards Coordinating Committee 21, “1547a-2014 - IEEE Standard for Interconnecting Distributed Resources with Electric Power Systems - Amendment $1, " 2014$.

[20] IEEE Std 929, IEEE Recommended Practice for Utility Interface of Photovoltaic (PV) Systems, vol. 2000. 2000.

[21] N. F. P. Association, National Electrical Code: 2008. NationalFireProtectionAssoc, 2007. 
[22] U. Standard and others, "Inverters, Converters, Controllers and Interconnection System Equipment for Use With Distributed Energy Resources.” Jan, 2010.

[23] C. P. U. Commission and others, "Recommendations for updating the technical requirements for inverters in distributed energy resources, Smart Inverter Working Group recommendations.” Jan, 2014.

[24] Y. Xue, L. Chang, S. B. Kjær, J. Bordonau, and T. Shimizu, "Topologies of singlephase inverters for small distributed power generators: An overview," IEEE Trans. Power Electron., vol. 19, no. 5, pp. 1305-1314, 2004.

[25] H. Xiao, S. Xie, Y. Chen, and R. Huang, "An optimized transformerless photovoltaic grid-connected inverter," IEEE Trans. Ind. Electron., vol. 58, no. 5, pp. 1887-1895, 2011.

[26] B. Chen, P. Sun, C. Liu, C. L. Chen, J. S. Lai, and W. Yu, "High efficiency transformerless photovoltaic inverter with wide-range power factor capability," in Conference Proceedings - IEEE Applied Power Electronics Conference and Exposition - APEC, 2012, pp. 575-582.

[27] P. Zacharias, R. Mallwitz, S. V. Araújo, and B. Sahan, "Inverter capable of providing reactive power.” Google Patents, 2014.

[28] N. F. P. Association., National electrical code : NFPA 70: 1993 edition. Quincy, MA: National Fire Protection Association, 1992.

[29] G. I. for Standardisation, "Automatic Disconnection Device Between A Generator And The Public Low-voltage Grid: VDE DIN 0126-1-1,” 2005.

[30] R. González, J. López, P. Sanchis, and L. Marroyo, "Transformerless inverter for 
single-phase photovoltaic systems," IEEE Trans. Power Electron., vol. 22, no. 2, pp. 693-697, 2007.

[31] E. Gub??a, P. Sanchis, A. Urs??a, J. L??pez, and L. Marroyo, "Ground currents in single-phase transformerless photovoltaic systems," Prog. Photovoltaics Res. Appl., vol. 15, no. 7, pp. 629-650, 2007.

[32] T. Kerekes, D. Sera, and L. Mathe, "Leakage current measurement in transformerless PV inverters," in Proceedings of the International Conference on Optimisation of Electrical and Electronic Equipment, OPTIM, 2012, pp. 887-892.

[33] G. Buticchi, D. Barater, E. Lorenzani, and G. Franceschini, "Digital control of actual grid-connected converters for ground leakage current reduction in PV transformerless systems," IEEE Trans. Ind. Informatics, vol. 8, no. 3, pp. 563-572, 2012.

[34] B. Yang, W. Li, Y. Gu, W. Cui, and X. He, "Improved transformerless inverter with common-mode leakage current elimination for a photovoltaic grid-connected power system," IEEE Trans. Power Electron., vol. 27, no. 2, pp. 752-762, 2012.

[35] F. Gebhardt, H. Vach, and F. W. Fuchs, "Comparison of transformerless multilevel topologies for photovoltaic application concerning efficiency, leakage current and mechanical volume," in PCIM Europe Conference Proceedings, 2012, pp. 11161123.

[36] H. F. Xiao, K. Lan, and L. Zhang, “A quasi-unipolar SPWM full-bridge transformerless PV grid-connected inverter with constant common-mode voltage," IEEE Trans. Power Electron., vol. 30, no. 6, pp. 3122-3132, 2015. 
[37] S. Mekhilef and M. Islam, "H6-type transformerless single-phase inverter for gridtied photovoltaic system," IET Power Electron., vol. 8, no. 4, pp. 636-644, 2015.

[38] S. Saeidabadi, A. Ashraf Gandomi, and S. H. Hosseini, "A novel transformerless photovoltaic grid-connected current source inverter with ground leakage current elimination," in 8th Power Electronics, Drive Systems and Technologies Conference, PEDSTC 2017, 2017, pp. 61-66.

[39] M. Victor, F. Greizer, S. Bremicker, and U. Hübler, "Method of converting a direct current voltage from a source of direct current voltage, more specifically from a photovoltaic source of direct current voltage, into a alternating current voltage." Google Patents, 2008.

[40] W. Yu, J. S. Lai, H. Qian, and C. Hutchens, "High-efficiency MOSFET inverter with H6-type configuration for photovoltaic nonisolated AC-module applications," IEEE Trans. Power Electron., vol. 26, no. 4, pp. 1253-1260, 2011.

[41] K. S. Alatawi, F. M. Almasoudi, and M. A. Matin, "Highly efficient GaN-based single-phase transformer-less PV grid-tied inverter," in 2017 North American Power Symposium, NAPS 2017, 2017.

[42] P. Friedrichs, "Silicon Carbide power devices - Status and upcoming challenges," in 2007 European Conference on Power Electronics and Applications, 2007, pp. $1-11$.

[43] M. Danilovic, Z. Chen, R. Wang, F. Luo, D. Boroyevich, and P. Mattavelli, "Evaluation of the switching characteristics of a gallium-nitride transistor," in IEEE Energy Conversion Congress and Exposition: Energy Conversion 
Innovation for a Clean Energy Future, ECCE 2011, Proceedings, 2011, pp. 26812688.

[44] Y. Cui et al., "High efficiency data center power supply using wide band gap power devices," 2014 IEEE Applied Power Electronics Conference and Exposition - APEC 2014. pp. 3437-3442, 2014.

[45] Z. Zhang, F. Wang, L. M. Tolbert, B. J. Blalock, and D. J. Costinett, "Realization of high speed switching of $\mathrm{SiC}$ power devices in voltage source converters," in Wide Bandgap Power Devices and Applications (WiPDA), 2015 IEEE 3rd Workshop on, 2015, pp. 28-33.

[46] S. Mao, R. Ramabhadran, J. Popovic, and J. A. Ferreira, "Investigation of CCM boost PFC converter efficiency improvement with $600 \mathrm{~V}$ wide band-gap power semiconductor devices," in 2015 IEEE Energy Conversion Congress and Exposition, ECCE 2015, 2015, pp. 388-395.

[47] R. a Wood and T. E. Salem, "Evaluation of a 1200-V, 800-A All-SiC Dual Module," Power Electron. IEEE Trans., vol. 26, no. 9, pp. 2504-2511, 2011.

[48] J. Popovic, J. Ferreira, J. D. van Wyk, and F. Pansier, "System Integration of GaN Converters - Paradigm Shift,” 2014 8th Int. Conf. Integr. Power Syst., pp. 1-8, 2014.

[49] A. Zapico et al., "SiC and $\mathrm{Si}$ transistors comparison in boost converter," in 15th International Power Electronics and Motion Control Conference and Exposition, EPE-PEMC 2012 ECCE Europe, 2012.

[50] M. Khan, G. Simin, and S. Pytel, "New developments in gallium nitride and the 
impact on power electronics," Power Electron. ..., pp. 15-26, 2005.

[51] S. L. Colino and R. Beach, "Fundamentals of Gallium Nitride Power Transistors," Power, pp. 1-4, 2011.

[52] Y. Xi, M. Chen, K. Nielson, and R. Bell, "Optimization of the drive circuit for enhancement mode power GaN FETs in DC-DC converters," in Conference Proceedings - IEEE Applied Power Electronics Conference and Exposition APEC, 2012, pp. 2467-2471.

[53] D. Costinett, H. Nguyen, R. Zane, and D. Maksimovic, "GaN-FET based dual active bridge DC-DC converter," in 2011 Twenty-Sixth Annual IEEE Applied Power Electronics Conference and Exposition (APEC), 2011, pp. 1425-1432.

[54] Infineon Inc., "IPW60R045CP Datasheet." [Online]. Available: https://www.infineon.com/dgdl/Infineon-IPW60R045CP-DS-v02_02en.pdf?fileId=db3a304412b407950112b42d8e55489b. [Accessed: 15-Mar-2018].

[55] GaN Systems Inc., "GS66516T Top-side cooled 650 V E-mode GaN transistor Preliminary Datasheet Circuit Symbol.”

[56] J. Millan, P. Godignon, X. Perpina, A. Perez-Tomas, and J. Rebollo, "A Survey of Wide Bandgap Power Semiconductor Devices," IEEE Trans. Power Electron., vol. 29, no. 5, pp. 2155-2163, 2014.

[57] D. Kranzer, C. Wilhelm, F. Reiners, and B. Burger, "Application of normally-off SiC-JFETs in photovoltaic inverters," Power Electron. Appl. 2009. EPE '09., pp. $1-6,2009$.

[58] B. Burger and D. Kranzer, "Extreme high efficiency PV-power converters," 2009 
13th Eur. Conf. Power Electron. Appl., pp. 1-13, 2009.

[59] E. Gurpinar and A. Castellazzi, "Single-Phase T-Type Inverter Performance Benchmark Using Si IGBTs, SiC MOSFETs, and GaN HEMTs,” IEEE Trans. Power Electron., vol. 31, no. 10, pp. 7148-7160, 2016.

[60] J. You, X. Lin, H. Jia, and H. Dong, "GaN HEMT based single-phase inverter control with consideration of nonlinear load," in 2016 IEEE 8th International Power Electronics and Motion Control Conference, IPEMC-ECCE Asia 2016, 2016, pp. 2296-2301.

[61] C. T. Morris, D. Han, and B. Sarlioglu, “A novel inverter topology for reduction of common mode voltage for GaN-based variable frequency inverter," in 2016 IEEE Transportation Electrification Conference and Expo, ITEC 2016, 2016.

[62] T. Morita et al., " $99.3 \%$ Efficiency of three-phase inverter for motor drive using GaN-based gate injection transistors," in Conference Proceedings - IEEE Applied Power Electronics Conference and Exposition - APEC, 2011, pp. 481-484.

[63] K. Alatawi, F. Almasoudi, M. Manandhar, and M. Matin, "Comparative Analysis of Si-and GaN-Based Single-Phase Transformer-Less PV Grid-Tied Inverter,” Electronics, vol. 7, no. 3, p. 34, 2018.

[64] Texas Instruments Inc, "Voltage Source Inverter Reference Design," 2015.

[65] A. Raciti, D. Cristaldi, G. Greco, G. Vinci, and G. Bazzano, "Electrothermal PSpice Modeling and Simulation of Power Modules," IEEE Trans. Ind. Electron., vol. 62, no. 10 , pp. 6260-6271, 2015.

[66] S. Ravikumar, P. S. Chandra, R. Harish, and T. Sivaji, "Experimental and 
Transient Thermal Analysis of Heat Sink Fin for CPU processor for better performance,” IOP Conf. Ser. Mater. Sci. Eng., vol. 197, no. 1, p. 12085, 2017.

[67] B. A. Zahn, "Using design of experiment simulation responses to predict thermal performance limits of the heatsink small outline package (HSOP) considering both die bond and heatsink solder voiding," in Fourteenth Annual IEEE Semiconductor Thermal Measurement and Management Symposium (Cat. No.98CH36195), 1998, pp. $153-160$.

[68] A. Pleşca, “Optimal heatsink design for a solid-state relay using a 3D modeling and simulation software," in 2006 International Conference on Power System Technology, POWERCON2006, 2007.

[69] P. Tarvydas, A. Noreika, and Z. Staliulionis, "Analysis of Heat Sink Modelling Performance," Res. J. Elektron. IR Elektrotechnika, vol. 19, no. 3, pp. 43-46, 2013.

[70] T. Sawamura and T. Igarashi, "Difference Between Various Sn / Ag / Cu Solder Compositions," 2005.

[71] J. Popović-Gerber et al., "Power electronics enabling efficient energy usage: Energy savings potential and technological challenges," IEEE Trans. Power Electron., vol. 27, no. 5, pp. 2338-2353, 2012.

[72] L. Collins and J. K. Ward, "Real and reactive power control of distributed PV inverters for overvoltage prevention and increased renewable generation hosting capacity," Renew. Energy, vol. 81, pp. 464-471, 2015.

[73] P. P. Barker and R. W. De Mello, "Determining the impact of distributed 
generation on power systems. I. Radial distribution systems," Power Eng. Soc. Summer Meet. 2000. IEEE, vol. 3, no. c, pp. 1645-1656 vol. 3, 2000.

[74] J. M. Carrasco et al., "Power-Electronic Systems for the Grid Integration of Renewable Energy Sources: A Survey," IEEE Trans. Ind. Electron., vol. 53, no. 4, pp. 1002-1016, 2006.

[75] Y. Ueda, K. Kurokawa, K. Kitamura, M. Yokota, K. Akanuma, and H. Sugihara, "Performance analysis of various system configurations on grid-connected residential PV systems," Sol. Energy Mater. Sol. Cells, vol. 93, no. 6-7, pp. 945949, Jun. 2009.

[76] Y. Ueda, K. Kurokawa, T. Tanabe, K. Kitamura, and H. Sugihara, “Analysis Results of Output Power Loss Due to the Grid Voltage Rise in Grid-Connected Photovoltaic Power Generation Systems," IEEE Trans. Ind. Electron., vol. 55, no. 7, pp. 2744-2751, Jul. 2008.

[77] M. Thomson and D. G. Infield, "Impact of widespread photovoltaics generation on distribution systems," IET Renew. Power Gener., vol. 1, no. 1, p. 33, 2007.

[78] R. Tonkoski, D. Turcotte, and T. H. M. El-Fouly, "Impact of High PV Penetration on Voltage Profiles in Residential Neighborhoods," IEEE Trans. Sustain. Energy, vol. 3, no. 3, pp. 518-527, Jul. 2012.

[79] Y. Yang, F. Blaabjerg, and H. Wang, "Low-Voltage Ride-Through of SinglePhase Transformerless Photovoltaic Inverters," IEEE Trans. Ind. Appl., vol. 50, no. 3, pp. 1942-1952, May 2014.

[80] X. Bao, P. Tan, F. Zhuo, and X. Yue, "Low voltage ride through control strategy 
for high-power grid-connected photovoltaic inverter," in 2013 Twenty-Eighth Annual IEEE Applied Power Electronics Conference and Exposition (APEC), 2013, pp. 97-100.

[81] C.-Y. Tang, Y.-T. Chen, and Y.-M. Chen, "PV Power System With Multi-Mode Operation and Low-Voltage Ride-Through Capability," IEEE Trans. Ind. Electron., vol. 62, no. 12, pp. 7524-7533, Dec. 2015.

[82] C. H. Benz, W.-T. Franke, and F. W. Fuchs, "Low voltage ride through capability of a $5 \mathrm{~kW}$ grid-tied solar inverter," in Proceedings of 14th International Power Electronics and Motion Control Conference EPE-PEMC 2010, 2010.

[83] G. M. Saeedul Islam, A. Al-Durra, S. M. Muyeen, and J. Tamura, "Low voltage ride through capability enhancement of grid connected large scale photovoltaic system," in IECON 2011 - 37th Annual Conference of the IEEE Industrial Electronics Society, 2011, pp. 884-889.

[84] Nguyen Hoang Viet and A. Yokoyama, "Impact of fault ride-through characteristics of high-penetration photovoltaic generation on transient stability," in 2010 International Conference on Power System Technology, 2010, pp. 1-7.

[85] P. . Rodriguez, A. V. Timbus, R. . Teodorescu, M. . Liserre, and F. . Blaabjerg, "Flexible Active Power Control of Distributed Power Generation Systems During Grid Faults," IEEE Trans. Ind. Electron., vol. 54, no. 5, pp. 2583-2592, Oct. 2007.

[86] R. Tonkoski, L. A. C. Lopes, and T. H. M. El-Fouly, "Coordinated Active Power Curtailment of Grid Connected PV Inverters for Overvoltage Prevention,” IEEE Trans. Sustain. Energy, vol. 2, no. 2, pp. 139-147, Apr. 2011. 
[87] S. Ghosh, S. Rahman, and M. Pipattanasomporn, "Distribution Voltage Regulation Through Active Power Curtailment With PV Inverters and Solar Generation Forecasts," IEEE Trans. Sustain. Energy, vol. 8, no. 1, pp. 13-22, Jan. 2017.

[88] K. Alatawi and M. Matin, “AN IMPROVED GAN-BASED SINGLE-PHASE TRANSFORMER-LESS PV GRID-TIED INVERTER WITH REACTIVE POWER CAPABILITY,” Int. J. Power Energy Syst., vol. 38, no. 2, 2018.

[89] Huijuan Li, Yan Xu, S. Adhikari, D. T. Rizy, Fangxing Li, and P. Irminger, "Real and reactive power control of a three-phase single-stage PV system and PV voltage stability," in 2012 IEEE Power and Energy Society General Meeting, 2012, pp. 18.

[90] M. T. L. Gayatri, A. M. Parimi, and A. V. Pavan Kumar, "A review of reactive power compensation techniques in microgrids," Renew. Sustain. Energy Rev., vol. 81, pp. 1030-1036, Jan. 2018.

[91] M. Castilla, M. Velasco, J. Miret, P. Martí, and A. Momeneh, “Comparative study of reactive power control methods for photovoltaic inverters in low-voltage grids," IET Renew. Power Gener., vol. 10, no. 3, pp. 310-318, Mar. 2016.

[92] O. Gandhi, C. Rodríguez-Gallegos, T. Reindl, and D. Srinivasan, "Competitiveness of PV Inverter as a Reactive Power Compensator considering Inverter Lifetime Reduction,” Energy Procedia, vol. 150, pp. 74-82, Sep. 2018.

[93] E. Troester, "New German grid codes for connecting PV systems to the medium voltage power grid," in 2nd Int. Workshop Concentrating Photovoltaic Power Plants: Opt. Design, 2009. 
[94] F. Bignucolo, A. Cerretti, M. Coppo, A. Savio, and R. Turri, "Impact of Distributed Generation Grid Code Requirements on Islanding Detection in LV Networks,” Energies, vol. 10, no. 2, p. 156, Jan. 2017.

[95] S. Ozdemir, N. Altin, and I. Sefa, "Single stage three level grid interactive MPPT inverter for PV systems," Energy Convers. Manag., vol. 80, pp. 561-572, Apr. 2014.

[96] A. Nabae and T. Tanaka, "A new definition of instantaneous active-reactive current and power based on instantaneous space vectors on polar coordinates in three-phase circuits," IEEE Trans. Power Deliv., vol. 11, no. 3, pp. 1238-1243, Jul. 1996.

[97] V. Soares, P. Verdelho, and G. D. Marques, "An instantaneous active and reactive current component method for active filters," IEEE Trans. Power Electron., vol. 15, no. 4, pp. 660-669, Jul. 2000.

[98] Jinjun Liu, Jun Yang, and Zhaoan Wang, “A new approach for single-phase harmonic current detecting and its application in a hybrid active power filter," in IECON'99. Conference Proceedings. 25th Annual Conference of the IEEE Industrial Electronics Society (Cat. No.99CH37029), vol. 2, pp. 849-854.

[99] B. N. Singh, V. Khadkikar, and A. Chandra, "Generalised single-phase p-q theory for active power filtering: simulation and DSP-based experimental investigation," IET Power Electron., vol. 2, no. 1, pp. 67-78, Jan. 2009.

[100] B. Crowhurst, E. F. El-Saadany, L. El Chaar, and L. A. Lamont, "Single-phase grid-tie inverter control using DQ transform for active and reactive load power 
compensation," in 2010 IEEE International Conference on Power and Energy, 2010, pp. 489-494.

[101] C. Roncero-Clemente, E. Romero-Cadaval, O. Husev, and D. Vinnikov, "P and Q control strategy for single phase Z/qZ source inverter based on d-q frame,” in 2014 IEEE 23rd International Symposium on Industrial Electronics (ISIE), 2014, pp. 2048-2053.

[102] M. J. Ryan and R. D. Lorenz, “A synchronous-frame controller for a single-phase sine wave inverter," in Proceedings of APEC 97 - Applied Power Electronics Conference, vol. 2, pp. 813-819.

[103] M. Gonzalez, V. Cirdenas, and F. Pazos, "DQ transformation development for single-phase systems to compensate harmonic distortion and reactive power," in 9th IEEE International Power Electronics Congress, 2004. CIEP 2004, pp. 177182.

[104] X. Serrano-Guerrero, J. González-Romero, X. Cárdenas-Carangui, and G. EscriváEscrivá, "Improved variable step size P\&O MPPT algorithm for PV systems," in Proceedings - 2016 51st International Universities Power Engineering Conference, UPEC 2016, 2017, vol. 2017-January, pp. 1-6.

[105] V. Salas, E. Olias, A. Barrado, and A. Lazaro, "Review of the maximum power point tracking algorithms for stand-alone photovoltaic systems," Sol. Energy Mater. Sol. Cells, vol. 90, no. 11. pp. 1555-1578, 2006.

[106] S. Ozdemir, N. Altin, and I. Sefa, "Single stage three level grid interactive MPPT inverter for PV systems," Energy Convers. Manag., vol. 80, pp. 561-572, 2014. 
[107] S. Jain and V. Agarwal, "A single-stage grid connected inverter topology for solar PV systems with maximum power point tracking," IEEE Trans. Power Electron., vol. 22, no. 5, pp. 1928-1940, 2007.

[108] M. A. G. De Brito, L. Galotto, L. P. Sampaio, G. De Azevedo Melo, and C. A. Canesin, "Evaluation of the main MPPT techniques for photovoltaic applications," IEEE Trans. Ind. Electron., vol. 60, no. 3, pp. 1156-1167, 2013.

[109] D. Sera, L. Mathe, T. Kerekes, S. V. Spataru, and R. Teodorescu, "On the perturband-observe and incremental conductance mppt methods for PV systems," IEEE J. Photovoltaics, vol. 3, no. 3, pp. 1070-1078, 2013.

[110] S. Jain and V. Agarwal, "Comparison of the performance of maximum power point tracking schemes applied to single-stage grid-connected photovoltaic systems," IET Electr. Power Appl., vol. 1, no. 5, pp. 753-762, 2007.

[111] National Electrical Manufacturers Association, "American National Standard for Electric power systems and equipment—Voltage ratings (60 Hertz),” Am. Natl. Stand. Inst., p. ANSI C84.1-2011, 2016.

[112] A. Q. Al-Shetwi, M. Z. Sujod, and F. Blaabjerg, "Low voltage ride-through capability control for single-stage inverter-based grid-connected photovoltaic power plant," Sol. Energy, vol. 159, pp. 665-681, Jan. 2018.

[113] K. S. Alatawi, F. M. Almasoudi, and M. A. Matin, "Highly efficient GaN HEMTs transformer-less single-phase inverter for grid-tied fuel cell," in Wide Bandgap Power Devices and Applications II, 2017, vol. 10381, p. 9.

[114] S. Dhanapal and R. Anita, "Voltage and Frequency Control of Stand Alone Self- 
Excited Induction Generator Using Photovoltaic System Based STATCOM,” J. Circuits, Syst. Comput., vol. 25, no. 4, p. 1650031, Apr. 2016. 


\section{List of Publications}

[1] K. Alatawi and M. Matin, "Multifunctional Control Strategy for High Efficiency Single-Phase Transformer-less PV Grid-Tied Inverter," International Journal of Power and Energy Systems, 2019. (submitted).

[2] K. Alatawi, and M. Matin, "Power management for PV-battery based hybrid microgrid using WBG devices," Proc.Wide Bandgap Materials, Devices, and Applications IV, September, 2019.

[3] K. Alatawi and M. Matin, "An improved GaN-based single-phase transformer-less PV grid-tied inverter with reactive power capability," International Journal of Power and Energy Systems, vol. 38, no. 2, 2018.

[4] K. Alatawi, F. Almasoudi, M. Mahesh, and M. Matin, " Comparative Analysis of Siand GaN-Based Single-Phase Transformer-Less PV Grid-Tied Inverter," Electronics, MDPI Journal, Vol. 7, 2018.

[5] M. Mahesh, K. Alatawi, F. Almasoudi, and M. Matin, "Comparative study of Heatsink materials for gallium nitride HEMT modules using thermal modelling," SPIE Wide Bandgap Power and Energy Devices and Applications III, August, 2018.

[6] K. Alatawi, F. Almasoudi, M. Matin, "Highly efficient GaN HEMTs transformer-less single-phase inverter for grid-tied fuel cell," Proc. SPIE, Wide Bandgap Power Devices and Applications II, August, 2017. 
[7] F. Almasoudi, K. Alatawi, M. Matin, "High efficiency H6 single-phase transformerless grid-tied PV inverter with proposed modulation for reactive power generation, " Proc. SPIE, Wide Bandgap Power Devices and Applications II, August, 2017.

[8] F. Almasoudi, K. Alatawi and M. Matin, "High efficiency three level transformerless inverter based on SiC MOSFETs for PV applications," 2017 IEEE International Conference on Electro Information Technology (EIT), Lincoln, NE, 2017.

[9] K. Alatawi, F. Almasoudi and M. Matin, "Highly efficient GaN-based single-phase transformer-less PV grid-tied inverter," 2017 North American Power Symposium (NAPS), Morgantown, WV, 2017.

[10] K. Alatawi, F. Almasoudi and M. Matin, "Performance enhancement of twoswitch forward converter using GaN FETs," 2016 North American Power Symposium (NAPS), Denver, CO, 2016.

[11] K. Alatawi, F. Almasoudi, M. Matin, "Switching performance and efficiency investigation of GaN based DC-DC Buck converter for low voltage and high current applications," Proc. SPIE, Wide Bandgap Power Devices and Applications, September, 2016.

[12] F. Almasoudi, K. Alatawi and M. Matin, "Design of isolated interleaved boost DC-DC converter based on SiC power devices for microinverter applications," 2016 North American Power Symposium (NAPS), Denver, CO, 2016. 
[13] F. Almasoudi, K. Alatawi, M. Matin, "Performance evaluation of a high power DC-DC boost converter for PV applications using SiC power devices," Proc. SPIE 9957, Wide Bandgap Power Devices and Applications, September, 2016. 